\title{
EFFECTS OF INCORPORATING POLYCAPROLACTONE AND FLAX FIBER INTO GLYCEROL-PLASTICIZED PEA STARCH
}

\author{
A Thesis Submitted to the \\ College of Graduate Studies and Research \\ in Partial Fulfillment of the Requirements for the \\ Degree of Master of Science \\ in the \\ Department of Agricultural and Bioresource Engineering \\ University of Saskatchewan \\ Saskatoon, Saskatchewan, Canada
}

By

Olayide Oyeyemi Fabunmi

(C) Copyright Olayide Oyeyemi Fabunmi, December 2008. All rights reserved. 


\section{PERMISSION TO USE}

In presenting this thesis/dissertation in partial fulfillment of the requirements for a Postgraduate degree from the University of Saskatchewan, I agree that the Libraries of this University may make it freely available for inspection. I further agree that permission for copying of this thesis/dissertation in any manner, in whole or in part, for scholarly purposes may be granted by the professor or professors who supervised my thesis/dissertation work or, in their absence, by the Head of the Department or the Dean of the College in which my thesis work was done. It is understood that any copying or publication or use of this thesis/dissertation or parts thereof for financial gain shall not be allowed without my written permission. It is also understood that due recognition shall be given to me and to the University of Saskatchewan in any scholarly use which may be made of any material in my thesis/dissertation.

Requests for permission to copy or to make other uses of materials in this thesis/dissertation in whole or part should be addressed to:

Department Head of Agricultural and Bioresource Engineering

University of Saskatchewan

Saskatoon, Saskatchewan S7N 5A9

Canada

OR

Dean, College of Graduate Studies and Research

University of Saskatchewan, 107 Administration Place

Saskatoon, Saskatchewan S7N 5A2

Canada 


\section{ABSTRACT}

The environmental menace associated with the existing eco-unfriendly conventional plastics prompted the exploration of natural polymers such as starch for the development of biodegradable plastics. These efforts have seen starch used in various ways, one of which is in the processing of thermoplastic starch (TPS). Thermoplastic starch (also known as plasticized starch) is the product of the interaction between starch and a plasticizer in the presence of thermomechanical energy. While starch blends with conventional plastics only yield products that biofragment, thermoplastic starch (TPS) offers a completely biodegradable option. However, it is limited in application due to its weak mechanical strength and poor moisture resistance. To this end, the objective of this study was to determine the effects of incorporating polycaprolactone (PCL) and flax fiber into glycerol-plasticized pea starch. The effects of processing moisture content on the physical properties of glycerol-plasticized pea starch were also evaluated. The physical properties investigated included morphology, tensile properties, moisture absorption, and thermal properties.

Accordingly, two thermoplastic pea starch mixtures containing 9.3 and $20 \%$ processing moisture contents were prepared while maintaining starch (pea starch) and glycerol in ratio 7:3 by weight (dry basis). Polycaprolactone was then compounded at $0,10,20,30$, and $40 \%$ by weight in the solid phase with the TPS mixtures to determine the effects of processing moisture content and PCL incorporation on the physical properties of glycerol-plasticized pea starch. This experiment was structured as a $2 \times 5$ factorial completely randomized design at $5 \%$ level of significance. Subsequently, $\mathrm{PCL}$ and flax fiber were 
compounded with the TPS mixture containing $20 \%$ processing moisture to determine the effects of PCL $(0,20$, and $40 \% \mathrm{wt})$ and flax fiber $(0,5,10$, and $15 \% \mathrm{wt}$ ) incorporation on the physical properties of glycerol-plasticized pea starch. This was structured as a $3 \times 4$ factorial completely randomized design at $5 \%$ level of significance. All the samples were compressed at $140^{\circ} \mathrm{C}$ for $45 \mathrm{~min}$ under $25000-\mathrm{kg}$ load. The compression-molded samples were characterized using scanning electron microscopy (SEM), tensile test, moisture absorption test, and differential scanning calorimetry (DSC) techniques.

The tensile fracture surfaces showed a moisture-induced fundamental morphological difference between the two TPSs. The TPS prepared at $20 \%$ processing moisture content revealed complete starch gelatinization, thus, exhibiting a rather continuous phase whereas the TPS prepared at $9.3 \%$ processing moisture content revealed instances of ungelatinized and partly gelatinized pea starch granules. Consequently, the tensile strength, yield strength, Young's modulus, and elongation at break increased by 208.6, 602.6, 208.5 , and $292.0 \%$, respectively at $20 \%$ processing moisture content. The incorporation of $\mathrm{PCL}$ reduced the degree of starch gelatinization by interfering with moisture migration during compression molding due to its (PCL) hydrophobicity. At both processing moisture levels of 9.3 and $20 \%, \mathrm{PCL}$ incorporation had significant impacts on the tensile properties of the plasticized pea starch. Flax fiber incorporation also increased the tensile strength, yield strength, and Young's modulus while concomitantly reducing the elongation at break of the plasticized pea starch. In the TPS/PCL/flax fiber ternary composites, both PCL and flax fiber improved the tensile strength by acting as 
independent reinforcing materials as no PCL-fiber interfacial bonding was observed. Maximum tensile strength of $11.55 \mathrm{MPa}$ was reached at $10 \%$ flax fiber and $40 \%$ PCL reinforcement. While the PCL-TPS interfacial interaction was poor, some degree of TPS-flax fiber interfacial bonding was noticed due to their chemical similarity.

TPS prepared at $20 \%$ moisture showed more moisture affinity than that prepared at $9.3 \%$ moisture. The moisture absorption of TPS dropped progressively with the addition of hydrophobic PCL. Fiber incorporation also reduced moisture absorption by the plasticized pea starch. PCL-fiber incorporation also yielded improved moisture resistance vis-à-vis pure TPS. Finally, the TPS processed at $9.3 \%$ moisture exhibited higher thermal stability than that processed at $20 \%$. Individual components of the composites retained their respective thermal properties, thus, implying thermodynamic immiscibility. 


\section{ACKNOWLEDGMENTS}

I will like to express my deepest appreciation to God Almighty for His guidance and wisdom throughout the period of this study. I acknowledge the invaluable input, guidance, and support of my supervisor, Dr. Lope G. Tabil (Jr), and co-supervisor, Dr. Peter R. Chang. The immeasurable contributions of Dr. Charles Maule (Chair) and Dr. Satyanarayan Panigrahi (Member) of my Graduate Advisory Committee cannot go unnoticed. I am equally grateful to Dr. Leon Wegner (external examiner) for his suggestions. Furthermore, I express profound gratitude to Natural Sciences and Engineering Research Council of Canada (NSERC) for funding this research and Nutri-Pea Limited (Portage la Prairie, MB) for generously supplying the pea starch used in this study.

I express many thanks to the technical staff and fellow graduate students of the Department of Agricultural and Engineering, University of Saskatchewan $(U$ of $S)$, for their contributions. The assistance of Dr. Chen Yun and Debbie Anderson of Agricultural and Agri-Food Canada (Saskatoon), Hans-Jürgen Steinmetz (Mechanical Engineering, $U$ of $S$ ), and Thomas Bonli (Geology, $U$ of S) are highly recognized.

Lastly, my profound gratitude goes to my dad, mum, and my siblings (Olamide Fabunmi, Olanihun Ogunyemi, and Adunola Fabunmi) for their love, prayers, support, and encouragements throughout this period. I am indeed grateful to my friends: Adedamola Oladeinde, Leanne Silzer, Samuel Adaramola, Olaniyi Fadeyi, Oluwaseun Kelani, Adekunbi Adeleke, and many others for their tremendous support and encouragements. And to all that contributed one way or the other to the success of this thesis, I say Thank You! 


\section{TABLE OF CONTENTS}

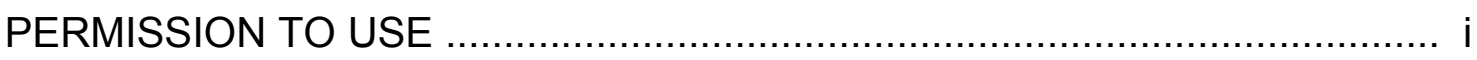

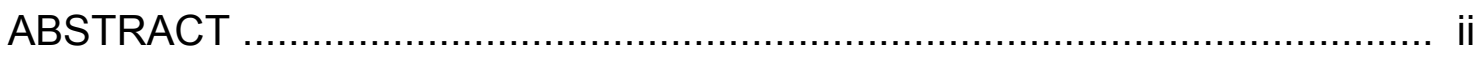

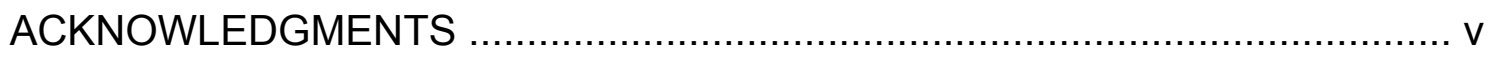

TABLE OF CONTENTS …................................................................ vi

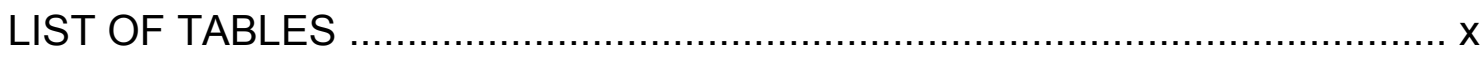

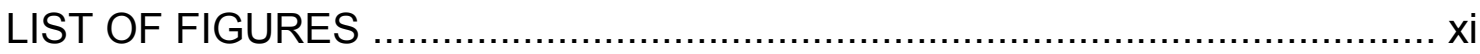

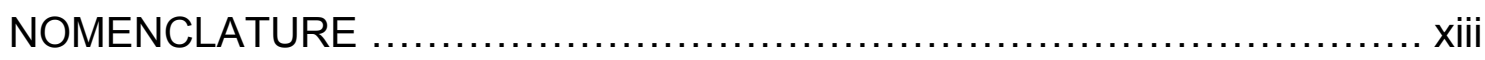

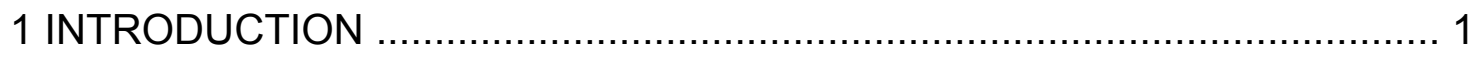

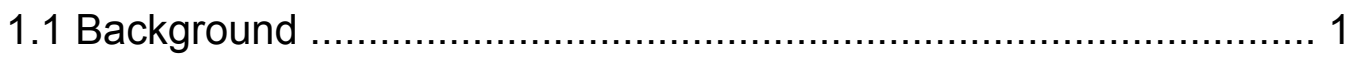

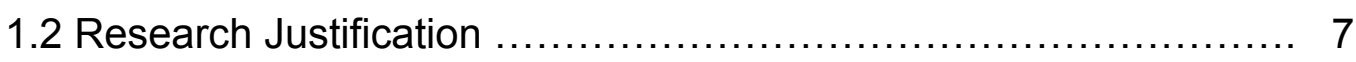

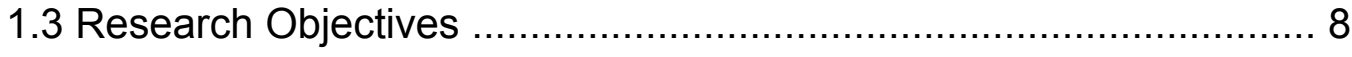

1.4 Organization of Thesis............................................. 9

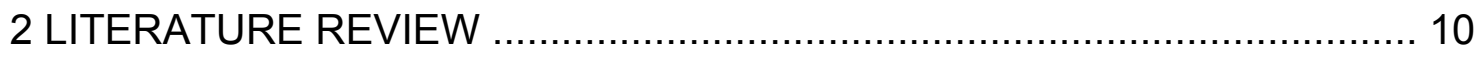

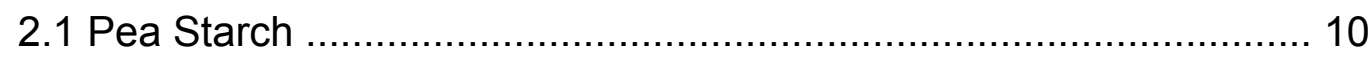

2.2 Pea Starch Extraction ............................................................ 11

2.2.1 Dry processing/milling.............................................. 11

2.2.1.1 Dry milling procedure for pea starch................... 12

2.2.2 Wet processing/milling................................................. 14

2.2.2.1 Extraction procedure for pea starch.................... 14

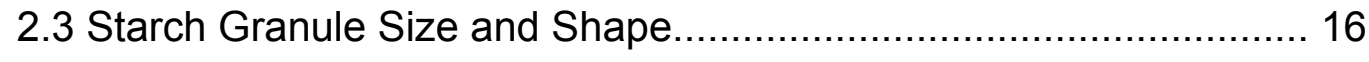

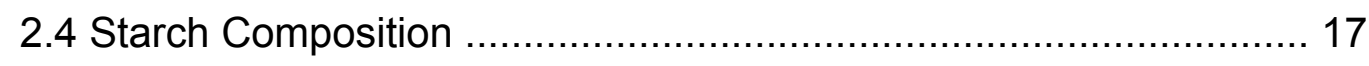

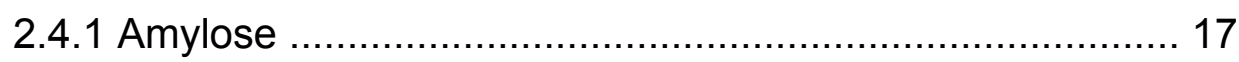




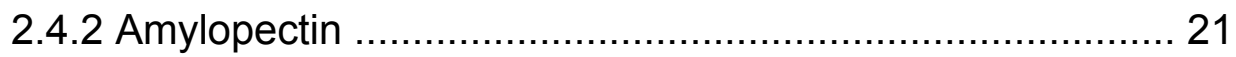

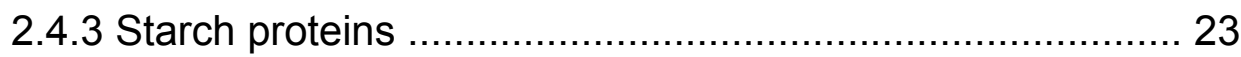

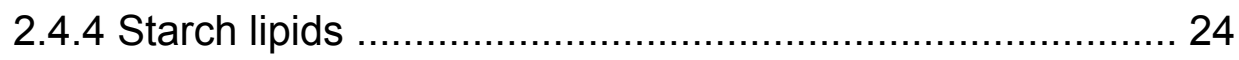

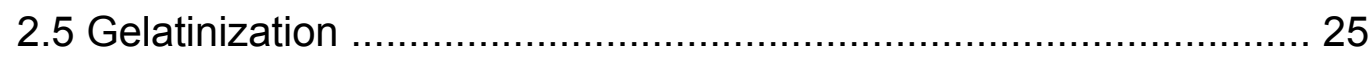

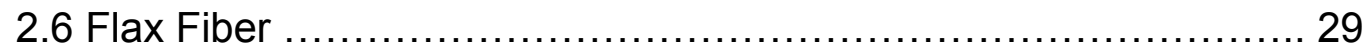

2.6.1 Reinforcement functionality of natural fibers ................ 30

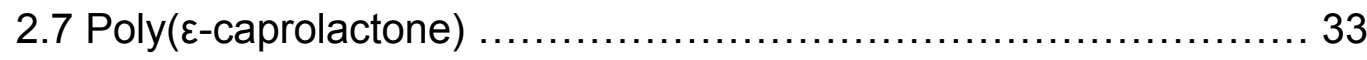

2.8 Developing Biodegradable Plastics - Role of Starch ............. 34

2.8.1 Starch as fillers ......................................................... 36

2.8.2 Thermoplastic starch (TPS) ......................................... 41

2.8.3 TPS/non-biodegradable synthetic polymers blends .......... 49

2.8.4 Starch/biodegradable synthetic polymer blends................ 51

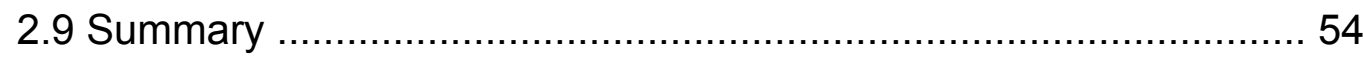

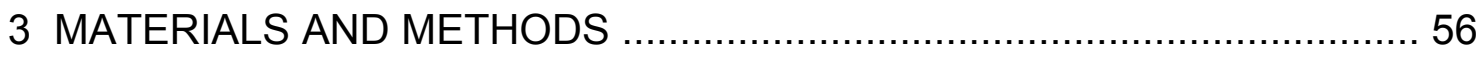

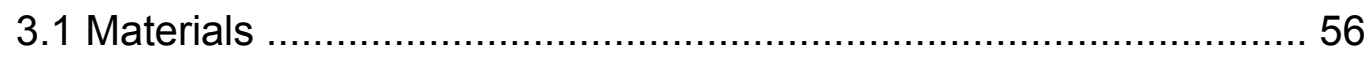

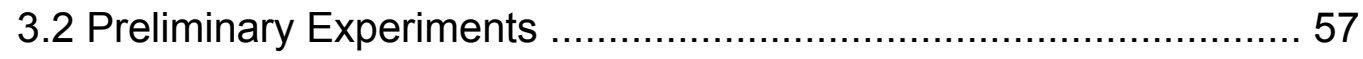

3.2.1 Moisture content of pea starch....................................... 57

3.2.2 Particle size distribution of pea starch..................... 58 using laser diffraction

3.2.3 Particle densities of pea starch, flax fiber, ................. 58 polycaprolactone

3.2.4 Gelatinization properties of the ........................... 60 supplied pea starch

3.2.5 Thermal behavior of the supplied.......................... 63 PCL and flax fiber 


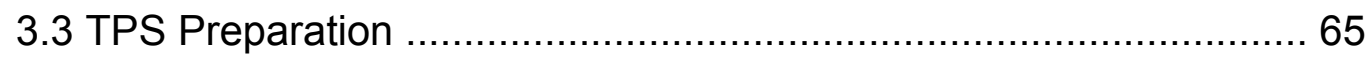

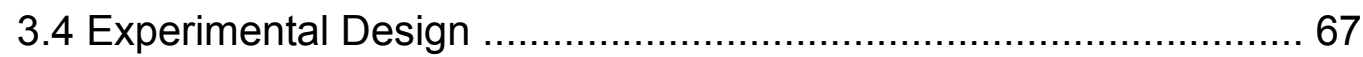

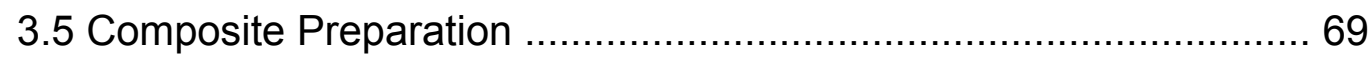

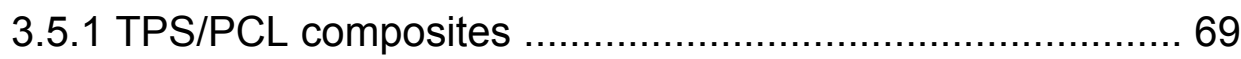

3.5.2 TPS/Fiber and TPS/PCL/Fiber composites ..................... 71

3.5.3 Compression molding .............................................. 71

3.6 Specimen Preparation and Characterization ............................... 72

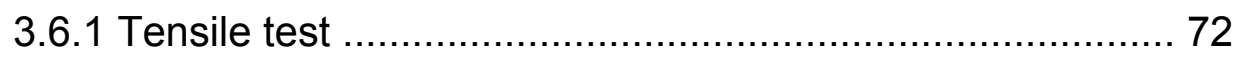

3.6.2 Moisture absorption test ................................................ 75

3.6.3 Scanning electron microscopy .................................... 76

3.6.4 Differential scanning calorimetry ................................... 76

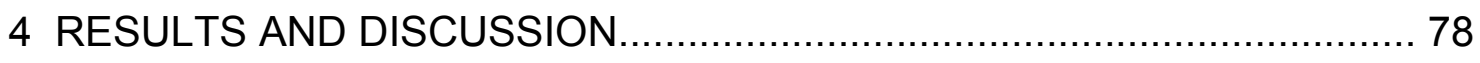

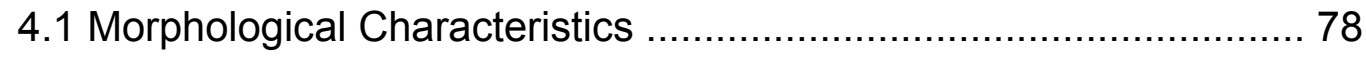

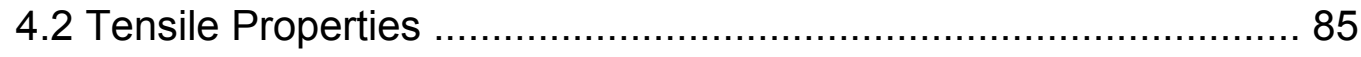

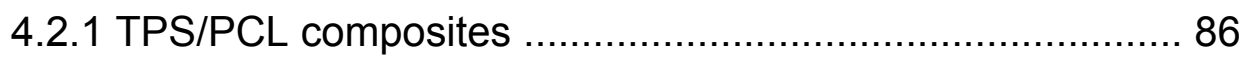

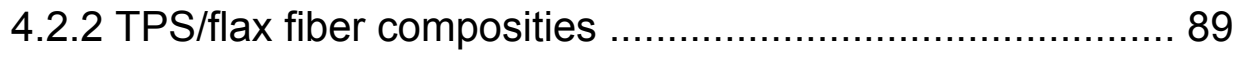

4.2.3 TPS/PCL/flax fiber composites ....................................... 91

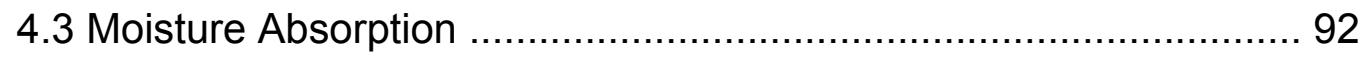

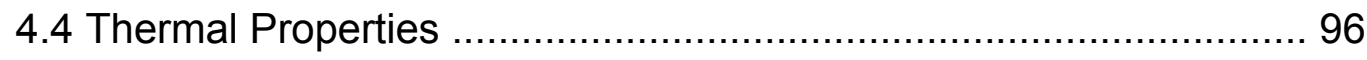

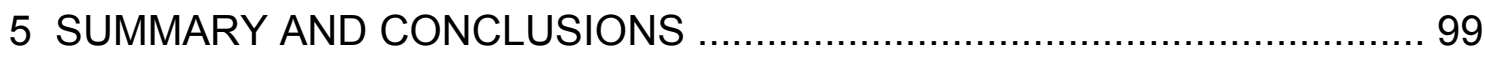

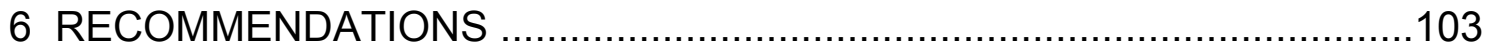

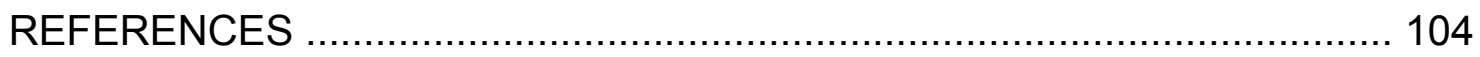


APPENDIX A

Data sheets for pea starch (accu-gel) and polycaprolactone............ 133

APPENDIX B

Derivation of the equation for the adjustment.......................... 136 of TPS processing moisture content

APPENDIX C

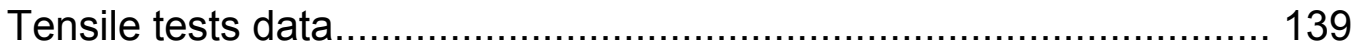

APPENDIX D

Moisture absorption test data...................................... 147 


\section{LIST OF TABLES}

Table No.

Title

Page No.

2.1 Granule dimensions and shapes of legume starches

$2.4 \quad$ Mechanical properties of some natural and synthetic fibers

3.2 Experimental design to determine the effects of moisture, polycaprolactone and flax fiber incorporation into plasticized pea starch

4.1 Thermal properties of plasticized pea starch/polycaprolactone and plasticized pea starch/ polycaprolactone/flax fiber composites 


\section{LIST OF FIGURES}

Figure No.

Title

Page No.

2.1 A schematic diagram of an air classification process

2.2 Starch extraction from field pea by wet processing

2.3 Amylose repeating unit

2.4 Chemical structure of amylopectin

3.1 Particle size distribution of pea starch using laser diffraction technique

3.2 Effects of moisture content on the gelatinization of pea starch using differential scanning calorimetry technique

3.3 Differential scanning calorimetry thermograms of

(a) polycaprolactone; (b) flax fiber.

3.4 Sample preparation equipment and tool

(a) Hamilton Beach 5 Speed OptiMixTM hand/stand Mixer; (b) laboratory scale mortar and pestle;

(c) automatic hydraulic press

3.5 Specimen characterization equipment

(a) Instron testing machine; (b) Environmental chamber; (c) Scanning electron microscope;

(d) Differential scanning calorimeter

4.1 Scanning electron micrograms (500X) of the tensile fracture surfaces of plasticized pea starch prepared at $9.3 \%$ (left column) and $20 \%$ (right column) moisture processing content and reinforced with polycaprolactone

4.2 Scanning electron micrograms (500X) of the tensile fracture surfaces of plasticized pea starch reinforced with flax fiber

4.3 Scanning electron micrograms (500X) of the tensile fracture surfaces of plasticized pea starch/ polycaprolactone/flax fiber 
Figure No.

Title

Page No.

4.4 Tensile effects of processing moisture content and polycaprolactone incorporation on glycerol-plasticized pea starch.

4.5 Tensile effects of polycaprolactone and flax fiber

90 incorporation on glycerol-plasticized pea starch

4.6 Compression-molded glycerol-plasticized pea

92 starch reinforced with polycaprolactone and flax fiber (1X)

4.7 Effects of processing moisture content and polycaprolactone incorporation on the moisture absorption properties of glycerol-plasticized pea starch

4.8 Effects of flax fiber and polycaprolactone incorporation on the moisture absorption properties of glycerol-plasticized pea starch

4.9 Differential scanning calorimetry thermograms of glycerol-plasticized pea starch prepared at processing moisture contents of (a) $9.3 \%$ and (b) $20 \%$ 


\section{NOMENCLATURE}

$\mathrm{PCL}=\mathrm{Poly}(\varepsilon$-caprolactone $)$ or polycaprolactone

TPS $=$ Thermoplastic starch

$M_{1}=$ moisture content of pea starch (\% w.b.)

$D=$ sample (pea starch or $\mathrm{PCL}$ ) particle density, $\mathrm{g} / \mathrm{cm}^{3}$

$M_{P}=$ sample (pea starch or $\left.\mathrm{PCL}\right)$ mass, $\mathrm{g}$

$V_{P}=$ sample (pea starch or $\mathrm{PCL}$ ) volume, $\mathrm{cm}^{3}$

$V_{P}=$ volume of powder (pea starch or PCL), $\mathrm{cm}^{3}$

$V_{C}=$ volume of sample cell, $\mathrm{cm}^{3}$

$V_{R}=$ reference volume, $\mathrm{cm}^{3}$

$P_{1}=$ pressure reading after pressurizing the reference volume, psi

$P_{2}=$ pressure reading after including $V_{\mathrm{C}}$, psi

$\mathrm{W}_{\mathrm{a}}=$ weight of extra water needed to achieve $100 x \%$ TPS processing moisture content, $g$

$x=$ targeted TPS processing moisture level (in decimal)

$M=$ moisture content of starch (in decimal)

$d_{s}=$ mass of dry starch, $\mathrm{g}$

$p=$ amount of glycerol, $\mathrm{g}$

$\sigma=$ Engineering stress, $\mathrm{MPa}$

$\varepsilon=$ Engineering strain

$\sigma_{\max }=$ Ultimate tensile stress, $\mathrm{MPa}$

$F_{\max }=$ Maximum load, $\mathrm{N}$

$I=$ Gauge length, $\mathrm{mm}$ 
$I_{b}=$ Length at point of break, $\mathrm{mm}$

$I=$ Length at any instant of loading, $\mathrm{mm}$

$A_{o}=$ Initial cross-sectional area of the specimen, $\mathrm{mm}^{2}$

$F=$ Load at any instant, $\mathrm{N}$

$F_{y}=$ Load at $0.2 \%$ offset, $\mathrm{N}$

$\sigma_{\max }=$ Yield stress at $0.2 \%$ offset, $\mathrm{MPa}$

$M^{\prime}=$ Moisture absorbed by sample during moisture absorption test, \% w.b.

$m_{01}=$ Initial mass of sample during moisture absorption test, $\mathrm{g}$

$m_{f 1}=$ Final mass of sample during moisture absorption test, $\mathrm{g}$

$\mathrm{T}_{\mathrm{g}}=$ Glass transition temperature,${ }^{\circ} \mathrm{C}$

$\mathrm{T}_{\text {od }}=$ Onset of thermal degradation, ${ }^{\circ} \mathrm{C}$

$\mathrm{T}_{\mathrm{m}}=$ Melting point, ${ }^{\circ} \mathrm{C}$ 


\section{INTRODUCTION}

Since their invention, plastics have become an essential part of our daily lives both in the commodity and industrial categories. Their ubiquity and prolific applications have established them as an indispensable engineering material. However, the growing environmental concerns about their non-biodegradability coupled with the non-renewability of their source have triggered a paradigm shift culminating in a search for biodegradable alternatives of renewable source.

\section{$1.1 \quad$ Background}

Conventional synthetic polymers such as polyethylene (PE), polypropylene (PP), polystyrene (PS), and polyvinyl chloride (PVC) to mention but a few, are petroleum-based products found in large quantities all over the globe. They come in various chemical compositions with different material properties and as such, enjoy diverse engineering applications. However, inherent in their array of strengths is their major weakness of non-biodegradability. Petrochemical-based plastics take an estimated 500 to 1000 years to biodegrade (Datta et al. 1995) because their molecules are too tightly bonded for microbial degradation. The large volumes of plastic waste products, especially single-use plastic commodities, churned out on a daily basis pose enormous environmental menace globally, with developing countries, where there are no adequate waste disposal management programs in place, bearing the brunt. Their nonbiodegradability also makes them potential threats to unsuspecting aquatic 
animals which unwittingly ingest plastic waste dumped into water bodies (Laist 1997).

Thus, there have been widespread intense efforts to address this issue both policy-wise and scientifically. On the policy front, there have been outright bans on ultra-thin plastic bags or imposition of levies on shopping plastic bags in some countries like Ireland, China (in 2008), South Africa (in 2003), Rwanda, Somalia, and Eritrea (in 2005), Tanzania (in 2006), Kenya and Uganda (in 2007), Belgium (in 2007), Italy, Switzerland, and Bangladesh (2002), Taiwan (in 2003), and Australia (in 2008). Some specific cities like Mumbai, India (in 2000), San Francisco, USA (in 2007), and Leaf Rapids, Canada (in 2006) have also followed suit ultimately to discourage and cut down on the use of plastic bags in favor of environment-friendly alternatives such as cloth and paper bags (Perry 2008; BBC 2008). The technical approach offers the recycling option which is becoming increasingly impracticable. Alternatively, researchers globally have been working on developing a new generation of biodegradable plastics commonly referred to as bioplastics or "green" plastics with a view to proffering a rather more practicable and sustainable solution.

According to the American Society for Testing and Materials (ASTM), biodegradability refers to the capability of "undergoing decomposition into carbon dioxide, methane, water, inorganic compounds, or biomass in which the predominant mechanism is the enzymatic action of microorganisms which can be measured by standardized tests in a specified period of time, reflecting available disposal condition". Besides biodegradable bioplastics, other classes 
of bioplastics based on the mechanism of degradation include compostable, bio-erodable, photo-biodegradable, and hydro-biodegradable plastics (NolanITU 2002).

According to the ASTM, a compostable plastic must be able to "undergo biological decomposition in a compost site as part of an available program, such that the plastic is not visually distinguishable and breaks down to carbon dioxide, water, inorganic compounds, and biomass, at a rate consistent with known compostable materials (e.g. cellulose)". Compostable bioplastics biodegrade and disintegrate in a compost system during the composting process usually around 12 weeks at temperatures above $50^{\circ} \mathrm{C}$ essentially producing a compost without ecotoxicity and any apparent distinguishable residues caused by polymer breakdown (Nolan-ITU 2002). Although the degradation of hydro-biodegradable and photo-biodegradable plastics is a twostep process that involves an initial hydrolysis and photo-degradation stage, respectively followed by biodegradation, one-step-degradation water-soluble and photodegradable polymers do exist. Bioerodable plastics on the other hand exhibit abiotic disintegration. This may include processes like dissolution in water, oxidative embrittlement (heat ageing) or photolytic embrittlement (UV ageing) (Nolan-ITU 2002). In other words, degradation warrants that the polymer linkages are hydrolytically unstable under specific chemical, biological or photochemical conditions (Wollerdorfer and Bader 1998).

Starch and cellulose, both of which are natural polymers, have the advantages of unlimited availability, non-toxicity, inexpensiveness, and 
biodegradability. They both have the generic chemical formula of $\left(\mathrm{C}_{6} \mathrm{H}_{10} \mathrm{O}_{5}\right)_{n}$. For over three decades now, starch has been largely studied (see Section 2.8) and harnessed for the production of biodegradable plastics for various purposes. This longstanding quest of developing starch-based biodegradable plastics has witnessed the use of different starches in many ways/forms which include, inter alia, native granular starch, physically or chemically modified starch, plasticized or thermoplastic starch, and also in blends with many synthetic thermoplastic polymers. Similarly, synthetic biodegradable polymers such as polyvinyl alcohol (PVOH), polylactic acid (PLA), polycaprolactone (PCL), polyhydroxybutyrate (synthesized by Alcaligenes eutrophus), modified PET, polyester carbonate (PEC), and other aliphatic polyesters (e.g. Bionelle ${ }^{\circledR}$, BAK) and aliphatic-aromatic copolyesters (e.g., Eastar BIO, Ecoflex) have also been successfully developed. Depending on their mode of production, biodegradable polymers can be generally grouped into synthetic and natural (of plant and microbial origins) polymers (Endres and Pries 1995). However, their relatively high costs encourage their blending with starch (a cheap and widely available biopolymer) in order to produce cheaper products (blends) with desirable complimentary properties (AAFC 2004).

Starches from cereal and root/tuber crops especially corn, wheat, cassava, and potato have mainly been researched for this purpose. Torres and co-workers (2007) proved that starch source is a significant material property determinant; thus, studying the potentials of starchy legumes which reportedly contain significant proportions of starch that can be harnessed for various 
industrial purposes including bioplastics can be quite revealing. Accordingly, recent studies have been conducted into the plastic potentials of pea starch with useful results (Ma et al. 2008a, Ma et al. 2009; Huneault and Li 2007). Emami and co-workers (2006) reported the starch content of pin-milled flour of chickpea as $47.98 \%(\mathrm{db})$ while Wu and Nichols (2005) reported the starch content for field pea as $48 \%(\mathrm{db})$. Lentils contain $35-53 \%$ of starch (Reddy and Pierson 1984) while brown cowpea contains $46.84-53.63 \%$ as reported by Preet and Punia (2000). Of interest to this research is field pea (Pisum sativum) for which Canada is the world's largest producer (accounting for about $28 \%$ of world production in 2004-2005 and 2005-2006) and exporter (responsible for about $50 \%$ of world's exports on average). The bulk of Canadian field pea production comes from Saskatchewan (about 78\% in 2005 to 2006) followed by Alberta (about 20\% in 2005 to 2006) while Manitoba and British Columbia contribute only a small proportion (Skrypetz 2006). Traditionally, pea undergoes preliminary processing involving de-podding and cleaning before being packaged for sale/export, primarily for human and livestock consumption, and also for seeds. However, the advent of commercial-scale fractionation of pea into its major chemical components, starch and protein, has opened up doors for various dynamic economic utilizations of the crop, even in the non-food industry.

Plasticized or thermoplastic starch (TPS), derived from the interaction between starch and a plasticizer in the presence of thermomechanical energy, is a completely biodegradable plastic of renewable origin. Unfortunately, its poor 
mechanical properties and moisture resistance militate against its independent use. Many approaches have therefore been exploited to enhance the material properties of thermoplastic starch as discussed in Section 2.8.2.

Accordingly, the potentials of blending starch in native granular $\mathrm{Wu}$ 2003), modified granular (Yavuz and Babaç 2003) and plasticized (Matzinos et

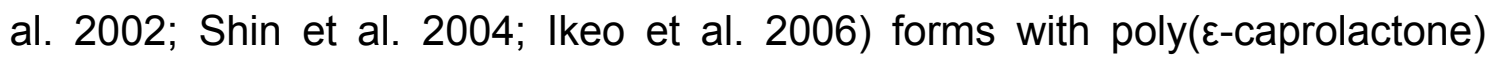
(PCL), a synthetic semi-crystalline biodegradable aliphatic polyester (Elzein et al. 2004; Shimao 2001), have also been studied. These studies were mainly aimed at reducing and improving the cost and biodegradability, respectively, of polycaprolactone (PCL) with starch; in other words, PCL was used as the base material. Ikeo and co-workers (2006) asserted that starch flexibility and compatibility were enhanced using plasticized starch. Furthermore, natural fibers such as flax, ramie, jute, sisal, and cabuya (Wollerdorfer and Bader 1998; Torres 2007) have been proven to enhance performance of TPS. In general, the properties of starch-based products are influenced by many factors which include starch type and form, processing technique, polymer orientation, moisture (relative humidity), amylose content, test procedure, type and method of reinforcement (if any), type and amount of plasticizer, and the kind of composite components (Biliaderis et al. 1999; Thunwall et al. 2006b; Schlemmer et al. 2007; Teixeira et al. 2007; Torres et al. 2007; De Carvalho et al. 2001; Yu and Christie 2005).

Extrusion technique (sometimes in combination with injection or compression molding) has been the most widely used processing technique in 
the preparation of starch/polycaprolactone composites understandably because it allows for melt compounding, a condition that yields finely dispersed starch within the polymer matrix particularly when thermoplastic starch is used (Prinos et al. 1998). Extrusion is also mostly used for starch plasticization (Matzinos et al. 2002). Although extruded fiber-reinforced composites show improved mechanical properties compared with the unreinforced, extrusion compounding as well as injection molding has been found to cause some fiber damage (particularly fiber length and diameter reduction) during processing (Wollerdorfer and Bader 1998; Puglia et al. 2003; Grande and Torres 2005; Vilaseca et al. 2007), a condition that may limit optimum realization of fiber reinforcing potentials.

\subsection{Research Justification}

Although plasticized starch is relatively inexpensive to produce and is completely biodegradable, its poor mechanical properties and high hydrophilicity militate against its potential industrial applications. Therefore, improving the mechanical and hydrophobic properties of plasticized starch was the principal idea behind this study. Although starch source and type are an important determinant of material properties, pea starch was used for this study with the latent possibility of increasing its economic value, thus, making it more profitable. Property enhancers investigated included flax fiber due to its inexpensiveness, renewability, biodegradability, and good strength, and polycaprolactone based on its biodegradability, good mechanical properties, 
and hydrophobicity. Lastly, it is expected that the demands for field pea for bioplastics will not be in contest with its demands as food since the quality needed for this process is below that needed for safe human consumption. In addition, the energy consumption and greenhouse gas emissions from bioplastics production are significantly lower than those from conventional plastics production (Patel 2002).

\section{$1.3 \quad$ Research Objectives}

The aim of this research was to ultimately improve the material properties of glycerol-plasticized pea starch with the incorporation of PCL and flax fiber achieved through solid-phase compounding followed by compression molding, thus, producing ternary biocomposites that are completely biodegradable. The specific objectives were to investigate:

- the effects of TPS processing moisture content and PCL incorporation on the physical properties of glycerol-plasticized pea starch; and

- the effects of incorporating flax fiber and PCL into glycerol-plasticized pea starch.

The physical properties examined included morphology, tensile properties, moisture absorption, and thermal properties. Thus, the methods of characterization used in this study included scanning electron microscopy (SEM), tensile test, moisture absorption test, and differential scanning calorimetry (DSC). 


\subsection{Organization of the Thesis}

This chapter is followed by Literature Review which discusses the extraction and composition of pea starch, starch gelatinization, and the roles of starch in the development of biodegradable plastics. Chapter three discusses the materials, sample formulation and preparation, experimental design, and material characterization techniques involved in this study. Results of relevant preliminary experiments conducted are also reported in this chapter. The results of the main experiments are presented and fully discussed in chapter four while chapter five gives a summary of this study and also highlights the major conclusions of this research. Recommendations for further work are put forward in chapter six. This is immediately followed by a list of references and the appendix section which contains formula derivation and experimental raw data. 


\section{LITERATURE REVIEW}

Starch is an organic food reserve which occurs as granules in the chloroplasts of green leaves and other photosynthesis cells, and in the amyloplasts of nonphotosynthetic storage organs such as seeds, roots, and tubers (Ellis et al. 1998; Slattery et al. 2000). Starch has a long history of being a choice raw material in the food, textile, paper, and pharmaceutical industries. However, its polymeric properties coupled with its biodegradability, renewability, and inexpensiveness have arguably positioned it as the most studied biopolymer in the quest for completely biodegradable plastics. Therefore, while this chapter essentially takes a broader look at the roles of starch in general in the development of bioplastics, some specific references are made to pea starch, the interest of this research.

\subsection{Pea starch}

In legume seeds such as field pea (Pisum sativum L.), starch granules are found embedded in a protein matrix in the cotyledons. Depending on the seed phenotype, the physicochemical properties vary. For instance, the 30 to $40 \%$ amylose content in smooth pea contrasts the 60 to $76 \%$ amylose in wrinkled pea (Colonna and Mercier 1984) with the latter having about 65 to $75 \%$ starch content of the former (Matters and Boyer 1982; Edwards et al. 1988). 


\subsection{Pea Starch Extraction}

The process of separating starchy legumes such as dry pea into its chemical components, primarily starch and protein, is generally referred to as fractionation. This fractionation can either be by dry processing or wet processing. In the case of pea, the presence of insoluble flocculent proteins and fine fiber which may appear as brownish deposits in the isolated starch reduces starch isolation efficiency (Schoch and Maywald 1968; Reichert and Youngs 1978). Therefore, regardless of the method used, the main objective of the extraction is to maximally separate starch from the other chemical constituents like proteins, lipids, and fibers with minimal damage to the starch granules. In other words, there is no starch extraction process that produces $100 \%$ starch. Starch thus obtained is referred to as native or unmodified starch and can be sold in this way or modified to improve its functionality and sold as modified starch.

\subsubsection{Dry Processing/Milling}

This involves air classification of field pea into starch and protein fractions. This process exploits size and density differences between starch and protein particles to separate the flour into coarse and fine fractions (Vose et al. 1976). The separation efficiency of this method has been found to be largely affected by two factors: lipid content and starch granule particle size distribution. It has been observed that the higher the lipid contents, such as 4.5 to $7.5 \%$ in

dehulled chickpea (Chavan et al. 1986) and $4.5 \%$ in wrinkled pea, the lower the 
separation efficiency (Colonna et al. 1980). Similarly, the broader the starch granule sizes the lower the separation efficiency. For instance, the sizes of isolated broad bean and smooth pea starches which are narrowly distributed between $26.5 \mu \mathrm{m}$ and $23.75 \mu \mathrm{m}$ favor better separation than the broad size range (6 to $80 \mu \mathrm{m}$ ) of wrinkled pea (Colonna et al. 1980). However, it has been observed that dry processing of pea concentrates protease inhibitors, phytic acid (Owusu-Ansah and McCurdy 1991), and the alpha-galactosides (Vose et al. 1976).

\subsubsection{Dry milling procedure for pea starch}

Figure 2.1 shows a schematic diagram of a typical air classification technique. According to Vose et al. (1976), dehulled pea seeds are finely ground to subcellular level $(<50 \mu \mathrm{m}$ particle size $)$ in a pin mill. Using alpha-amylase test susceptibility, Colonna and co-workers (1980) discovered that pin milling and air classification did not cause significant starch granule damage although some slight exfoliation of the granule surface was observed with the aid of scanning electron microscopy. The flour is then separated into fine (protein-rich) and coarse (starch-rich) fractions by the action of a spiral air classifier. The starch granules obtained from the first run still have some protein bodies attached to them on the surface. Therefore, this starch fraction is pin-milled and airclassified again in order to further purify the starch. The whole process can be repeated several times but studies have shown that a process based on more than two runs is unnecessary (Gueguen 1983). With a two-run process, the pea 
starch fraction, E, obtained by Vose and co-workers (1976) was 65\% with protein content of $20 \%$ as indicated in Figure 2.1.

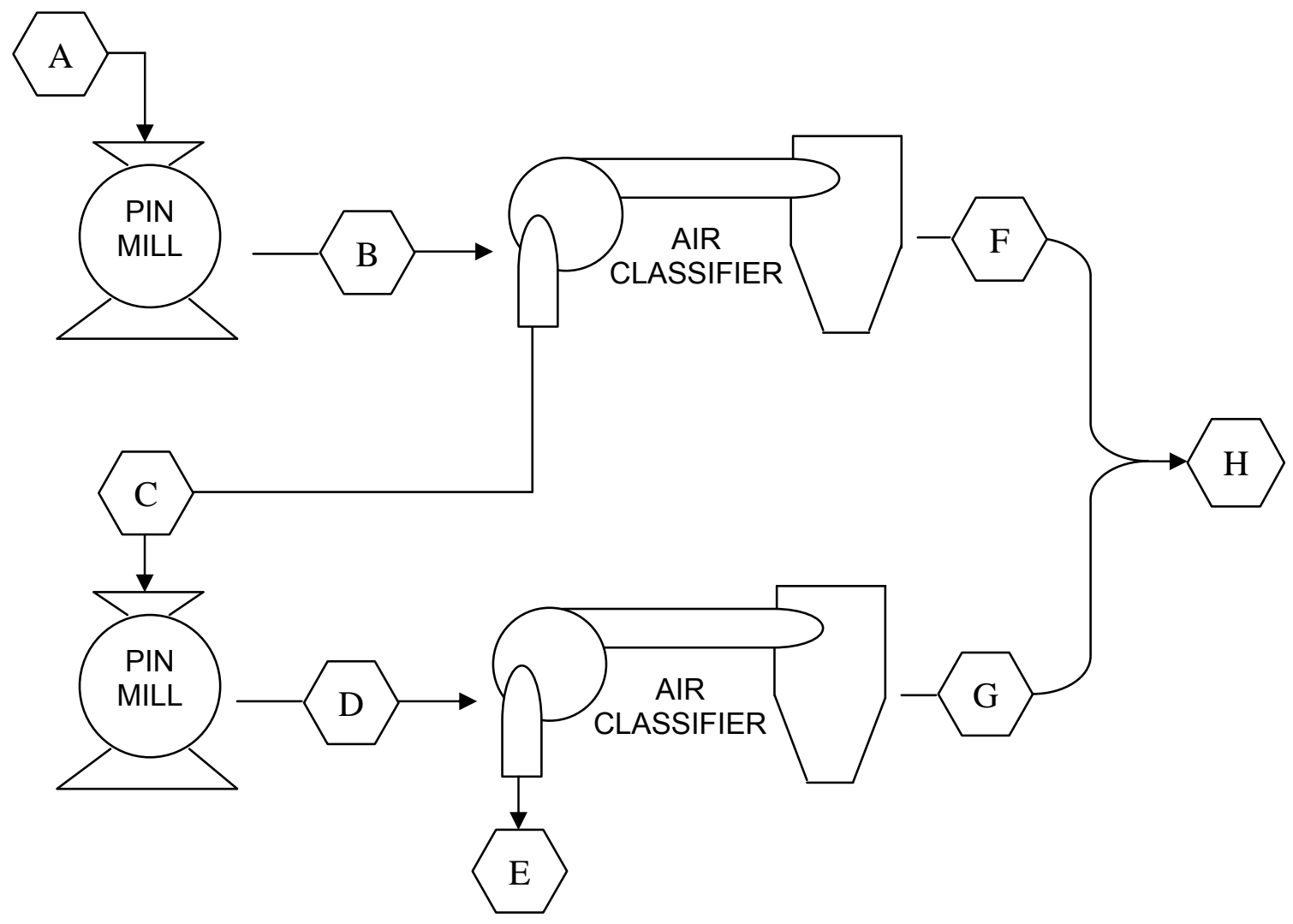
A $100 \mathrm{~kg}$ whole peas $(21 \%$ protein)
E $65 \mathrm{~kg}$ pea starch $(20 \%$ protein $)$
B $100 \mathrm{~kg}$ pea flour (21\% protein)
F $25 \mathrm{~kg}$ pea protein (60\% protein)
C $75 \mathrm{~kg}$ pea starch ( $8 \%$ protein)
G $10 \mathrm{~kg}$ pea protein (46\% protein)
D $75 \mathrm{~kg}$ pea starch (8\% protein)
$\mathrm{H} 35 \mathrm{~kg}$ pea protein (56\% protein)

Figure 2.1 A schematic diagram of an air classification process (Reproduced from Vose et al. 1976 with units converted from lb to kg). 


\subsubsection{Wet Processing/Milling}

The most widely used wet milling technique for starchy legumes is the one patented by Anson and Pader (1957). It involves alkaline solubilization of protein followed by centrifugation to separate the insoluble components, predominantly starch. Hydrochloric acid is added to the supernatant to precipitate the protein component isoelectrically. Seeds used in this method are dehulled in order to reduce the fiber contents of the isolated starch. Flour particle size range of 100 to $150 \mu \mathrm{m}$ is considered as most suitable as larger sizes have been discovered to only increase the amount of protein in the starch isolate (Gueguen 1983). Wet processing of starchy legumes results in the recovery of much purer starch (and the by-product, protein). In addition, unlike dry milling, wet milling also yields protein isolates with fairly bland flavor since most of the volatile flavor compounds are flashed off during the drying stage. However, on a commercial scale, the primary drawback is the involvement of high costs of drying and effluent management (Slinkard et al. 1990).

\subsubsection{Extraction procedure for pea starch}

Figure 2.2 shows the process for the isolation of starch from pea by wet milling. Dehulled seeds are finely ground in water. The slurry is screened to recover cell wall fiber and then adjusted to $\mathrm{pH} 9$ to solubilize the protein components. The cell wall fiber fraction is dewatered and dried (it may contain 50:50 mix of cell wall fiber and starch). The slurry is then centrifuged to separate starch-rich and protein-rich fractions. In order to purify the extracted starch fraction (to $<1 \%$ 
protein), the residue is re-adjusted to $\mathrm{pH} 9$ and then centrifuged. Starch obtained as residue is then washed and dried. The by-product, protein, may then be further extracted via isoelectric precipitation as shown (Figure 2.2).

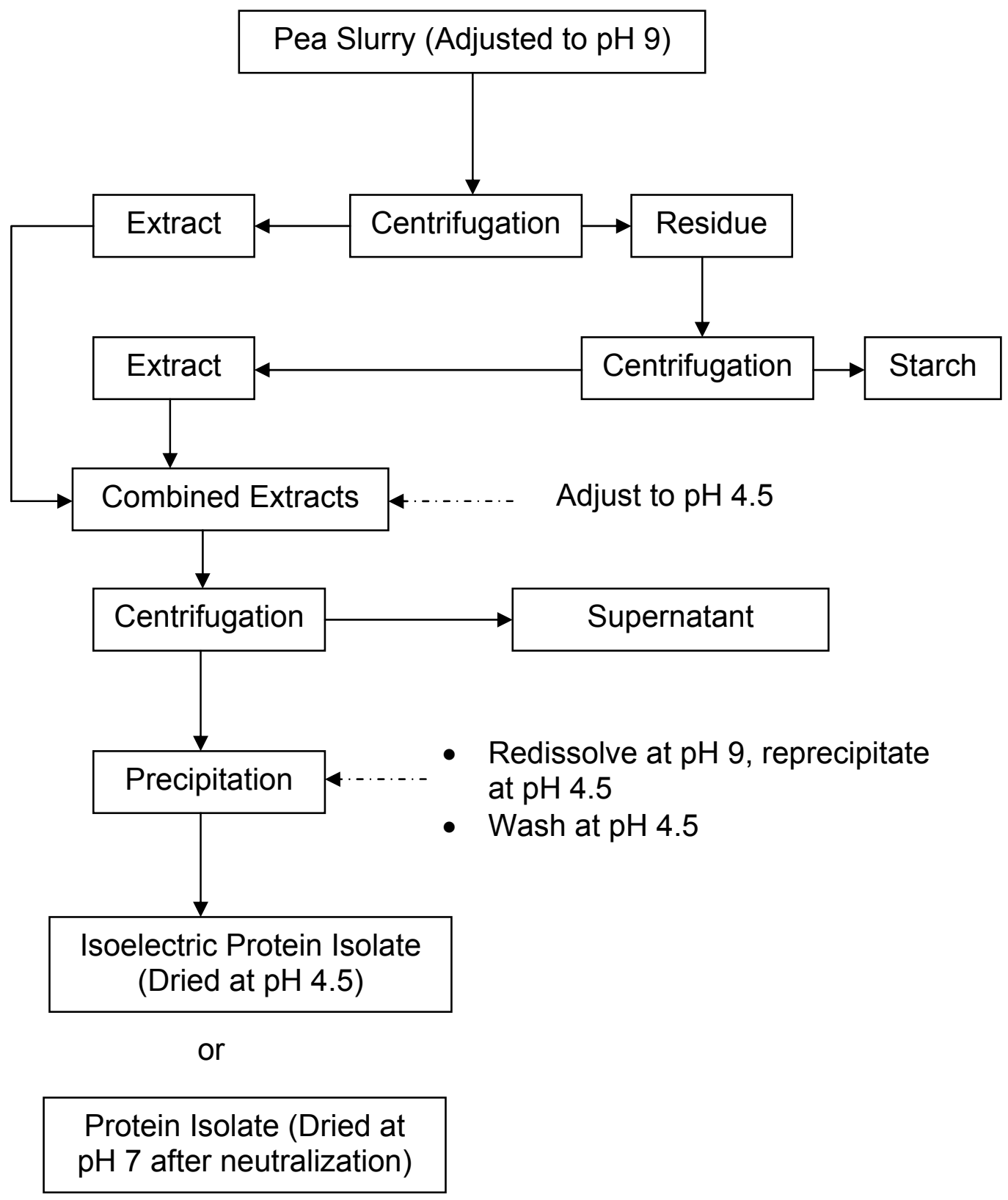

Figure 2.2 Starch extraction from field pea by wet processing. 


\subsection{Starch Granule Size and Shape}

Many studies have been done to ascertain the size and shape of legume starch granules from different sources. Table 2.1 shows results of such investigations as compiled by Hoover and Sosulski (1991). The possibilities are oval, spherical, round, elliptical, and even irregular shapes, with oval being the most common. Starch particle size is an influential factor in certain composite applications (Lim et al. 1992).

Table 2.1 Granule dimensions and shapes of legume starches (Hoover and Sosulski 1991).

\begin{tabular}{|c|c|c|c|c|}
\hline \multirow{2}{*}{$\begin{array}{l}\text { Starch } \\
\text { Source }\end{array}$} & \multicolumn{3}{|c|}{ Dimension (Range) } & \multirow[b]{2}{*}{ Shape } \\
\hline & $\begin{array}{c}\text { Width } \\
(\mu \mathrm{m})\end{array}$ & $\begin{array}{c}\text { Length } \\
(\mu \mathrm{m})\end{array}$ & $\begin{array}{c}\text { Unspecified } \\
(\mu \mathrm{m})\end{array}$ & \\
\hline Kidney bean & $16-42$ & $16-60$ & & Elliptical, oval \\
\hline $\begin{array}{l}\text { Northern } \\
\text { bean }\end{array}$ & $12-40$ & $12-62$ & & $\begin{array}{l}\text { Oval, irregular, } \\
\text { round } \\
\text { Oval, round }\end{array}$ \\
\hline Navy bean & $12-40$ & $12-49$ & & elliptical \\
\hline Black bean & $8-34$ & $8-55$ & & $\begin{array}{l}\text { Oval, spherical } \\
\text { Oval, irregular, }\end{array}$ \\
\hline Mung bean & $7-20$ & $10-32$ & & $\begin{array}{l}\text { round } \\
\text { Oval, irregular, }\end{array}$ \\
\hline Pinto bean & $10-30$ & $12-48$ & & round \\
\hline Faba bean & $12-24$ & $20-48$ & & Oval, spherical \\
\hline Horse bean & & & $6-31$ & Oval, irregular \\
\hline Smooth pea & & & $20-40$ & Oval, round \\
\hline Wrinkled pea & & & $6-80$ & Round \\
\hline Chickpea & & & $8-54$ & Oval, spherical \\
\hline Cowpea & & & $4-40$ & Oval, spherical \\
\hline Lentil & $15-30$ & $10-36$ & & ellipsoid \\
\hline
\end{tabular}




\subsection{Starch Composition}

According to Ellis and co-researchers (1998), starch predominantly consists of two main polymers of glucose namely amylose (molecular weight (MW) $10^{5}$ to $10^{6} \mathrm{~g} / \mathrm{mol}$ ) and amylopectin (MW $10^{7}$ to $10^{9} \mathrm{~g} / \mathrm{mol}$ ), both of which possess distinct characteristics. The relative proportion of these polymers in starch influences its physicochemical properties which, in turn, determine its functionality and hence, its applications. Other components, though present in small amounts, include starch proteins and lipids. The composition and structure of starch granules vary considerably between crop varieties thereby affecting the properties and functions of starches obtained from different crops and/or cultivars. As mentioned earlier, smooth pea and wrinkled pea both differ in amylose/amylopectin ratio. For instance, Ratnayke and co-workers (2002) reviewed amylose contents of 33.1 to $49.6 \%, 8$ to $72 \%$, and 60.5 to $88 \%$ for smooth pea (normal pea), pea mutants, and wrinkled pea, respectively.

\subsubsection{Amylose}

Amylose consists of several thousands of glucose units linearly linked by $\alpha-1,4$ bonds as shown in Figure 2.3. Recent studies suggest that small number of branches do exist in amylose molecules too (Kennedy et al. 1983; Madhusudhan and Tharanathan 1996). According to Curá and co-researchers (1995), the incomplete amylose degradation by $\beta$-amylase must be as a result

of its slightly branched nature since $\beta$-amylase can only hydrolyze alpha-1,4 bonds and not alpha-1,6 bonds. Although slightly branched to the level of about 
1 to $2 \%$ (Cura and Krisman 1990), amylose behaves essentially like an unbranched entity (Eliasson and Larsson 1993; Hoseney 1994) since its branches are quite long and few (Hoseney 1994). Generally, amylose makes up 20 to $30 \%$ of normal starch and its synthesis takes place within the granule by the granule-bound starch synthase (GBSS) which is the only starch synthase found exclusively within the granule (Jobling 2004). However, the amylose contents of legume starches are high, mostly in the range of 24 to $65 \%$ (Hoover and Susulski 1991).

According to Ellis and co-workers (1998), amylose can be extracted from starch by leaching in hot $\left(50^{\circ} \mathrm{C}\right)$ water. As the resultant gel or paste cools, recrystallization of the starch chains (also known as retrogradation) takes place via the alignment of linear segments of amylose chains thereby associating into a more thermodynamically stable form through hydrogen bonding. Consequently, the molecular size of the amylose increases and its solubility decreases, with insoluble particles eventually being formed (Ellis et al. 1998).

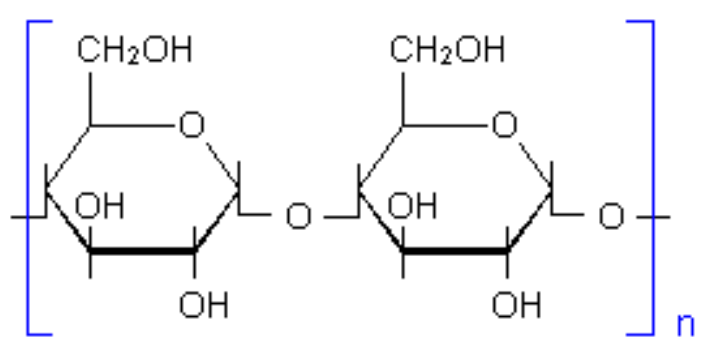

Figure 2.3 Amylose repeating unit. 
In other words, retrogradation decreases storage stability by causing shrinkage and the release of water (syneresis); it also decreases the eating quality of starch-based products (Biliaderis and Zawistowski 1990; Keetles et al. 1996).

The tendency to retrograde is directly proportional to the amylose content (Fanta et al. 2002). Increasing amylose concentration decreases gel stickiness (Tanaka et al. 2006) but increases gel firmness; the higher the amylose content, the lower the swelling power ${ }^{1}$ and the smaller the gel strength for the same starch concentration. Furthermore, Czuchajowska and fellow researchers (1991) reported retrograded amylose as being more resistant to degradation by amylolytic enzymes than the native form. High-amylose starch can therefore be processed into resistant starch which is non-digestible in the small intestine but is fermented in the large intestine by gut bacteria, producing short-chain fatty acids such as butyrate which helps to prevent colon cancer (Bird et al. 2000).

Lastly, the amylose content greatly influences other physicochemical properties of starch such as gelatinization, pasting, and gelation (Zeng et al. 1997; Araki et al. 2000; Noda et al. 2001) such that the higher the amylose content the higher the gelatinization temperature. The helical structure of amylose makes it readily combine with iodine molecules to form complexes that absorb certain wavelengths of light. Therefore, a sample containing amylose produces a blue-black coloration when mixed with small amount of yellow iodine solution; the color intensity can be assessed with a colorimeter using a red filter

\footnotetext{
${ }^{1}$ Swelling power is determined after heating the starch in excess water and is defined as the ratio of the wet weight of the (sedimented) gel formed to its dry weight. It depends on the processing conditions (temperature, time, stirring, and centrifugation) and may be thought of as its water binding capacity (http://www.lsbu.ac.uk/water/hysta.html).
} 
(Teitelbaum et al. 1978; McGrance et al. 1998). Amylose also forms similar insoluble helical complexes with alcohols and lipids (fatty acids) (Milus et al. 1946; Rundle and French 1943(a, b); Rundle 1947; Rundle and Baldwin 1943). Table 2.2 summarizes some properties of legume and cereal amyloses. Except for wrinkled pea with $79-84.7 \%$ (Biliaderis et al. 1979, 1980, 1981; Banks and Greenwood 1967) and mung bean 78.4\% (Naivikul and D'Appolonia 1979;

Table 2.2 Properties of legume and cereal amyloses.

\begin{tabular}{|c|c|c|c|c|}
\hline \multirow[b]{2}{*}{ Properties } & \multicolumn{4}{|c|}{ Starch Sources } \\
\hline & Legumes $^{a}$ & $\begin{array}{c}\text { Wrinkled } \\
\text { Pea }^{\mathrm{a}}\end{array}$ & Wheat $^{b}$ & Corn ${ }^{c}$ \\
\hline $\begin{array}{l}\text { Molecular } \\
\text { weight } \times 10^{5} \\
(\mathrm{~g} / \mathrm{mol})\end{array}$ & $1.65-3.12$ & 1.25 & 2.6 & 2.0 \\
\hline $\begin{array}{l}\text { lodine binding } \\
\text { capacity }(\%)\end{array}$ & $16-22$ & $17.99-19.20$ & $18.5-19.90$ & $\begin{array}{c}19.2 \\
\text { (amylomaize) }\end{array}$ \\
\hline $\begin{array}{l}\text { lodine coloration } \\
\lambda \max (\mathrm{nm})\end{array}$ & $625-630$ & 625 & 660 & $\sim 660$ \\
\hline $\begin{array}{l}\text { Degree } \\
\text { polymerization } \\
\text { (\# glucose units) }\end{array}$ & $573-1900$ & $1000-1100$ & $270-1300$ & $295-960$ \\
\hline $\begin{array}{l}\beta \text {-amylolysis } \\
\operatorname{limit}(\%)\end{array}$ & $>85$ & $79.0-84.7$ & $77.0-79.0$ & $\begin{array}{c}77.0 \\
\text { (amylomaize) }\end{array}$ \\
\hline $\begin{array}{l}\text { Limiting } \\
\text { viscosity } \\
\text { number }[\mathrm{n}] \\
(\mathrm{mL} / \mathrm{s})\end{array}$ & $>180$ & $136-150$ & 330 & 170 \\
\hline $\begin{array}{l}\text { 'Banks and Greenwo } \\
\text { (1979); Lai and Varria } \\
\text { 'Medcalf and Gilles ( } \\
\text { (1988); Sterling 1978; } \\
\text { Greenwood and Thon } \\
\text { 'Banks et al. (1973); } \\
\text { (1969) }\end{array}$ & $\begin{array}{l}\text { d (1967); Bilia } \\
\text { lo-Marsten (19 } \\
\text { 965); Lii and Li } \\
\text { Banks and Gre } \\
\text { son (1962) } \\
\text { terling (1978); }\end{array}$ & $\begin{array}{l}\text { eris et al. (1979, } \\
\text { 9); Kawamura (1 } \\
\text { eback (1977); Ba } \\
\text { nwood (1975); M } \\
\text { anks and Green }\end{array}$ & $\begin{array}{l}\text { 80, 1981); Naivik } \\
\text { 9); Colonna et al. } \\
\text { is et al. (1973); L } \\
\text { vin (1979); Glicks } \\
\text { od (1975); Melvir }\end{array}$ & $\begin{array}{l}\text { land D'Appolonia } \\
\text { (1981b) } \\
\text { neback and Rasper } \\
\text { man (1969); } \\
\text { (1979); Glicksman }\end{array}$ \\
\hline
\end{tabular}


Biliaderis et al. 1979), the $\beta$-amylolysis limits of most legume amyloses exceed $85 \%$ (Biliaderis et al. 1981) which is higher than those of cereal. This implies that legume amyloses are less branched than wheat and corn amyloses.

\subsubsection{Amylopectin}

Amylopectin is a branched polymer of glucose clustering a large amount of short linear ( $\alpha-1,4$ glucosidic) chains by $\alpha-1,6$ glucosidic bonds which itself constitute about $5 \%$ of the total glucosidic bonds (Gallant et al. 1992). Figure 2.4 shows the basic chemical structure of amylopectin. According to Aberle and fellow workers (1994), amylopectin is the predominant constituent of field pea starch. Amylopectin molecular weight of $10^{7}$ to $10^{9} \mathrm{Da}$ makes it one of the largest known molecules (Banks and Greenwoods 1975; Aberle et al. 1992). Amylopectin is synthesized by several enzymes (such as starch synthases,
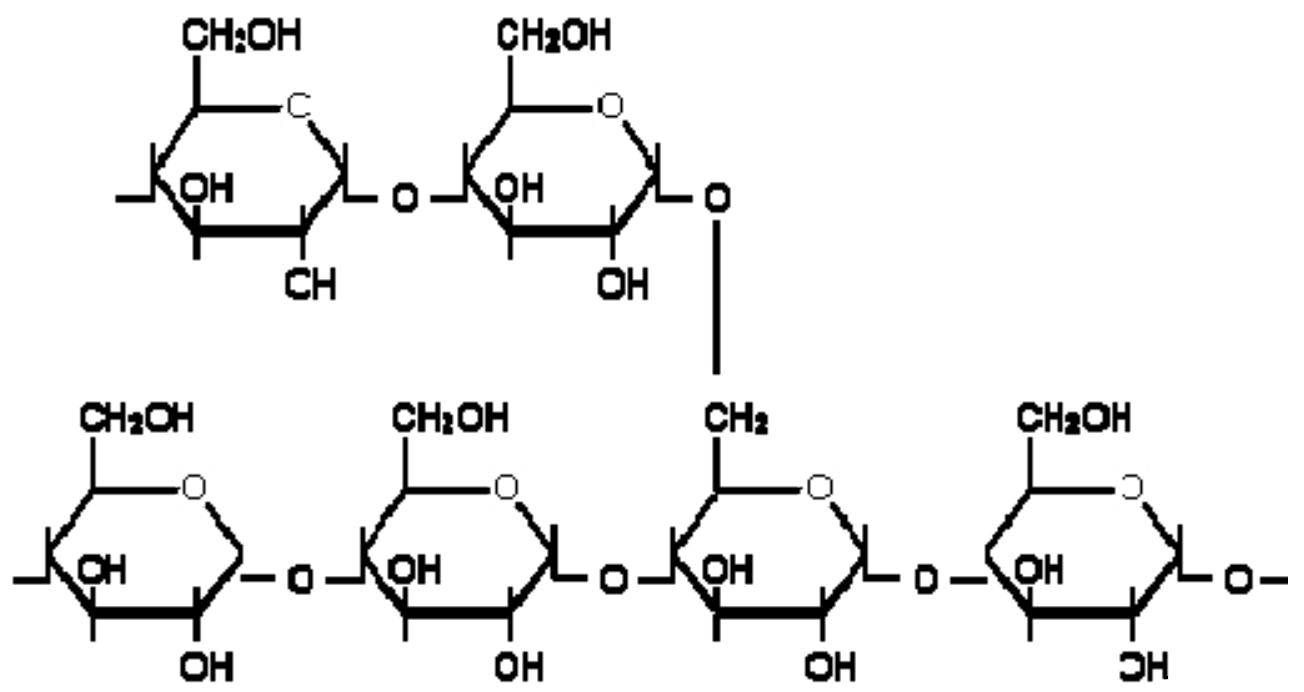

Figure 2.4 Chemical structure of amylopectin. 
branching enzymes, and debranching enzymes) each of which has multiple isoforms, and predominantly on the outer surface of the granule (Ball and Morell 2003). Amylopectins from high-amylose starches have lower degree of branching than those from normal and waxy starches, with the highest degree of branching occurring in waxy maize (Salomonsson and Sunderberg 1994; Falk et al. 1996). Since the branch points in the amylopectin molecules are not randomly distributed (Hizukuri et al. 1989), adjacent linear chains are able to form thin crystalline lamellar domains of about 5 to $7 \mathrm{~nm}$ in width (Ratnayake et al. 2002).

Gernat and co-workers (1993) suggested that starch granule crystallinity increased with amylopectin content. The chain length in high-amylose-starch amylopectin, as observed by Wang and co-workers (1993), is greater than that of normal or waxy starch. As shown in Table 2.3, the average chain length of most legume amylopectins is about 20 to 24 glucose units (Biliaderis et al. 1981 ) with that of wrinkled pea as 34 . Legume amylopectins have longer chain lengths that most cereal amylopectins (Colonna and Mercier 1984) with the exception of high amylose cultivars like amylomaize; however, they have lower molecular weights. Amylopectin is characterized by lower $\beta$-amylolysis limit (55 to $60 \%$ ) than amylase principally due to its branched points which cannot be hydrolyzed by $\beta$-amylase (Hizukuri 1986; Kobayashi et al. 1986). Generally, the intrinsic viscosity and weight average molecular weight of smooth pea amylopectin surpass those of wrinkled pea (Ratnayake et al. 2002). 


\subsubsection{Starch proteins}

Starch granules are also associated with varying amounts of proteins which are classified as either surface proteins or integral proteins. Surface proteins are readily extracted at temperatures below the gelatinization temperature while integral proteins are extracted at temperatures near or above the gelatinization temperature (Ellis et al. 1998).

Table 2.3 Properties of legume and cereal amylopectins.

\begin{tabular}{|c|c|c|c|}
\hline \multirow{2}{*}{ Properties } & \multicolumn{3}{|c|}{ Starch sources } \\
\hline & Legumes $^{a}$ & Wheat $^{\mathrm{b}}$ & Corn ${ }^{c}$ \\
\hline $\begin{array}{l}\text { Molecular weight } \\
\times 10^{6}(\mathrm{~g} / \mathrm{mol})\end{array}$ & $\begin{array}{c}80 \text { (smooth pea) } \\
19.4 \text { (wrinkled pea) }\end{array}$ & $\sim 250$ & - \\
\hline $\begin{array}{l}\text { lodine binding } \\
\text { capacity }(\%)\end{array}$ & $\begin{array}{l}0.9 \text { (smooth pea) } \\
1.7 \text { (wrinkled pea) }\end{array}$ & $<1.0-2.0$ & - \\
\hline $\begin{array}{l}\text { lodine coloration } \\
\lambda \max (\mathrm{nm})\end{array}$ & $540-560$ & $530-550$ & 570 (waxy) \\
\hline $\begin{array}{l}\text { Degree } \\
\text { polymerization (\# } \\
\text { glucose units) }\end{array}$ & 6195 (wrinkled pea) $^{d}$ & $2 \times 10^{6}$ & $2 \times 10^{6}$ \\
\hline $\begin{array}{l}\text { Chain length (\# } \\
\text { glucose units) }\end{array}$ & 34 (wrinkled pea) & $17-25$ & $\begin{array}{c}28 \\
\sim 19 \text { (waxy) } \\
44 \\
\text { (amylomaize) }\end{array}$ \\
\hline$\beta$-amylolysis limit (\%) & $56.1-66.5$ & $\sim 55.0$ & 57.2 (waxy) \\
\hline $\begin{array}{l}\text { Limiting viscosity } \\
\text { number }[\mathrm{\eta}](\mathrm{mL} / \mathrm{s})\end{array}$ & $\begin{array}{c}126-131 \\
114 \text { (wrinkled pea) }\end{array}$ & $90-150$ & $35-100$ (waxy) \\
\hline
\end{tabular}


By another definition, starch granule surface proteins are those that are susceptible to hydrolysis upon treatment of intact granules with exogenous proteases while internal granule proteins are those that (a) become susceptible to proteolysis only following thermal disruption of the starch matrix, and (b) resist extraction by $2 \%$ sodium dodecyl sulfate (SDS) at room temperatures (Denyer et al. 1993; Rahman et al. 1995; Mu-Forster et al. 1996). Friabilin, a granule surface protein, has been linked to kernel hardness (Anjum and Walker 1991), a factor that affects the starch granule extraction energy costs (Ellis et al. 1998).

Another form of starch proteins is present as enzymes trapped within the starch granule which may be remnants of starch biosynthesis or enzymes needed for starch hydrolysis during seed germination (Eliasson and Larsson 1993; Lineback and Rasper 1988; Lowy et al. 1981). These enzymes include alpha- and beta-amylases. Beta-amylase works from the non-reducing end

cleaving the alpha-1,4 linkages, 'biting off' two sugars at a time to give maltose while alpha-amylase can cleave the alpha-1,4 linkages at any point in the starch chain (Eliasson and Larsson 1993). However, the two cannot cleave the alpha1,6 linkages. Instead, alpha-amylase bypasses such bonds while beta-amylase, which cannot, leaves beta-limit dextrins (Eliasson and Larsson 1993).

\subsubsection{Starch lipids}

According to Ellis and co-workers (1998), lipids extracted from starch granules may be integral components of the granules or have originated elsewhere in the 
tissues and become associated with the granules during the starch extraction process. Starch granules from cereal endosperms uniquely contain integral lipids whereas those from legume seeds, potato tubers, or other cereal tissues other than the endosperm do not (Galliard and Bowler 1987). Legume starches (as well as waxy cereal and tuber starches) have small amounts of surface lipids and little or no internal lipids, while high amylose cereal starch tend to have more lipid (most of which is internal) than the corresponding normal starch.

Two classes of starch granule lipids exist: starch lipids and non-starch lipids. According to Vasanthan and Hoover (1992), non-starch lipids are surface lipids (easily extracted) which occur as spherosomes and membrane lipids which may be present on the granule surface in situ within the plant tissue. They may also be monoacyl non-starch lipids which have become bound to the carbohydrate surface of starch granules, perhaps as amylose-inclusion complexes (Morrison 1983). Internal starch lipids, also known as true starch lipids, reside inside the starch granules and are thought to exist as amyloseinclusion complexes. They are difficult to extract and are predominantly monoacyl lipids which primarily include lysophospholipids and free fatty acids (Morrison 1983).

\subsection{Gelatinization}

The outer layer of each starch granule consists of closely packed starch molecules that are impervious to cold water. When starch slurry is heated, 
water penetrates the outer layers of the granules and the granules begin to radially swell. The swelling may continue until the granule volume is as much as five times the original volume (SSC 2006). During this process, the bundles of starch molecules separate as the granule absorbs water and the slurry viscosity increases until the granular state of the starch has largely disappeared leaving behind an amorphous mass of starch and water bound together forming a gel.

Gelatinization is therefore the collapse (disruption) of molecular order within the starch granule manifested in irreversible changes in properties such as granular swelling, native crystallite melting, loss of crystallinity, loss of birefringence (optical anisotropy or double refraction under polarized light), and starch solubilization (Atwell et al. 1988; Zobel 1984). In other words, gelatinization is an irreversible process and it requires excess water to occur. According to Ellis and fellow researchers (1998), the energy required to break up the molecular order differs between granules and as a result, gelatinization occurs over a range of temperatures; individual granules gelatinize over a range of 1 to $2^{\circ} \mathrm{C}$ and there are considerable variations between granules; hence, the need to quote a temperature range, a parameter that is source dependent (Ratnayake et al. 2002). Jenkins (1994) postulated that in the presence of excess water, granular swelling, which destabilizes the amylopectin crystallites within the crystalline lamellae (happening rapidly for an individual crystallite and over a range for the whole granule), drives gelatinization.

In a more detailed and comprehensive way, the mechanism of gelatinization has been broken down into some phases (Xie et al. 2006). The 
first phase involves gradual and reversible granule absorption of water with water mobility decreasing as the temperature increases from 20 to $60^{\circ} \mathrm{C}$. Any granule change at this stage is reversible (Gough and Pybus 1971). In other words, this process takes place prior to the onset of gelatinization and does not result in the disruption of the starch granules as water is believed to be reversibly complexed with starch molecules in the granule (Olkku and Rha 1978). However, as the temperature of starch slurry increases up to the initial gelatinization temperature, the hydrogen bonds within the granule weaken to an extent, thereby, allowing for further granule water absorption (Tester and Debon 2000). Concomitantly, dissociation of double helices predominantly in the crystalline region, irreversible granule swelling and loss of granule birefringence result (Tester and Debon 2000). This irreversible transformation, which starts in the intercellular areas having the weakest hydrogen bonds, takes place over a range of temperature depending on the starch under study (Olkku and Rha 1978). Loss of birefringence has been shown to precede granule rupture (Yeh et al. 1996).

Furthermore, as the heating of the starch slurry progresses, the hydrogen bonds of the starch molecules continue to be severed thus allowing for water molecules to bind with the starch $-\mathrm{OH}$ by hydrogen bonding. Consequently, there is crystallite melting and greater granule swelling (Lim et al. 2000) which, in turn, leads to an increase in starch solubility, paste consistency, and clarity (Tester and Debon 2000). It has been observed that swelling also makes the granule prone to shear disintegration. According to Tester and 
Debon (2000), as the end of gelatinization temperature $\left(T_{c}\right)$ is surpassed, total breakdown of all the amylopectin double helices would have occurred but not necessarily the rupturing of the swollen granules, a process that may require higher temperature and applied shear. Olkku and Rha (1978) noted that hot starch pastes contained swollen starch granules, granule fragments, and starch molecule colloids (attributable to soluble components, essentially amylose, leached out during the process). The above mechanism essentially applies to an excess water scenario.

Nonetheless, gelatinization is also possible in limited water situation as it is in the processing of thermoplastic starch only that it will require higher temperature and shear forces to produce a microscopically homogeneous material since granule swelling and disintegration are severely impeded by insufficient water (Hullemen et al. 1998). In the same vein, Ratnayake and coworkers (2002) concurred that gelatinization in the presence of limited water has the same mechanism only that there is insufficient water for total gelatinization to occur; however, melting of the remnant crystallites occurs at higher temperatures. Burt and Russell (1983) also observed that gelatinization endpoint temperature increased with decrease in water content.

Gelatinization can also occur in the presence of shear stresses which physically separate the starch molecules in the granule, thereby, allowing water to be absorbed. Furthermore, alkaline reagents such as a hydroxide or hypochlorite can gelatinize starch because they are capable of initializing the 
oxidization of starch molecules thereby disrupting the composition of the starch granule which, in turn, facilitates water absorption (PA 2006).

\subsection{Flax Fiber}

In addition to the oil extractable from flax (Linum usitatissimum L.) seeds, flax is also recognized as a veritable source of industrial fibers that are processed into long-line fibers used in manufacturing high value linen apparel and short fibers used for less value products (van Sumere 1992). Two traditional methods employed in flax fiber extraction are water retting and dew retting; the former which produces high quality fiber has nevertheless been discontinued in western countries decades ago owing to associated stench and pollution (from fermentation) coupled with high cost of drying (Brown 1984).

Water retting involves submerging flax stems into river and lake followed by anaerobic breakdown of the pectins and other matrix substances, thus, freeing up individual fibrils. Dew retting, on the other hand, entails spreading the stems out in the field for selective fungal attack over several weeks. However, this procedure results in heavily contaminated, coarser, and lower quality fiber than water retting. Other associated problems include poor consistency in fiber characteristics and occupation of agricultural fields for several weeks (van Sumere 1992). Hence, enzyme retting technique (which involves the use of enzyme mixtures such as Flaxzyme in controlled tanks with the advantage of producing fibers with fineness, strength, color, and waxiness comparable to the best water-retted fiber and without the issues of stench and pollution) was 
developed. Other advantages of enzyme retting include time savings (of four to five days) and fiber consistency (van Sumere and Sharma 1991).

\subsubsection{Reinforcement functionality of natural fibers}

Sequel to economic and environmental concerns associated with synthetic fibers such as glass fiber as plastic reinforcement, there has been huge interest in developing inexpensive 'green' substitutes. The natural role natural fibers (also known as biofibers) play in providing support to the plant parts where they are found (with the exception of seed fibers) is currently being harnessed in polymer reinforcement. However, in order to maximally exploit the reinforcement potentials of any biofiber in fiber-polymer composites, the fiber content should not exceed an optimum value which is obtainable experimentally. Beyond this value, stress transfer is impeded due to agglomeration and, hence, the composite properties drop, even below those of the pure polymer (Indicula and Thomas 2004).

Bast fibers run through the stem impacting structural firmness and strength, and so do leaf fibers. Physical properties of plant fibers are basically a function of fiber chemistry such as cellulose content, degree of polymerization, orientation, and crystallinity, all of which depend on plant growing conditions and extraction methods. These properties have also been found to vary largely with respect to the source plant part, plant quality, and location (Herrera Franco and Valadez-González 2005). The mechanical properties of some natural fibers in comparison to some synthetic fibers are as given in Table 2.4 . 
Natural fibers are light-weight, non-abrasive (thus prolonging the service-life of fabrication equipment), and exhibit good mechanical properties (De Carvalho and Curvelo 2002). In fact, biofibers are preferred alternatives to the widely used glass fiber in that they are inexpensive, recyclable, renewable, and biodegradable, while possessing high strength-to-weight ratio (Morton and Hearle 1975; Bürger et al. 1995). This high strength-to-weight ratio property coupled with low cost favorably disposes them for consideration and subsequent adoption in large-volume engineering applications like automobile, aircraft and construction industries (Gouanve et al. 2006). Biofibers can readily be used with polar matrices without the need for compatibilizing agents (De Carvalho and Curvelo 2002).

However, unlike glass fiber that starts to degrade at temperature about $2000^{\circ} \mathrm{C}$, they exhibit low thermal stability: their first degradation occurs at temperatures above $180^{\circ} \mathrm{C}$. Therefore, they are only suitable for processing conditions at or below this temperature; hence their use with plastic matrixes such as polyethylene, polypropylene, and polyvinylchloride with melting points equal or below the degradation temperature (Gassan and Bledzki 2001). Their relatively high sensitivity to heat makes the recycling option for fiber-reinforced composites less feasible (De Carvalho and Curvelo 2002). They are also used to reinforce thermoset polymers like polyester, epoxies, and phenolics (Herrera Franco and Valadez-González 2005). Some of the changes that take place when a cellulose-based material is heated to temperatures at about 100 to $250^{\circ} \mathrm{C}$ can be attributed to physical or chemical changes such as 
depolymerization, hydrolysis, oxidation, dehydration, decarboxylation, and recrystallization (Zeronian 1977).

Table 2.4 Mechanical properties of some natural and synthetic fibers (Bledzki and Gassan (1999); Paul et al. (1997); Frederick and Norman (2004); Murali Mohan Rao et al. (2007)).

\begin{tabular}{ccccc}
\hline Fiber & $\begin{array}{c}\text { Fiber Density } \\
\left(\mathbf{g} / \mathbf{c m}^{\mathbf{3}} \mathbf{)}\right.\end{array}$ & $\begin{array}{c}\text { Elongation } \\
\mathbf{( \% )}\end{array}$ & $\begin{array}{c}\text { Tensile } \\
\text { Strength } \\
\mathbf{( M P a )}\end{array}$ & $\begin{array}{c}\text { Young's } \\
\text { Modulus } \\
(\mathbf{G P a})\end{array}$ \\
\hline Cotton & $1.50-1.6$ & $3.0-10.0$ & $287-597$ & $5.5-12.6$ \\
Jute & $1.30-1.46$ & $1.5-1.8$ & $393-800$ & $10.0-30.0$ \\
Flax & $1.40-1.50$ & $1.2-3.2$ & $345-1500$ & $27.6-80.0$ \\
Hemp & 1.48 & 1.6 & $550-900$ & 70.0 \\
Ramie & 1.50 & $2.0-3.8$ & $220-938$ & $44.0-128.0$ \\
Sisal & $1.33-1.5$ & $2.0-14.0$ & $400-700$ & $9.0-38.0$ \\
Coir & 1.20 & $15.0-30.0$ & $175-220$ & $4.0-6.0$ \\
Softwood & 1.50 & - & 1000 & 40.0 \\
kraft & 1.35 & $1.0-3.5$ & $529-759$ & $8.0-20.0$ \\
Banana & 0.82 & 2.5 & 185 & 7.4 \\
$\begin{array}{c}\text { Elephant } \\
\text { grass }\end{array}$ & 2.50 & $2.5-3.0$ & $2000-3500$ & 70.0 \\
$\begin{array}{c}\text { E-glass } \\
\text { S-glass }\end{array}$ & 2.50 & 2.8 & 4570 & 86.0 \\
$\begin{array}{c}\text { Aramide } \\
\text { (normal) }\end{array}$ & 1.40 & $3.3-3.7$ & $3000-3150$ & $63.0-67.0$ \\
$\begin{array}{c}\text { Carbon } \\
\text { (standard) }\end{array}$ & 1.40 & $1.4-1.8$ & 4000 & $230.0-240.0$ \\
\hline & & & & \\
\hline
\end{tabular}


Furthermore, the highly polar nature of cellulose fibers renders them incompatible with nonpolar polymers. The more dissimilar the components of a polymer composite are, the less compatible they will be. Since strong adhesion at the interface between two phases is essential for an effective stress transfer and load distribution throughout the interface, poor compatibility ultimately results in composites with poor mechanical properties (Herrera Franco and Valadez-González 2005). Cellulose is a polyhydroxy substance and is, therefore, very hydrophilic since the polar hydroxyl groups provide sites for interaction/bonding with water molecules (Kondo 1994). Consequently, natural fibers are less compatible with non-polar matrices. They also possess poor moisture resistance which makes them less suitable for exterior applications. To these end, techniques involving surface modification of cellulosic fibers (not discussed in this thesis) have been investigated.

\subsection{Poly( $\varepsilon$-caprolactone)}

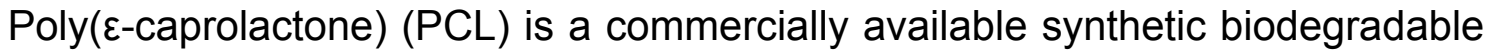
polyester that possesses good mechanical strength and is hydrophobic (Hung and Edelman 1995; Wu 2003). It has the chemical formula of $\left(\mathrm{C}_{6} \mathrm{H}_{10} \mathrm{O}_{2}\right) \mathrm{x}$.

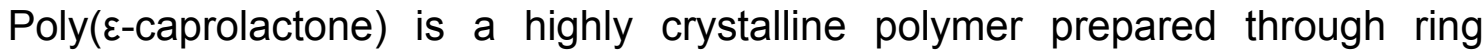
opening polymerization of $\varepsilon$-caprolactone (Núñez 2004; Hong et al. 2005). It has a low melting point of about $60^{\circ} \mathrm{C}$ (Wu 2006) which militates against its widespread industrial applications (Vertuccio et al. 2009) and a glass transition temperature of about $-60^{\circ} \mathrm{C}$. $\mathrm{PCL}$ is relatively expensive (Wu 2006) and is quite 
suitable for biomedical applications due to its physiological hydrolytic degradability (Ratner 1997). It has also been found to be compatible with some other polymers (Hung and Edelman 1995).

\subsection{Developing Biodegradable Plastics - Role of Starch}

The disposal problems associated with the non-biodegradation of conventional oil-based plastics constitute grave environmental menace across the globe considering the amounts churned out as waste on a regular basis. While taking cognizance of the fact that some plastics (particularly thermosets) are intrinsically not recyclable, it is important to mention that plastic recycling faces additional problems of high energy consumption and difficulties arising from contaminants and fiber reinforcements (Widmer 2003). Difficulties in plastic removal, collection, and classification prior to recycling are also issues of concern (Prinos et al. 1998). In addition, the production of complex multiphased products makes recycling increasingly infeasible.

In 2005, the US alone generated about 28.9 billion $\mathrm{kg}$ of plastic waste (11.8\% of the total 245.7 billion $\mathrm{kg}$ of municipal solid waste) with only a very small amount of about 1.7 billion $\mathrm{kg}(5.7 \%$ of the total plastic waste) recovered for recycling while discarding the remaining 27.3 billion $\mathrm{kg}$ (about $16.4 \%$ of the total municipal solid waste discards) to landfills, with the container and packaging category constituting the highest tonnage (EPA 2006). This is understandably so because these products are mostly single-use items. 
Therefore, the current revolution taking place in the plastics industry focuses on developing novel plastics possessing material properties comparable to their conventional counterparts in addition to the added advantage of biodegradability. Sustained scholarly efforts have been directed towards building and perfecting a new generation of plastics that have renewable resources as the base material. The idea of bioplastics is rooted in the quest for eco-friendly products. For instance, bioplastics are capable of significantly reducing environmental impact such as energy consumption and greenhouse effect in certain applications (Bastioli 2001).

At the core of this effort is starch, an abundant naturally occurring biopolymer. Starch, a biomass only second to cellulose in availability (Jane 1995), consists predominantly of two polymers of glucose, namely, amylose and amylopectin (Figures 2.3 and 2.4, respectively). The amylose/amylopectin ratio, which is a function of the starch source, is significant as it influences other physicochemical properties of starch which, in turn, determine starch overall functionality and eventual applications. Of these physicochemical properties, gelatinization is of importance to starch plastic prospects and is defined according to Atwell and co-workers (1988) as the collapse (disruption) of molecular order within the starch granules manifested in irreversible changes in properties such as granular swelling, native crystallite melting, loss of crystallinity, loss of optical birefringence, and starch solubilization. The amylose content is known to influence starch gelatinization as well as gelation and retrogradation (starch chain realignment on cooling after gelatinization) 
(Fredriksson et al. 1998; Varavinit et al. 2003). Other factors that affect gelatinization and swelling properties according to Tester (1997) include amylopectin molecular structure (in terms of unit chain length, molecular weight, degree of branching, and polydispersity), lipid-complexed amylose chains, phosphorous content, and granule structure (crystalline/amorphous ratio).

The advantages of starch exploited in plastic production include its renewability, good oxygen barrier in the dry state, abundance, and low cost (Thunwall et al. 2006). In the past three decades, starch has been incorporated into petroleum-based plastics to enhance their after-use degradation. In starchsynthetic polymer blends, starch has played roles as filler in the granular form, matrix directly as in thermoplastic starch (TPS), and indirectly as in the production of poly (lactic acid), a synthetic biodegradable polymer made from ring-opening polymerization of lactic acid obtained from starch fermentation.

\subsubsection{Starch as fillers}

Starch has been incorporated into conventional plastics in an attempt to impart some level of biodegradability on the resultant composites. Starch is a good biodegradable filler candidate because it possesses satisfactory thermal stability and causes minimum interference with melt-flow properties of most materials used in the plastics industry unlike common cellulosic fillers such as wood flour and paper pulp that were found to interfere with flow properties. A remarkable success was recorded when starch was experimented with lowdensity polyethylene even during critical film extrusion process (Griffin 1974). 
Since starch is hydrophilic, unlike plastics that are generally hydrophobic, there is therefore poor starch-polymer interfacial interaction with a resultant loss of mechanical properties (Albertsson and Karlsson 1995) in starch-filled polymer composites. In other words, high surface energy between the hydrophobic polymer (say, polyethylene) and hydrophilic starch yields low degree of adhesion; in a perfect adhesion scenario, loading stresses would be transferred to the filler phase without any reduction in effective surface area (Willet 1994).

However, a stronger interaction between the starch granules and the plastic matrix can be achieved with gelatinized or 'destructured' starches (Ellis et al. 1998). In addition, using chemically modified starch offers improved mechanical properties (Takagi et al. 1994; Kim and Lee 2002) of starch-filled composites. Upon exposure to microbial activities, the composite structure is weakened as a result of the degradation of the starch component (Vallini et al. 1994), thus leading to a partial breakdown process referred to as biofragmentation. The granule size is an important factor in choosing the appropriate starch for composite use especially in the production of thin films (Lim et al. 1992). At constant filler content, modulus, tensile stress, and yield stress decrease with increase in particle size. Nonetheless, Willett (1994) noted that adhesion played a greater role than particle size on starch-polyethylene composite tensile strength. On the other hand, Nielsen (1974) earlier opined that good adhesion was not that important provided the frictional forces between the phases were not surpassed by the applied external stresses. 
These two schools of thought proposed by Willet (1994) and Nielsen (1974) may differ in perspective but they indeed converge in tenet, in that they both underscore the importance of effective stress transfer between the polymer matrix and the filler.

Furthermore, the fact that rigid fillers such as granular starch are capable of improving certain physical properties, essentially dimensional stability and stiffness (tensile modulus), of the polymers to which they are added (Nielsen and Landel 1994) is noteworthy. Corn starch granule has a modulus of $15 \mathrm{GPa}$ as estimated by Willet (1994), a value more than those of most unfilled commercial polymers ( 1 to $4 \mathrm{GPa}$ ) but less than those of cellulose fibers. By incorporating dried native sago starch (average size of $20 \mu \mathrm{m}$ ) into linear low density polyethylene (LLDPE) via melt-mixing, Nawang and co-researchers (2001) observed a reduction in mechanical properties such as tensile strength, yield strength, and elongation at break, but an increase in modulus (stiffness) with increase in filler (starch) content. Even at the optimum filler content of $15 \%$ wt (the proportion beyond which a steep decline in mechanical properties was recorded), a scanning electron microgram (SEM) of the composite fracture surface revealed poor interaction (poor wettability) between the starch granules and the polymer matrix and a non-uniform distribution of the granules, a situation that led to the formation of stress concentration points.

In a further work, Abdul Khalil and co-workers (2001) investigated the mechanical and water absorption properties of composites of LLDPE and sago starches modified separately by esterification with 2-dodecen-1-yl succinic 
anhydride (DSA) and propionic anhydride (PA) using N,N-dimethylformamide (DMF) as solvent. It was observed that the tensile moduli of both the DSA- and PA-modified starch-LLDPE composites increased as starch content increased (with the latter showing higher stiffness), and were greater than those of the native starch-LLDPE composites for the measured starch range. Decrease in tensile strength and elongation at the break was also noticed for all the composites with unmodified starch showing the most reduction in tensile strength, PA-modified starch composite showing the most reduction in elongation at break, and unmodified starch the least, an overall indication that modification improved starch-LLDPE interfacial interaction.

Kim and Lee (2002) reported similar improvements in tensile strength and percent elongation with cross-linked potato starch over native starch (starch as is) in starch-filled LLDPE composites. In addition, the modifications expectedly improved water stability of the composites since starch was made more hydrophobic (Abdul Khalil et al. 2001). In a related study, Szymanowski and co-researchers (2005) reported an improvement in the tensile strength of radio-frequency methane plasma-modified potato starch-LDPE composite over the unmodified, regardless of starch content. The modification did not only increase the starch hydrophobicity but also produced a substantially deagglomerated starch, the main reason adduced for the observed improved strength. It therefore goes without saying that starch modifications (both chemical and physical) yield positive, yet differing, results. 
Willet (1994) also reported that the use of compatibilizer (ethylene-coacrylic acid copolymer, EAA) remarkably increased the tensile modulus but did not significantly affect the tensile strength and elongation of native granular corn starch-LDPE composites; thus, it was concluded that the improvement in adhesion was only effective within the elastic range. According to Dubnikova and co-workers (1997), in any filled polymer, three factors that influence the specific stress interval over which filler debonding takes place include the size of the filler particles, interfacial strength, and filler volume fraction. More complex multi-phase composites have been investigated in the hope of improving the composite mechanical properties (Kolarik and Jancar 1992; Benderly et al. 1995). In a ternary (three-phase) composite system, there are two possibilities; these include: (1) both the filler and the minor components being separately dispersed in the continuous matrix; or (2) the minor component encapsulating the filler particles. The latter has been shown to improve some composites mechanical performance provided there is strong interaction between the coating on the filler and the matrix (Alberola et al. 1997).

Lawrence and co-workers (2004) investigated the tensile properties of some binary and ternary composites prepared using corn starch, LDPE and poly(hydroxyester ether) (PHEE) composites and reported that the tensile strength of starch-PE-PHEE composite was greater than that of starch-PE composite, and both decreased with increase in starch volume fraction. At total filler volume fraction below 0.20 , the yield strengths differed in the following order: starch-PE-PHEE>starch-PE>pure PE, an indication that the minimum 
debonding energy was greater than the matrix (PE) yield stress. It was also observed that the PHEE interlayer (coating) on the starch granules raised the debonding stress interval (or in other words, enhanced filler-matrix interfacial interaction) which in turn translated into better tensile and yield strengths for the starch-PE-PHEE blend. An SEM of the fracture surface of the starch-filled blends revealed that the debonded starch granules still had PHEE coating on them, an indication that the starch-PHEE bond was stronger than the PHEE-PE bond (Lawrence et al. 2004).

\subsubsection{Thermoplastic Starch (TPS)}

The production of TPS (also known as plasticized starch, PS) basically involves three essential components, namely: starch, plasticizer, and thermomechanical energy. According to Xie and co-workers (2006), developing TPS is more involved than conventional thermoplastics as it entails gelatinization, melting, volume expansion, molecular degradation, and various starch physicochemical changes. The thermoplastification of starch entails the collapse of starch crystallinity (which in general is about $15-45 \%$ of the granule molecular order) through the formation of hydrogen bonds between the plasticizer and starch molecules in the presence of some energy, invariably severing the hydrogen bonds between the hydroxyl groups of the starch molecules to form TPS (Yang et al. 2006). Therefore, the crystallinity observed in TPS is due to the hydrogen bonds formed between starch and the plasticizer molecules and according to Thunwall and co-researchers (2006a), this degree of crystallinity is expected to 
be rather low. It is important to mention that there must be sufficient amount of plasticizer $(30 \% \mathrm{wt}$ for glycerol-plasticized starch) for the formation of a homogeneous (continuous) phase to occur, otherwise some starch granules will remain intact in the TPS, a condition that can make the TPS fracture under tension at very low strains (Yang et al. 2006).

Plasticizers impart pliability by modifying the free volume (that is, increasing intermolecular distances) of the matrix such that starch chains enjoy more mobility (Torres et al. 2007). The use of starch alone is not encouraged because of its lack of melt-processability and humidity-resistance which in turn militates against its suitability for extrusion or injection molding (Wang et al. 2003). The most common plasticizers used are water and glycerol, which often times are used together. The TPS thus produced exhibits two major drawbacks, namely, poor mechanical properties and moisture resistance (Carvalho et al. 2003; Schlemmer et al. 2007; Huneault and Li 2007).

To this end, five areas of consideration are being explored; these include plasticizers, starch type and form (in relation to chemical modification and amylose/amylopectin ratio), reinforcements (organic and inorganic), polymer orientation, and blends with other synthetic polymers (discussed in the following Sections).

Accordingly, chemicals such as ethylenebisformamide (Yang et al. 2006), urea (Kazuo et al. 1998), formamide (Ma and Yu 2004b), sorbitol (Wang et al. 2000), and xylitol (Kirby et al. 1993) have been investigated for their plasticizing abilities. Using corn starch, Yang and co-workers (2006) reported 
that extruded ethylenebisformamide-PS showed better moisture resistance than glycerol-PS but rather lower corresponding tensile strengths at plasticizer contents measured, with both decreasing in strength with increase in plasticizer contents. The glass transition of the ethylenebisformamide-PS was found higher than that of glycerol-PS $\left(63.3^{\circ} \mathrm{C}\right.$ against $\left.38.3^{\circ} \mathrm{C}\right)$ since ethylenebisformamide formed stronger hydrogen bonds with starch than glycerol.

Thunwall and co-researchers (2006b) reported that glycerol-plasticized potato starch produced using hydroxypropylation/oxidation-modified starch exhibited a modestly higher moisture resistance than that of native starch. However, increase in glycerol content reduced the moisture resistance of the TPS regardless of the type of starch used. Modified native potato starch and high amylose starch offered reduced viscosity levels (measured at $140^{\circ} \mathrm{C}$ ) for starch melts containing 30\% (dry mass) glycerol. In comparison with a highdensity polyethylene, Thunwall and co-workers (2006b) further noted that polyethylene melt at $180^{\circ} \mathrm{C}$ had lower viscosity than native potato PS and hydroxypropylation/oxidation-modified high amylose PS but higher than that of hydroxypropylation/oxidation modified native potato PS, all at $140^{\circ} \mathrm{C}$. Interestingly enough, Govindasamy and co-workers (1996) implied that increased viscosity could translate into increased degree of gelatinization because of its resultant increased residence time in the extruder barrel. Thunwall and co-workers (2006b) also discovered that starch melt drawability, a crucial property in film production, generally increased with glycerol and chemical modification but decreased with temperature; but in comparison with 
PE melt, PS melt was very much low in extensibility. It is important to mention that it is rather difficult to make thin blown films with granular starches as fillers in polymer composites due to their big particle size range $(5-100 \mu \mathrm{m})(\mathrm{Hwan}$ Man et al. 2003), hence the preference for TPS.

Schlemmer and fellow researchers (2007) approached the issue slightly differently by blending cassava starch $(74.70 \pm 1.76 \%)$ plasticized with water and glycerol, and another with water and buriti oil, all in ratio 50:15:35 (mass/vol/vol) with polystyrene in different ratios by mass. It was observed that blends with TPS plasticized by buriti oil were apparently more thermally stable than those by glycerol. A reduction of up to $60 \%$ in the water uptake of TPS could be achieved by replacing glycerol with sugar/water mixture as plasticizer with a concomitant reduction in the TPS crystallinity though (Teixeira et al. 2007).

One property peculiar to TPSs plasticized with polyols (such as glycerol, sorbitol, glycol, and sugars) is their retrogradation (recrystallization due to reformation of hydrogen bonds between starch molecules) propensities as they age, a condition that leads to embrittlement. This phenomenon could be inhibited using formamide as plasticizer (since it could form stronger or more stable hydrogen bonds with starch $-\mathrm{OH}$ groups), however with a reduction in tensile strength and modulus against an increase in energy break and elongation at break vis-à-vis glycerol plasticized starch (Ma and Yu 2004b). Amides generally form stronger hydrogen bonds with starch -OH groups than polyols in the following order: urea > formamide > acetamide $>$ polyols ( $\mathrm{Ma}$ and 
Yu 2004a). Although with a compromise on tensile stress, similar result of inhibited retrogradation coupled with reduced shear viscosity (improved fluidity) of TPS, improved elongation, thermal stability, and moisture resistance at high relative humidities was achieved by $\mathrm{Yu}$ and co-researchers (2005) when glycerol-plasticized TPS was modified with citric acid in comparison with the unmodified.

The natural role biofibers (with the exception of seed fibers) play in providing support to the plant parts where they are found has also been harnessed to reinforce TPS. Generally, good wettability and compatibility of fiber with the matrix are paramount to fiber's performance as a reinforcing material. According to Vilaseca and fellow researchers (2007), fiber-matrix interaction can be due to mechanical friction, van der Waals forces, hydrogen bonds, and covalent bond formation between the fiber and matrix. Natural fibers are more suited to this purpose than synthetic ones because they bear similar surface polarity (arising from the $-\mathrm{OH}$ groups on both which, in turn, facilitates the formation of hydrogen bonds between the fiber and the matrix TPS) with starch, a property that promotes good interfacial interaction (Wollerdorfer and Bader 1998; Vilaseca et al. 2007). In addition, they are inexpensive, lightweight, non-abrasive, renewable, and biodegradable, and also possess high strength-to-weight ratio (Morton and Hearle 1975; Bürger et al. 1995). However, unlike glass fiber that starts to degrade at temperatures about $2000^{\circ} \mathrm{C}$, natural fibers exhibit low thermal stability: their first degradation occurs at temperatures above $180^{\circ} \mathrm{C}$ (around $200-220^{\circ} \mathrm{C}$ for flax fiber) (Wielage et al. 1999; Gassan 
and Bledzki 2001). Therefore, they are only suitable for processing conditions at or below this temperature. Worse still, Fleming and co-workers (1995) pointed out that mechanical properties of biofibers vary significantly with climatic and growing conditions, preparation methods, and water adsorption.

Torres and fellow workers (2007) explored some natural fibers reinforcing potentials for thermoplastic starch in their work published recently. Three material variables were considered, namely: starch (sweet potato, corn, and potato starches), plasticizer (ethylene glycol, glycerol, chitosan, water, and propylene glycol), and fiber (jute, sisal, and cabuya with fiber lengths of $5 \pm 1$ $\mathrm{mm}$ ). All these factors coupled with processing (compression molding) conditions such as time and temperature were found to affect the tensile strength of the TPS. Individual assessments (done keeping other variables constant) showed that potato starch, sisal, and ethylene glycol gave the highest tensile strength results whereas water and cabuya fiber gave the highest impact strength. Earlier studies by Wollerdofer and Bader (1998) with thermoplastic wheat starch (sorbitol and glycerol as plasticizers) reinforced with flax and ramie fibers via the combination of extrusion and injection molding techniques yielded significant improvements in the tensile strength and modulus, but a reduction in elongation.

Karmaker and Youngquist (1996) postulated that while tensile strength is significantly affected by fiber-matrix interaction, Young's modulus (stiffness) is dependent on fiber content and dispersion within the matrix and not significantly by fiber-matrix interaction. Results from Vilaseca and co-workers' (2007) studies 
with a starch-based biopolymer reinforced with $\mathrm{NaOH}$-treated jute fiber concurred with this postulation. Specifically, in addition to impurities removal, the $\mathrm{NaOH}$ treatment was reported to have resulted in partial delignification of the jute fiber thereby exposing more fiber surface $-\mathrm{OH}$ groups for hydrogen bonding with the matrix, thus leading to improved tensile strength. These findings are at sharp contradiction to earlier work by Cyras and fellow researchers (2003) that reported a reduction in the tensile strength of TPSbased biodegradable polymer reinforced with $\mathrm{NaOH}$-treated sisal fiber. They rationalized this underperformance to be a consequence of reduced fiber compatibility with the matrix caused by increased fiber surface $-\mathrm{OH}$ groups.

Furthermore, besides discrete macrofibers as reinforcements for TPS, cellulosic nanofibers, such as cellulose microfibrils (Dufresne and Vignon 1998) and tunicin whiskers (Angles and Dufresne 2001) have also been investigated. Two types of wood pulps (bleached Kraft pulp from Eucalyptus urograndis and unbleached thermomechanical pulp of Eucalyptus grandis) were evaluated by De Carvalho and co-researchers (2002) in reinforcing TPS produced with corn starch (28\% amylose) and glycerol. It was found that although increase in glycerol (above 30\%) decreased both the tensile strength and modulus, increase in fiber (pulp) contents (from $5-15 \%$ of matrix mass) remarkably increased both the tensile strength and modulus in all cases. On the other hand, the tensile strains of the composites decreased with the addition of fiber or glycerol to the raw matrix. Interestingly, regardless of glycerol amounts, fiber breakage as against debonding was observed on all fracture surfaces, an 
indication of a strong fiber-matrix interfacial bonding. In agreement with similar work, the water absorption at equilibrium of the TPS matrix increased with glycerol and was found higher than those of TPS-fiber composites (thus, implying improved moisture resistance with fiber inclusion), which were similar irrespective of formulation.

Apart from organic materials like natural fibers, the potentials of inorganic minerals such as hydroxyapatite (Reis et al. 1997) and kaolin (De Carvalho et al. 2001) as reinforcement materials for TPS have also been reported. The reinforcing potentials of clay were examined by Hwan-Man and co-workers (2003) whereby TPS/clay nanocomposites produced from native potato starch and natural montrorillonite (clay) were found to possess higher tensile strength and thermal stability, and lower water vapor transmission rate than ordinary TPS. The hydrophilicity of clay makes it compatible with plasticized starch (Ikeo et al. 2006). In addition, Ma and co-researchers (2007), in their recent study of the effectiveness of fly ash in reinforcing corn PS prepared with glycerol and formamide-urea as plasticizers, observed considerable increase in the tensile stress, Young's modulus, and moisture resistance, although with a corresponding decrease in ductility. Fly ash was also found to inhibit retrogradation.

Lastly, Yu and Christie (2005) exploited polymer orientation technique in improving extruded corn TPS sheet. The orientation was achieved by drawing at different speeds TPS sheet extrudates from the die under positive tension by a three-roller system in front of the die after which the mechanical properties 
were measured along and across the extrusion direction. Unlike elongation, both tensile modulus and yield strength improved in both directions. However, the effect of orientation was influenced by amylose/amylopectin ratio, such that differences in modulus and yield stress in the two directions widened with increase in amylose while differences in elongation became pronounced at higher amylopectin contents. These directional differences in tensile properties are much higher in conventional polymers and for instance, may be in the order of 10 times in polypropylene (Nadella et al. 1978). On a broader view, amylose contents have actually been found to proportionately influence mechanical properties such as tensile modulus, tensile strength, and elongation of TPS (van Soest and Essers 1997; Yu and Christie 2005). Amylose/amylopectin ratio affects the degree of conversion of starch into homogeneous mass during extrusion (van Soest and Essers 1997).

\subsubsection{TPS/non-biodegradable synthetic polymers blends}

Towards achieving more environmentally friendly polymer products, another area of research that has captured the attention of researchers in recent times is TPS/conventional non-biodegradable polymer blends. In this case, starch is blended with the synthetic polymer matrix in the plasticized form and not as granules. The approach can potentially reduce cost, improve biodegradation of conventional plastics (St-Pierre et al. 1997), and also lower dependence on non-renewable resources (essentially crude oil). From literature, adding starch

granules to conventional polymers as fillers increases the tensile modulus but 
causes significant reduction in tensile strength and ductility. For plastic bag applications, two mechanical properties, namely, tensile strength and ductility, are of paramount importance. One way of achieving improved elongation at break for starch/conventional polymer composites is by using TPS in lieu of granular starch. St-Pierre and co-researchers (1997) investigated the properties of TPS/LDPE and TPS/LLDPE composites using wheat starch and glycerolwater combination as plasticizer and observed very high elongation properties even at high TPS loadings.

However, when blending TPS with non-polar synthetic polymers, the question of immiscibility arises. There is bound to be high interfacial tension (surface energies) between the polar TPS and the non-polar polymer. Wang and co-workers (2007) approached the issue with the inclusion of citric acid as an additive in glycerol TPS/PE blends. They reported that citric acid improved the dispersion of TPS with a corresponding decrease in TPS particle volume. The tensile strength and elongation greatly improved over the non-citric TPS/PE blends. Earlier work by Wang and co-researchers (2005) revealed that maleic anhydride (MAH) could improve compatibility of TPS with PE and of course with attendant improvement of the mechanical properties in relation to non-MAH TPS/PE blend. According to them, MAH, though relatively costly, is arguably the most effective compatibilizer for starch and PE. Other compatibilizers include ethylene-acrylic acid (EAA) copolymer and ethylene-vinyl alcohol (EVA) copolymer. Ethylene-acrylic acid (EAA) copolymer comprises both polyethylene segments and acrylic acid units and is capable of forming stable V-type 
complexes with starch due to hydrogen bond formation between the carboxylic groups of acrylic acid and hydroxyl groups of starch (Prinos et al. 1998).

\subsubsection{Starch/biodegradable synthetic polymer blends}

In addition to non-biodegradable synthetic polymers, TPS blends with biodegradable synthetic polymers have also been explored. Examples of biodegradable synthetic polymers include polyvinyl alcohol $(\mathrm{PVOH})$, polylactic acid (PLA), polycaprolactone (PCL), modified polyethylene tetraphthalate (PET), polyester carbonate (PEC), and other aliphatic polyesters (e.g., Bionelle $\left.{ }^{\circledR}, \mathrm{BAK}\right)$ and aliphatic-aromatic copolyesters (e.g., Eastar BIO, Ecoflex). These products are relatively expensive and thus, blending with starch can help reduce cost. For instance, PLA, which is produced through the polymerization of lactic acid obtained from the fermentation of carbohydrate crops such as corn, wheat, barley, cassava, and sugar cane (Chandra and Rustgi 1998), is hydrophobic, expensive, and degrades slowly compared to the accumulation rate of solid waste (Wang et al. 2003). It can be blended with starch to slash cost and accelerate biodegradation of the composite (Jacobsen and Fritz 1996) but not without some compromise on the composite properties such as an increase in moisture sensitivity due to the hydrophilic nature of native starch and a reduction in mechanical properties such as tensile strength and elongation (Griffin 1974; Evangelista 1991).

Although improved biodegradation accompanies higher starch contents, the problem of incompatibility between starch granules and PLA matrix, 
essentially due to their difference in polarities, still lingers. To this end, several compatibilizers such as methylenediphenyl diisocyanate (MDI) (Wang et al. 2002), maleic anhydride (MAH) (Zhang and Sun 2004) and acrylic acid (AA) (Wu 2005) have been investigated with a view to promoting better interfacial bonding between the starch granules and PLA matrix. For starch/PCL blends, similar effect could be obtained with the use of PCL-co-pyromellitic anhydride as compatibilizer (Avella et al. 2000) and also by grafting PCL with MAH thereby producing $\mathrm{PCl}-\mathrm{g}-\mathrm{MAH}$ (a modified $\mathrm{PCL}$ ) which has greater compatibility with starch (Wu 2003). In addition, an NMR study by Spevacek and co-workers (2007) revealed that O-formylation of starch (starch modification into starch formate) could also enhance starch miscibility with $\mathrm{PCL}$ in starch/PCL composites.

In an attempt to completely go 'green', Chen and co-researchers (2003) explored blending cellulose acetate with chemically modified potato starch. Cellulose acetate, a derivative of cellulose, is considered fit for plastics owing to its relatively high stiffness and low density (Bledzki and Gassan 1999) and is capable of improving the mechanical properties and moisture resistance of products (Gross and Kalra 2002). Chen and co-workers (2003) discovered that blending cellulose acetate with acetylated potato starch resulted in increased tensile strength and moisture stability of the composite. It was also observed that the composite tensile strength, which decreased with increase in equilibrium moisture content, when equilibrated at relative humidity lower than 93\% was higher than low density polyethylene (LDPE) and high density 
polyethylene (HDPE) values. In addition to being higher than LDPE and HDPE values, the tensile strength of the composite when equilibrated below $76 \% \mathrm{RH}$ was found to be in polystyrene tensile strength range. They explained that high moisture content in the composite caused an increase in intermolecular freedom for the starch acetate and cellulose acetate molecules, thereby, resulting in decreased tensile strength.

Furthermore, the possibilities of blending biodegradable polymers with TPS have also been researched. Two synthetic biopolymers namely PLA and PCL are in the forefront of this exploration. Although Ikeo and co-workers (2006) asserted that starch compatibility is enhanced using plasticized starch, Martin and Avérous (2001) still encountered the problem of low level of compatibility between PLA and TPS. This perhaps informed a recent work by Huneault and $\mathrm{Li}$ (2007) on MAH grafting of PLA to enhance its compatibility with TPS. Better elongation at break of 100 to $200 \%$ (against 5 to $20 \%$ for unmodified PLA/TPS and pure PLA) was reported and was attributed to improved dispersion of TPS in the PLA matrix together with improved interphase bonding.

Interestingly, some degree of compatibility was observed between plasticized corn starch and PCL (Matzinos et al. 2002; Shin et al. 2004), although the blend was thermodynamically immiscible because the melting and glass transition temperatures of PCL were not affected by blending with TPS (Shin et al. 2004). This low compatibility could be as a result of formation of hydrogen bonds between the ester carbonyl groups of PCL and starch hydroxyl 
groups (Matzinos et al. 2002; Shin et al. 2004). Nonetheless, as TPS contents increased, both tensile strength and elongation decreased while modulus showed an upward trend. More so, Ikeo and co-researchers (2006) reported that the addition of MAH could enhance PCL compatibility with TPS. Clay has also been used to further improve the properties of PCL/TPS composites (Ikeo et al. 2006; Perez et al. 2007).

\subsection{Summary}

From the foregoing review, it is evident that quite a lot has been done in the development of starch-based products in the move towards developing biodegradable plastics. Accordingly, starch has basically been used in two forms; these include granular (native or modified) form and thermoplastic (plasticized) form. Blends of starch in these two forms with synthetic biodegradable and non-biodegradable polymers have been explored. Virgin thermoplastic starch suffers poor mechanical and moisture properties. Many factors reportedly affect the performance of starch-based products, some of which include starch particle size, starch modification, amylose/amylopectin ratio, plasticizer, processing method and conditions, moisture, type and amount of reinforcement, and compatibilizer.

Although some branded thermoplastic starch blends such as Bioplast $\AA$, Cereloy ${ }^{\circledR}$, and Mater-Bi® are now available, many of these materials have not been able to make their way to the market. The deficiencies still experienced by these starch-based composites is not easy to overcome owing to the complex 
interplay between the performance factors such that an increase in one factor may improve one performance property while decreasing another, and vice versa. The elusiveness of a panacea therefore necessitates the optimization of these performance factors. This may require maintaining a well-organized rich database. As evident in the review, most of the work done is on cereal and root/tuber crops. There is therefore the need to widen the scope of this research by investigating other sources of starch like the legumes.

In conclusion, while acknowledging the great efforts of researchers in this worthy course, the need for more work especially in the area of mechanical strength, moisture resistance, and thermal stability cannot be over-emphasized in the bid towards developing bioproducts that can successfully supersede existing eco-unfriendly petroleum-based plastics in functionality and economics. 


\section{MATERIALS AND METHODS}

The ultimate aim of this research was to improve on the properties of thermoplastic pea starch with the incorporation of flax fiber and polycaprolactone $(\mathrm{PCL})$. The methodology thus involved two aspects namely, material preparation and characterization. Material preparation involved material (such as pea starch, glycerol, flax fiber, and polycaprolactone) procurement and compression molding of the starch-based composites while the techniques of characterization were tensile test, DSC, moisture absorption test, and SEM. Some relevant preliminary experiments were also conducted.

\subsection{Materials}

Pea starch (Accu-Gel, 95\% purity, 35\% amylose) isolated from Canadian yellow pea via wet milling was supplied by Nutri-Pea Limited (Portage La Prairie, MB) while glycerol ( $\geq 99.5 \%$ purity) was purchased from Sigma-Aldrich, (St. Loius, MO). Chemical composition of Accu-Gel is given in Appendix A. Poly ( $\varepsilon$ caprolactone) (PCL) powder, $\left(\mathrm{CAPA}^{\circledR} 6506,50000\right.$ molecular weight, Appendix A) was obtained from Perstorp UK Ltd. (Cheshire, UK). Short flax fiber (10 mm long) was procured from Saneco (Nieppe, France), washed in a 10\% (vol/vol) detergent (Tide detergent) solution at $65^{\circ} \mathrm{C}$ for $30 \mathrm{~min}$ and then rinsed with deionized water at room temperature. The washed fiber was drained and subsequently oven-dried at $75^{\circ} \mathrm{C}$ for $24 \mathrm{~h}$, after which it was further ground with a knife mill using a 4-mm screen. Material mixing was done using a Hamilton Beach 5 Speed OptiMixTM hand/stand mixer (Hamilton Beach, Washington, 
NC) while the samples were compressed using an automatic hydraulic press Model 3891 Auto M (Carver Inc., Wabash, IN).

\subsection{Preliminary Experiments}

In order to obtain useful information needed for effective material processing, some relevant properties of the base material, pea starch, were evaluated. These properties included moisture content, particle size distribution, gelatinization properties, and particle density. The particle densities of PCL and flax fiber were measured. In addition, thermal behavior of PCL (glass transition and melting temperatures) and flax fiber was also evaluated.

\subsubsection{Moisture content of pea starch}

Samples of the supplied pea starch with initial mass, $\mathrm{m}_{\mathrm{o}}$, of 1.72 to $3.05 \mathrm{~g}$ were placed in pans, oven-dried at $110^{\circ} \mathrm{C}$, and periodically measured until constant mass (final mass) was reached. The final mass of the dried starch, $\mathrm{m}_{\mathrm{f}}$, was recorded and the moisture content, $\mathrm{M}_{1}$, (in percent wet basis) of the starch was determined as follows:

$$
M_{1}=\frac{m_{o}-m_{f}}{m_{o}} \times 100
$$

The moisture content of the pea starch was obtained as an average of five replications and was found to be $12.76 \pm 0.14 \%$ wb. 


\subsubsection{Particle size distribution of pea starch using laser diffraction}

Ten percent aqueous suspension of pea starch was prepared at room temperature by stirring a mixture of starch and water at $950 \mathrm{rpm}$ for $20 \mathrm{~min}$ using a magnetic stirrer. The sample dispersion unit of the Mastersizer 2000 (Malvern Instruments, Malvern, UK) was rinsed thoroughly before use. Mastersizer 2000 operates on the principle that a laser beam gets scattered by particles passing through it at angles and intensities inversely and directly proportional to their sizes, respectively (Malvern 2008). The starch suspension was fed in drops into the small sample volume dispersion unit until the laser obscuration was between 10 to $20 \%$ before running the particle size determination experiment. The equipment was set to perform two scans of the same sample and return their average.

The volumetric particle size distribution of the pea starch as obtained using laser diffraction technique is shown in Figure 3.1. The starch particles were predominantly between 10 and $100 \mu \mathrm{m}$ in diameter with the average size being $31 \mu \mathrm{m}$.

\subsubsection{Particle densities of pea starch, flax fiber, and polycaprolactone}

A nitrogen-operated multipycnometer (Quantachrome Instruments, Boynton Beach, FL) was used to determine the particle densities of both pea starch and PCL. Pea starch was used as is. A sample cell was first of all weighed empty, filled to about two-thirds of its volume with starch, flax fiber or PCL and reweighed in order to obtain the sample mass. The procedure outlined in the 
multipycnometer manual was followed for the particle density determination.

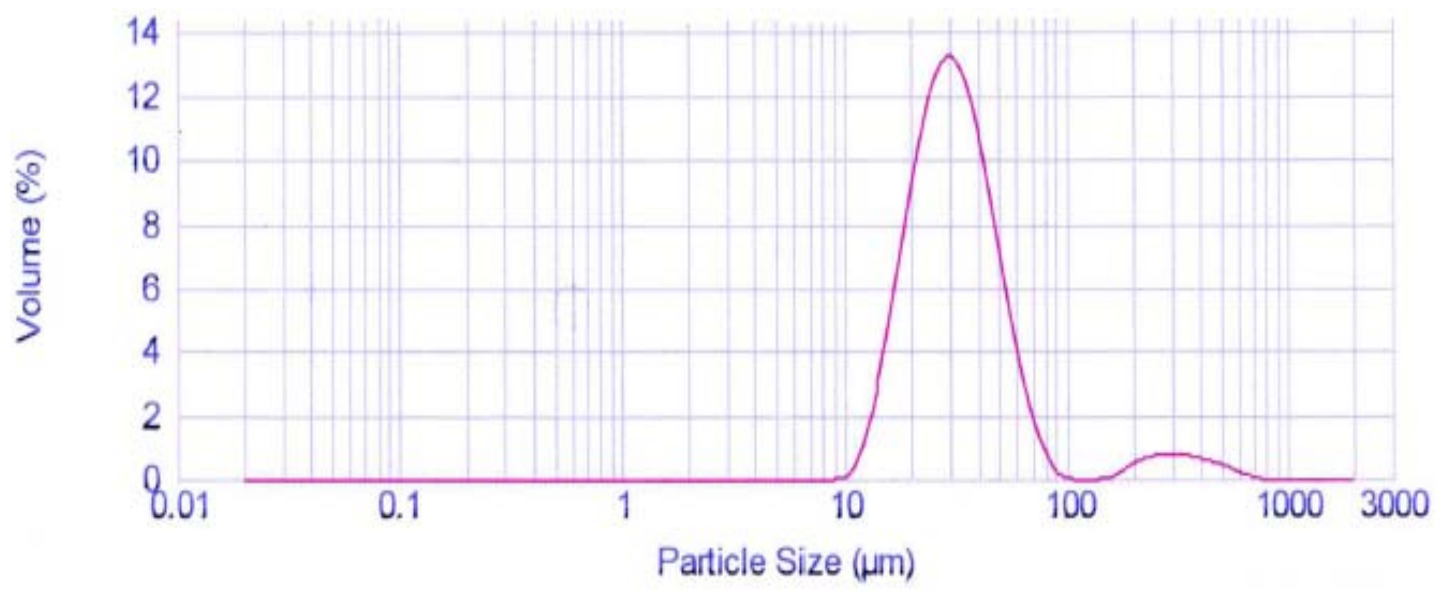

Figure 3.1 Particle size distribution of pea starch using laser diffraction technique.

The operational equation as obtained from the equipment manual is as given below:

$D=\frac{M_{P}}{V_{P}}$

where:

$D=$ sample (pea starch or $\mathrm{PCL}$ ) particle density, $\mathrm{g} / \mathrm{cm}^{3}$

$M_{P}=$ sample (pea starch or $\mathrm{PCL}$ ) mass, $\mathrm{g}$

$V_{P}=$ sample (pea starch or $\mathrm{PCL}$ ) volume, $\mathrm{cm}^{3}$

and

$V_{P}=V_{C}-V_{R}\left(\left(\frac{P_{1}}{P_{2}}\right)-1\right)$ 
where:

$V_{P}=$ volume of powder (pea starch or PCL), $\mathrm{cm}^{3}$

$V_{C}=$ volume of sample cell, $\mathrm{cm}^{3}$

$V_{R}=$ reference volume, $\mathrm{cm}^{3}$

$P_{1}=$ pressure reading after pressurizing the reference volume, psi

$P_{2}=$ pressure reading after including $V_{\mathrm{C}}$, psi

The particle densities of pea starch, flax fiber, and PCL taken as average of three measurements were found to be $1.46 \pm 0.02,1.41 \pm 0.02$, and 1.15 $\mathrm{g} / \mathrm{cm}^{3}$, respectively. This shows the starch particles were heavier than $\mathrm{PCL}$ particles.

\subsubsection{Gelatinization properties of the supplied pea starch}

Aqueous suspensions containing 17.45 and $26.17 \%$ by weight of the supplied pea starch were prepared with distilled water and left to hydrate for $12 \mathrm{~h}$. Ten to $20 \mathrm{mg}$ of the samples were placed in aluminum hermetic pans, crimped tightly to avoid vapour escape and then run through a DSC Q2000 (TA Instruments, New Castle, DE) from 20 to $150^{\circ} \mathrm{C}$ at a scan rate of $5^{\circ} \mathrm{C} /$ min under nitrogen atmosphere. Endothermic peaks attributable to gelatinization transition were obtained and the gelatinization properties such as onset, mid-point, and endpoint gelatinization temperatures were obtained from the endotherms. The gelatinization enthalpy was obtained by finding the area under the graph within the gelatinization transition boundaries. 
The gelatinization transitions obtained by the DSC are shown in Figure 3.2. The DSC thermograms show endotherms typical of starch gelatinization in excess water (Stevens and Elton 1971; Wooton and Bamunuarachchi 1980; Donovan 1979; Eliasson 1980; Fukuoka et al. 2002; Yu and Christie 2001). From Figure 3.2a, pea starch onset, peak (mid-point), and end of gelatinization temperatures were found to be $57.60^{\circ} \mathrm{C}, 68.24^{\circ} \mathrm{C}$, and $80.33^{\circ} \mathrm{C}$, respectively. The enthalpy of gelatinization obtained as the area under the curve between the transition limits was $2.87 \mathrm{~J} / \mathrm{g}$.

It is however important to emphasize that starch gelatinization is a function of water and temperature (Fukuoka et al. 2002). This is evident in the presence of two endothermic peaks when the starch (dry mass) concentration was increased to $26.17 \%$ as shown in Figure $3.2 \mathrm{~b}$. The enthalpies of gelatinization obtained from the first and second endotherms were $1.24 \mathrm{~J} / \mathrm{g}$ and $5.65 \mathrm{~J} / \mathrm{g}$, respectively. Although there was a decrease in the specific enthalpy of gelatinization from 2.87 to $1.24 \mathrm{~J} / \mathrm{g}$ with decrease in moisture content, the onset, mid-point, and end point gelatinization temperatures remained fairly the same for the common first endothermic peak. These results are in agreement with Fukuoka and fellow workers' (2002) observation.

Possibilities of three endothermic peaks have been reported in limited water conditions (Fukuoka et al. 2002; Donovan 1979). The first and second (which unlike the first shifts further to the right with decrease in moisture content) endothermic peaks are due to moisture-induced breakdown of starch crystallites and subsequent "melting" of remnant crystallites, respectively 


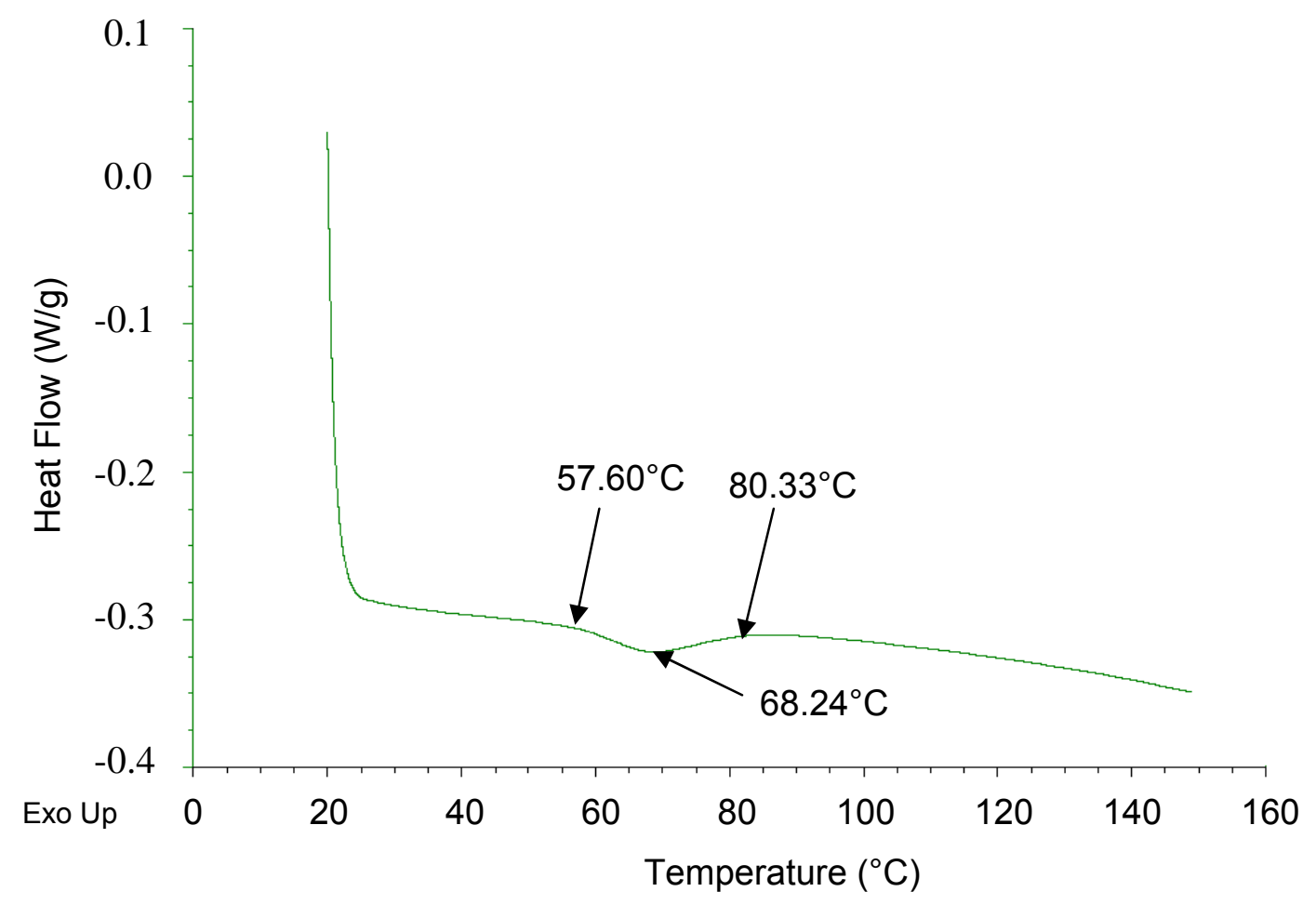

(a) $17.45 \%$ aqueous suspension of pea starch

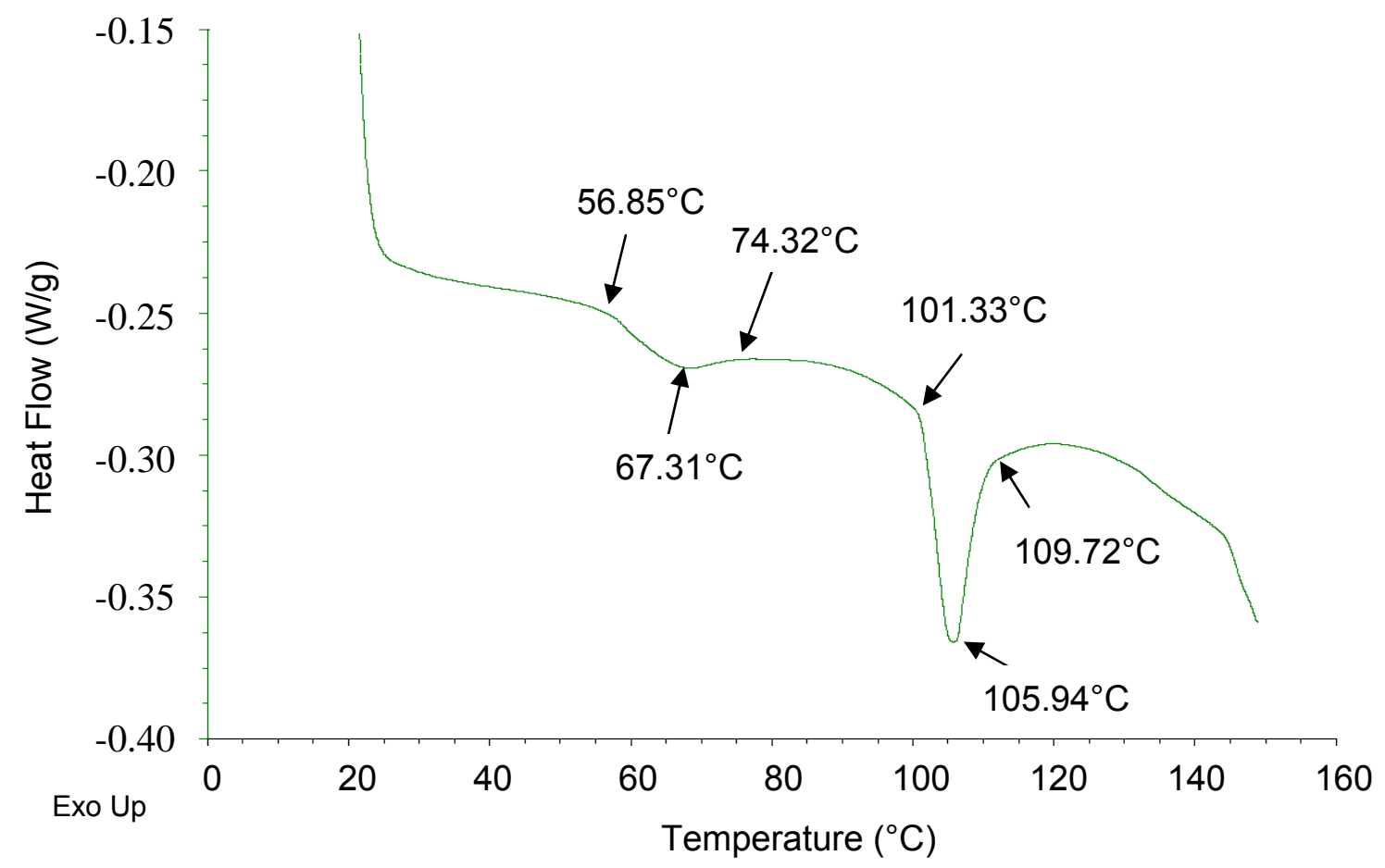

(b) $26.17 \%$ aqueous suspension of pea starch

Figure 3.2 Effects of moisture content on the gelatinization of pea starch using differential scanning calorimetry technique. 
(Donovan 1979; Fukuoka et al. 2002). The order-disorder transition of amyloselipid complexes is essentially believed to be responsible for the third peak (Biliaderis 1990). By and large, the first peak is usually analyzed for gelatinization parameters (Fukuoka et al. 2002).

\subsubsection{Thermal behavior of the supplied PCL and flax fiber}

PCL powder of $11.81 \mathrm{mg}$ was placed in hermetic aluminum pans, crimped tightly, and run through the DSC Q2000. A heat-cool-heat method was employed. The sample was heated to $100^{\circ} \mathrm{C}$ and cooled to $-80^{\circ} \mathrm{C}$ at a scan rate of $15^{\circ} \mathrm{C} / \mathrm{min}$, and then heated to $400^{\circ} \mathrm{C}$ at $10^{\circ} \mathrm{C} / \mathrm{min}$ under nitrogen atmosphere. The first heating cycle was to erase the thermal history of the sample (Wielage et al. 1999) and therefore, only the second heating cycle was used for analytical purposes. Similarly, $4.38 \mathrm{mg}$ of washed flax fiber was placed in aluminum hermetic pan and run through the DSC from -80 to $400^{\circ} \mathrm{C}$ under nitrogen atmosphere at a scan rate of $10^{\circ} \mathrm{C} / \mathrm{min}$ to determine its thermal behavior.

The DSC thermogram obtained for PCL is as shown in Figure 3.3a. PCL is known to undergo three thermal transitions when heated. These are glass transition, melting, and thermal decomposition. As shown in Figure 3.3, the glass transition and melting temperatures were found to be $-62.63^{\circ} \mathrm{C}$ and $58.96^{\circ} \mathrm{C}$ (Appendix A) while at about $400^{\circ} \mathrm{C}$, the material exhibited thermal decomposition. Similar results have been obtained in previous studies (Chrissafis et al. 2007; Polo Fonseca et al. 2007; Shin et al. 2004; Sarazin et al. 2008). Figure 3.3b shows the thermal behavior of flax fiber using DSC. The 


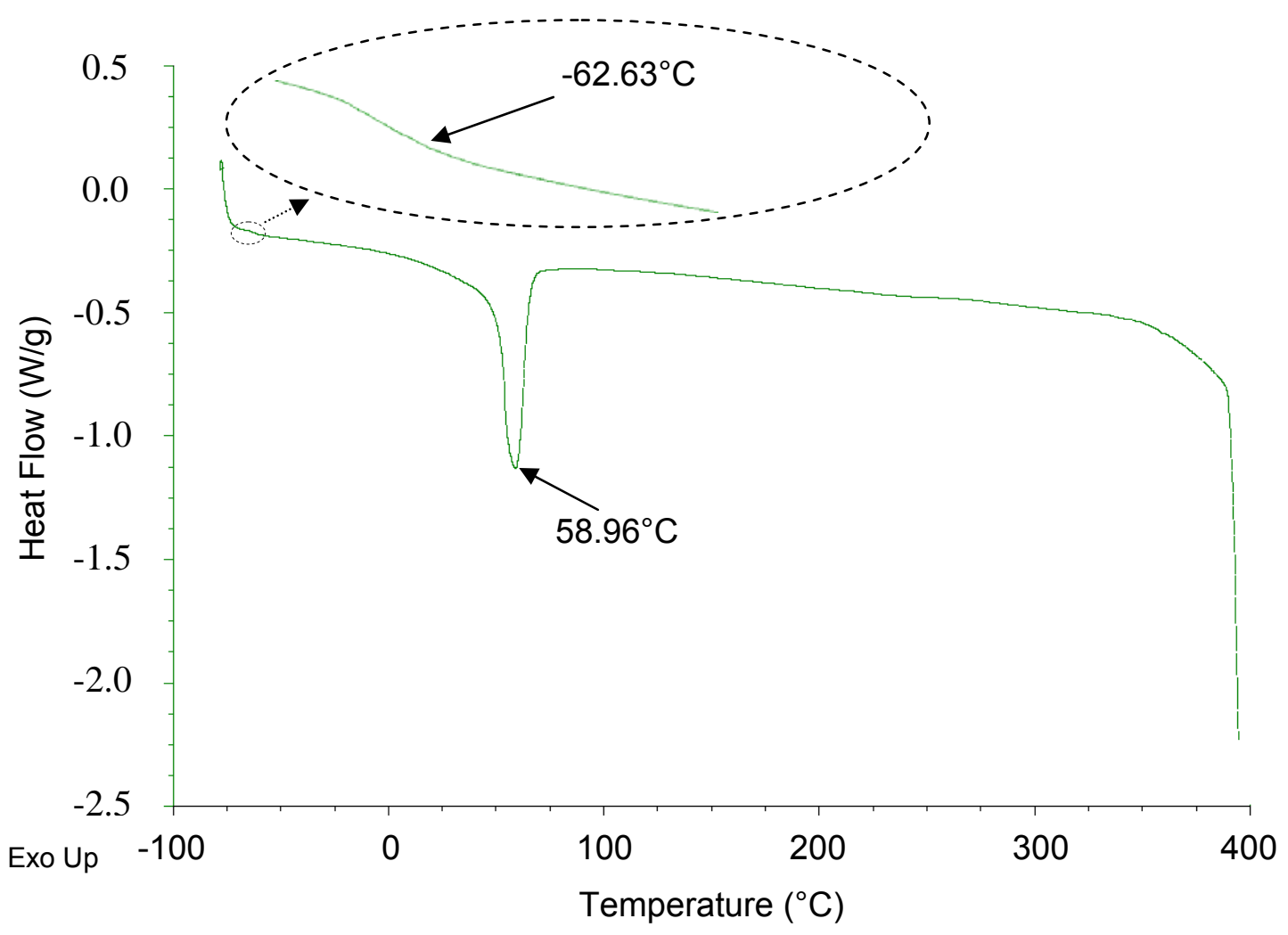

(a)

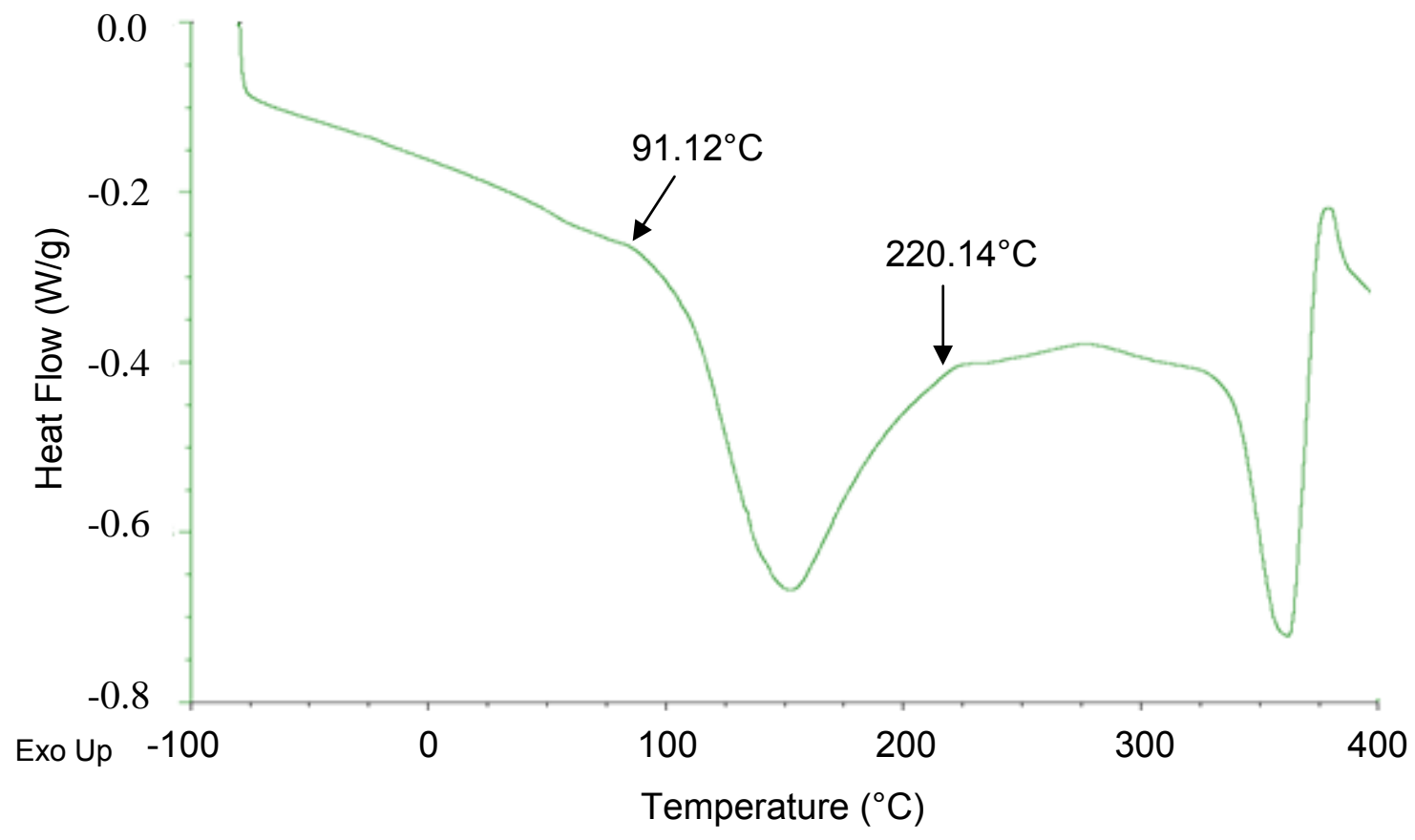

(b)

Figure 3.3 Differential scanning calorimetry thermograms of (a) polycaprolactone; (b) flax fiber. 
broad peak could be attributed to moisture vaporization from the fiber which is then followed by thermal degradation beyond $350^{\circ} \mathrm{C}$. Similar thermal degradation of flax fiber has been reported using DSC and thermogravimetric analysis (TGA) in previous studies (Manfredi et al. 2006; Wielage et al. 1999).

\subsection{TPS Preparation}

Two separate TPS mixtures (primarily containing starch and glycerol) differing in moisture contents were prepared: the one containing 9.3\% moisture (no extra water addition) was designated as $\mathrm{S}$ and the other, which had its moisture raised to $20 \% \mathrm{wb}$, as S20 (Table 3.1). This approach was important to ascertain the effects of processing moisture content and hence, starch gelatinization on the properties of the composites thus produced, thereby, determining the optimum moisture level. (TPS mix containing 30\% moisture contained lots of air bubbles after compression thus making the material unfit for testing. Hence, two moisture content levels of TPS mixture were studied).

Since the pea starch contained $12.76 \%$ moisture (as is) as determined in Section 3.2.1, the extra water needed to obtain an S20 mix was calculated using Equation 3.4 (Appendix B) and mixed with the appropriate amount of glycerol. The glycerol-water combination was then mixed with pea starch. In both compositions, the ratio of dry starch to glycerol was fixed at 7:3 by weight (Table 3.1; Equation 3.5). Pea starch was mixed with the plasticizers (glycerol in the case of S and glycerol-water combination for S20) using Hamilton Beach 5 Speed OptiMixTM hand/stand mixer (Hamilton Beach, Washington, NC) for 
about 15 min. The mixtures, which contained some hard lumps, were put in plastic bags, sealed, and left for at least $48 \mathrm{~h}$. This step allowed starch granules to sufficiently absorb the plasticizers thus yielding mixtures with easily disintegratable lumps. The elimination of lumps was quite crucial as experimental trials conducted revealed that pressing lumpy samples yielded TPS with brittle spots, that is, samples with uneven stiffness.

$$
w_{a}=\frac{x}{1-x}\left[d_{s}\left(\frac{10}{7}+\frac{M}{1-M}\left(\frac{x-1}{x}\right)\right)\right]
$$

where $\quad \mathrm{w}_{\mathrm{a}}=$ weight of extra water needed to achieve $100 \times \%$ TPS processing moisture content, $\mathrm{g}$

$x=$ targeted TPS processing moisture level (in decimal)

$M=$ moisture content of starch (w.b., in decimal)

$d_{s}=$ mass of dry starch, $\mathrm{g}$

$$
d_{s}=\frac{7}{3} p
$$

where $\quad p=$ amount of glycerol, $g$

Table 3.1 Formulation of glycerol-plasticized pea starch.

\begin{tabular}{cccc}
\hline TPS mix & $\begin{array}{c}\text { Dry starch } \\
(\%)\end{array}$ & $\begin{array}{c}\text { Glycerol } \\
(\%)\end{array}$ & $\begin{array}{c}\text { Water } \\
(\%)\end{array}$ \\
\hline S & 63.5 & 27.2 & 9.3 \\
S20 & 56 & 24 & 20 \\
\hline
\end{tabular}


Further mixing for another 10 min was needed to achieve well-pulverized TPS mixtures suitable for compression molding and subsequent compounding with PCL and flax fiber.

\subsection{Experimental Design}

In order to achieve the two stated objectives, the whole experiment was divided into two modules.

- Module one was to determine the effects of TPS processing moisture content and PCL incorporation into glycerol-plasticised pea starch.

- Module two was to determine the effects of flax fiber and PCL incorporation into glycerol-plasticised pea starch.

The two experimental modules were structured as two-way factorial completely randomized designs (CRD) to determine the effects on the tensile and moisture absorption properties. Module one had two factors, namely moisture and PCL at levels two and five, respectively, thus, having a $2 \times 5$ factorial treatment structure (Table 3.2). Module two equally had two factors namely PCL and fiber at levels three and four, respectively, thus, having a $3 \times 4$ factorial treatment structure (Table 3.2). Only TPS mix S20 was used for module 2 . The respective composites were prepared as outlined in Section 3.5. The statistical analysis was done using SAS 9.1 Mixed Model procedure (Statistical Analysis System, Inc., Cary, NC) at $5 \%$ level of significance. Tukey's method was used for means separation for both the tensile and moisture absorption properties. 
Table 3.2 Experimental design to determine the effects of moisture, polycaprolactone and flax fiber incorporation into plasticized pea starch.

\begin{tabular}{|c|c|c|}
\hline \multicolumn{3}{|c|}{$\begin{array}{c}\text { Module } 1 \text { (2 X } 5 \text { factorial completely randomized } \\
\text { design) }\end{array}$} \\
\hline & \multicolumn{2}{|c|}{ Factor } \\
\hline Sample Code & $\begin{array}{l}\text { Processing } \\
\text { Moisture (\%) }\end{array}$ & $\begin{array}{l}\text { Polycaprolactone } \\
(\%)\end{array}$ \\
\hline$T$ & 9.3 & 0 \\
\hline 1P9T & 9.3 & 10 \\
\hline $2 \mathrm{P} 8 \mathrm{~T}$ & 9.3 & 20 \\
\hline 3P7T & 9.3 & 30 \\
\hline 4P6T & 9.3 & 40 \\
\hline $\mathrm{T} 20$ & 20 & 0 \\
\hline 1P9T20 & 20 & 10 \\
\hline 2P8T20 & 20 & 20 \\
\hline 3Р7T20 & 20 & 30 \\
\hline 4P6T20 & 20 & 40 \\
\hline \multicolumn{3}{|c|}{$\begin{array}{c}\text { Module } 2 \text { (3 X } 4 \text { factorial completely randomized } \\
\text { design) }\end{array}$} \\
\hline & \multicolumn{2}{|c|}{ Factor } \\
\hline Sample Code & $\begin{array}{l}\text { Polycaprolactone } \\
(\%)\end{array}$ & Flax Fiber (\%) \\
\hline T20 & 0 & 0 \\
\hline $1 \mathrm{~F}$ & 0 & 5 \\
\hline $10 \mathrm{~F}$ & 0 & 10 \\
\hline $15 \mathrm{~F}$ & 0 & 15 \\
\hline 2P8T20 & 20 & 0 \\
\hline $5 F 20 P$ & 20 & 5 \\
\hline 10F20P & 20 & 10 \\
\hline $15 F 20 P$ & 20 & 15 \\
\hline 4P6T20 & 40 & 0 \\
\hline $5 F 40 P$ & 40 & 5 \\
\hline 10F40P & 40 & 10 \\
\hline $15 \mathrm{~F} 40 \mathrm{P}$ & 40 & 15 \\
\hline
\end{tabular}




\subsection{Composite Preparation}

Results of the preliminary experiments discussed previously came in handy in the preparation of the composites. Two separate binary composites of TPS/PCL and TPS/flax fiber, and a ternary composite of TPS/PCL/flax fiber composites were prepared for subsequent characterizations. The equipment for sample preparations are shown in Figure 3.4.

\subsubsection{TPS/PCL composites}

Since no mechanical mixing takes place during compression molding, effective mixing of PCL and the TPS mixtures (S and S20) prior to compression was expedient. Therefore, for PCL/TPS binary composites, PCL powder was compounded separately with S and S20 at 10, 20,30, and $40 \%$ by weight as shown in Table 3.2 using a laboratory scale ceramic mortar and pestle (Figure 3.4b). The density, particle size, and moisture affinity differentials between the two components necessitated the choice of mortal and pestle for this solidphase compounding. The particle size of the polycaprolactone was $98 \%<600$ $\mu \mathrm{m}$ (as specified by the manufacturer) and that of the pea starch was $31 \mu \mathrm{m}$ (mean particle size diameter as determined in Section 3.2.2 using Mastersizer 2000 , respectively while their densities were 1.15 and $1.46 \mathrm{~g} / \mathrm{cm}^{3}$, respectively (as determined above with a gas-operated multipycnometer. PCL is hydrophobic while starch is hydrophilic. The PCL/S and PCL/S20 mix for each sample were thoroughly compounded for about $10 \mathrm{~min}$ to ensure homogeneity before and after compression molding. 


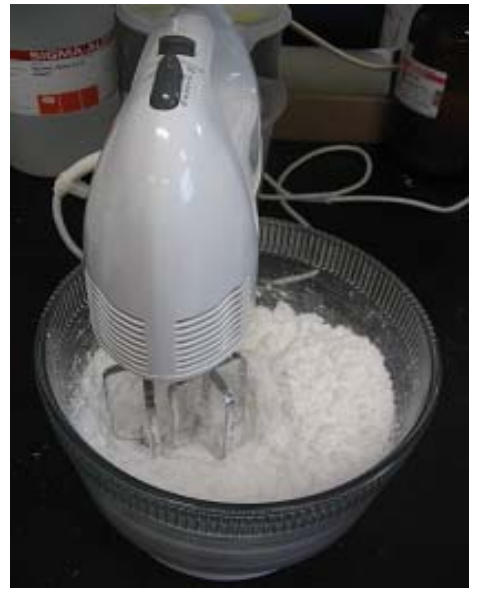

(a)

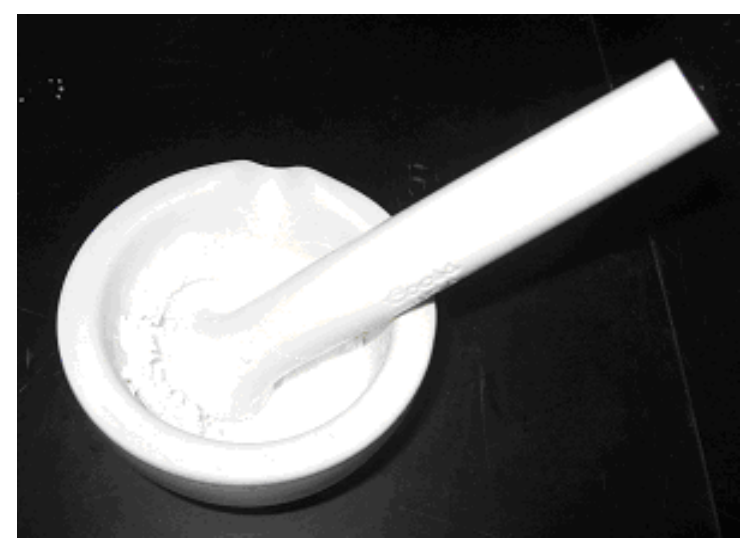

(b)

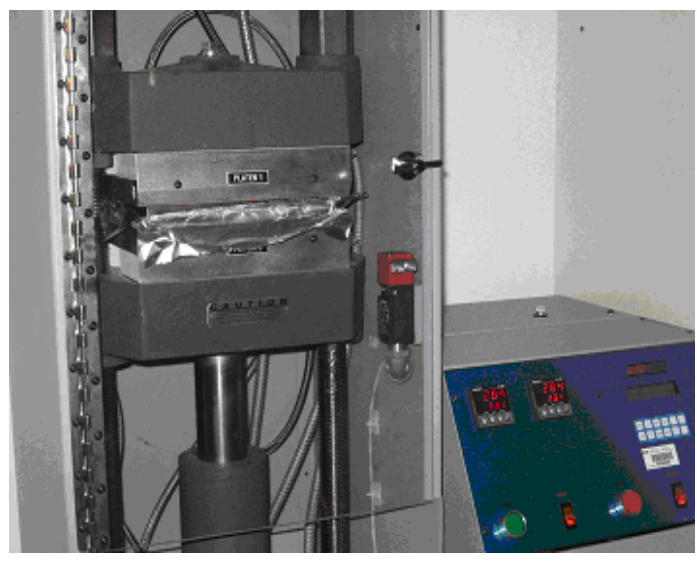

(c)

Figure 3.4 Sample preparation equipment and tool (a) Hamilton Beach 5 Speed OptiMixTM hand/stand mixer; (b) laboratory scale mortar and pestle; (c) automatic hydraulic press. 


\subsubsection{TPS/fiber and TPS/PCL/fiber composites}

For the TPS/fiber binary composites, the ground fiber was initially mixed with S20 at levels 5, 10, and 15\% using the Hamilton Beach 5 Speed OptiMixTM hand/stand mixer (Figure $3.4 \mathrm{a}$ ) for $10 \mathrm{~min}$. Water of about $25 \%$ of the fiber weight in each formulation was sprayed to the mixture to aid mixing. The mixture which still contained starch and fiber clumps at this stage was further compounded with a steel mortar and pestle until the mixture became homogeneous, thus putting it in good shape for compression molding. The same procedure was followed for the preparation of TPS/PCL/fiber ternary composites but with the inclusion of PCL at levels 20 and $40 \%$.

\subsubsection{Compression molding}

The composites were prepared by compression molding at $140^{\circ} \mathrm{C}$ for $45 \mathrm{~min}$ under a load of $25000 \mathrm{~kg}$ into 0.89 to $1.42-\mathrm{mm}$ thick sheets using an automatic hydraulic press (Carver Inc., Wabash, IN) (Figure 3.4c). The processing temperature and pressure were arrived at after several experimental trials (not reported). In addition, it can be seen from the DSC thermograms of pea starch, $\mathrm{PCL}$, and flax fiber discussed earlier that $140^{\circ} \mathrm{C}$ is within the safe temperature ranges for these individual components as no thermal degradation is apparent. The effective contact area of the mold was $152 \mathrm{~mm} \times 152 \mathrm{~mm}$. Before each hot pressing, the plates of the press were stabilized at $140^{\circ} \mathrm{C}$. For sheets made from S-TPS mix, it was observed that compressing immediately after placing the mold on the press led to bubbles being trapped in the sheets. Therefore, a 
particular approach was adopted to avoid this. Accordingly, the mix was welllaid on the mold and then placed on the lower hot plate. The upper hot plate was immediately lowered to press the mold lightly leaving a small opening to allow for moisture escape as the whole set-up was left until the press temperature indicator restabilized at $140^{\circ} \mathrm{C}$. Afterwards, the mold was fully closed under a load of $25000 \mathrm{~kg}$. This procedure avoided bubble formation in the prepared composites. Bubbles serve as weak points, thereby, causing materials to fracture at lower-than-expected stress and strain (Torres et al. 2007). However, this procedure was not necessary for the sheets made from S20-TPS mix as it was observed that the increased viscosity of the gelatinized starch due to the higher water content allowed bubbles to readily exit the mold through its side grooves.

\subsection{Specimen Preparation and Characterization}

The functionality and applications of a material are largely hinged on its properties. Accordingly, four different techniques were used to characterize some of the material properties of the prepared composites. These included tensile test, moisture absorption test, SEM, and DSC.

\subsubsection{Tensile test}

The tensile tests were carried out on an Instron testing machine Model 5500R (Instron Corporation, Grove City, PA) (Figure 3.5a) according to ASTM D 3039 specifications. The composite samples were cut into dogbone-shaped test 
specimens using a commercial wood router and a dogbone-shaped patterning jig and then conditioned at $22 \pm 1{ }^{\circ} \mathrm{C}$ and $50 \pm 2 \%$ relative humidity for six days in an environment chamber (Model UY 150, Angelantoni Climatic Systems, Massa Martana, Italy) before testing. The tests were conducted at crosshead speed of $4 \mathrm{~mm} / \mathrm{min}$. The crosshead displacement was used to estimate tensile elongation. The ambient conditions of the lab at the time of testing were $21^{\circ} \mathrm{C}$

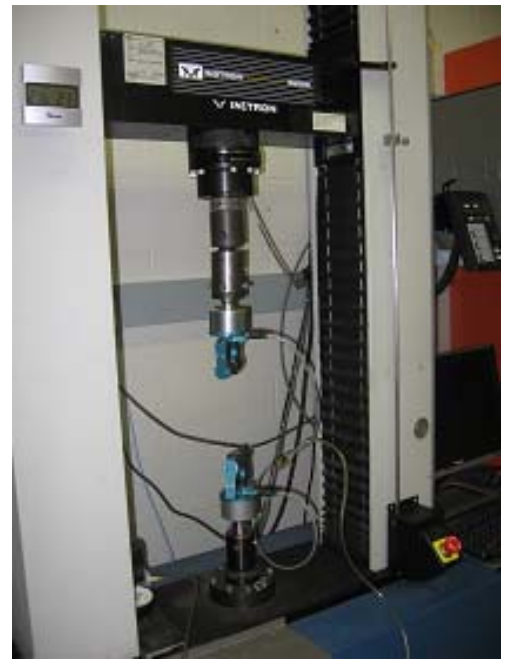

(a)

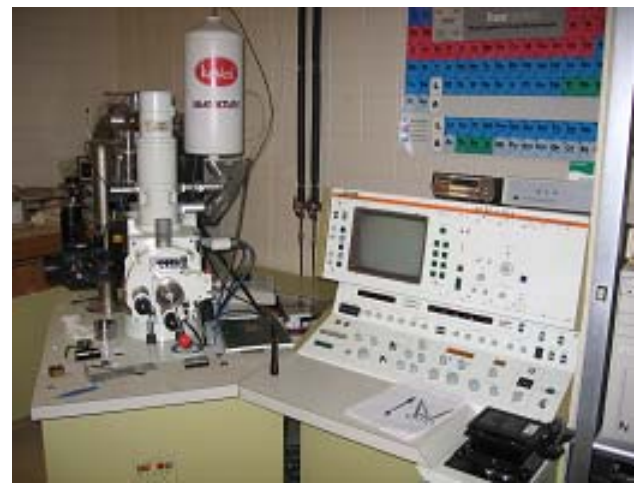

(c)

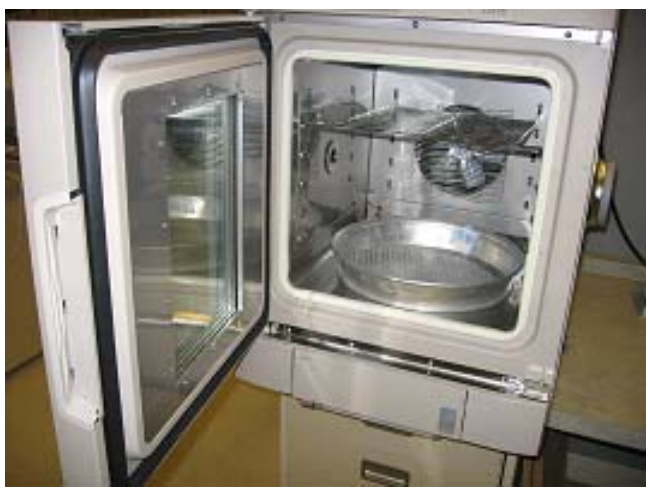

(b)

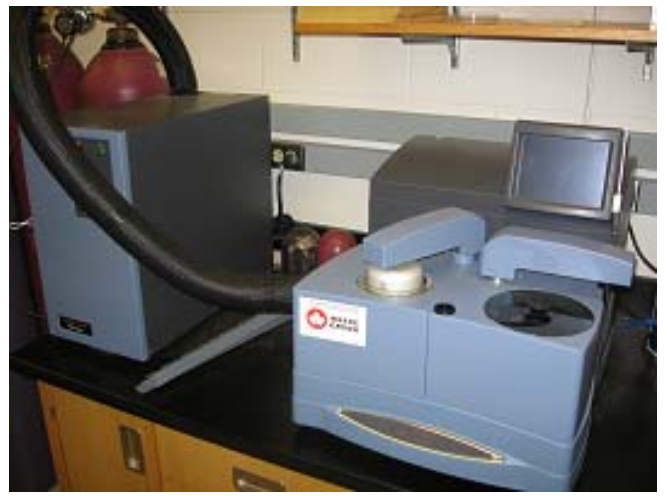

(d)

Figure 3.5 Specimen characterization equipment (a) Instron testing machine; (b) Environmental chamber; (c) Scanning electron microscope; (d) Differential scanning calorimeter. 
and $21 \% \mathrm{RH}$. The data were acquired real-time and the desired mechanical properties, namely, Young's modulus (E), ultimate tensile strength (UTS), yield strength $\left(\sigma_{y}\right)$, and elongation at break $\left(\varepsilon_{b}\right)$ (Equations 3.6 to 3.11 ) were computed automatically by the operating software, Bluehill 2.5 (Instron Corporation, Grove City, PA). Ten replications of each formulation were carried out (Appendix C).

$$
\begin{aligned}
& E=\frac{\Delta \sigma}{\Delta \varepsilon} \\
& \sigma=\frac{F}{A_{o}} \\
& \varepsilon=\frac{l-l_{o}}{l_{o}} \\
& U T S=\sigma_{\text {max }}=\frac{F_{\text {max }}}{A_{o}} \\
& \sigma_{y}=\frac{F_{y}}{A_{o}} \\
& \varepsilon_{b}=\frac{l_{b}-l_{o}}{l_{o}}
\end{aligned}
$$

where

$\sigma=$ Engineering stress, $\mathrm{MPa}$

$\varepsilon=$ Engineering strain

$\sigma_{\max }=$ Ultimate tensile stress, $\mathrm{MPa}$ 
$\mathrm{F}_{\max }=$ Maximum load, $\mathrm{N}$

$\mathrm{I}_{\mathrm{o}}=$ Gauge length, $\mathrm{mm}$

$\mathrm{I}_{\mathrm{b}}=$ Length at point of break, $\mathrm{mm}$

$\mathrm{I}=$ Length at any instant of loading, $\mathrm{mm}$

$\mathrm{A}_{\mathrm{o}}=$ Initial cross-sectional area of the specimen, $\mathrm{mm}^{2}$

$\mathrm{F}=$ Load at any instant, $\mathrm{N}$

$F_{y}=$ Load at $0.2 \%$ offset, $N$

$\sigma_{\max }=$ Yield stress at $0.2 \%$ offset, $\mathrm{MPa}$

\subsubsection{Moisture absorption test}

The samples were cut into $20 \times 20 \times 1$-mm pieces, dried in a VWR gravity oven Model $1370 \mathrm{GM}$ (Sheldon Manufacturing Inc., Cornelius, OR) at $45^{\circ} \mathrm{C}$ for $48 \mathrm{~h}$ and their mass, $\mathrm{m}_{\mathrm{o}}$, taken. They were subsequently transferred into the ESPEC environment chamber Model SH-641 (ESQEC, Osaka, Japan) (Figure 3.5b) already stabilized at $22^{\circ} \mathrm{C}$ and $97 \pm 2 \%$ relative humidity for the moisture uptake measurements. After three days, the samples were taken out, the water condensation/layer on the surfaces of the samples was carefully wiped, and their mass, $m_{\mathrm{f} 1}$, taken. The measurements were taken as fast as possible to limit error arising from the samples losing their absorbed moisture due to the low ambient relative humidity of about $21 \%$ at the time of experimentation. Three replications were made for each formulation (Appendix D). 
Moisture absorbed during the period, M', was calculated thus:

$$
M^{\prime}=\frac{m_{f 1}-m_{o 1}}{m_{o 1}} \times 100
$$

\subsubsection{Scanning electron microscopy}

A JEOL scanning electron microscope Model 8AOA (JEOL Ltd, Akishima, Tokyo, Japan) (Figure 3.5c) was used to study the morphologies of the tensile fracture surfaces of the composites. Prior to feeding into the microscope, the non-conductive composites were cleaned in an ultrasound bath and coated with about $200 \AA$ of gold using an Edwards Gold Coater (Wilmington, MA). The purpose of the gold coating was to make the samples conductive, thereby avoiding electron build-up on the surface during examination. The images were captured at 500X magnification.

\subsubsection{Differential scanning calorimetry}

A DSC Q2000 V23.3 Build 61 (TA Instruments, New Castle, DE) (Figure 3.5d) was used to study some of the thermal properties of the materials, namely, glass transition and melting. The glass transition which is linked directly to molecular mobility is not only important because it affects other thermal properties such as specific heat, coefficient of thermal expansion, enthalpy, and entropy, but it also affects mechanical properties such as Young's and shear moduli. For instance, the Young's modulus of a material drops drastically as it 
transits from the glassy phase to the rubbery phase (Sperling 1986). Samples were conditioned at room temperature of $22 \pm 1^{\circ} \mathrm{C}$ and at relative humidity of 50 $\pm 2 \%$ for six days before testing. Ten to $15 \mathrm{mg}$ of each sample was placed in hermetic aluminum pans, crimped, and fed into the heating chamber of the differential scanning calorimeter. A heat-cool-heat procedure was adopted for the samples: heated from 20 to $140^{\circ} \mathrm{C}$ and cooled to $-80^{\circ} \mathrm{C}$ both at $20^{\circ} \mathrm{C} / \mathrm{min}$ and then heated at the rate of $10^{\circ} \mathrm{C} / \mathrm{min}$ from -80 to $400^{\circ} \mathrm{C}$. The first heating was to remove the specimens' thermal history (Wielage et al. 1999). Glass transition temperature was taken as the mid-point of the glass transition while melting point corresponded to the peak of the melting endotherm. 


\section{RESULTS AND DISCUSSION}

Completely biodegradable bubble-free plasticized pea starch and its composites with polycaprolactone and flax fiber were prepared and characterized. The outcomes of the material characterizations are hereby presented and analyzed. The effects of the factors investigated, which included TPS processing moisture content, flax fiber, and PCL reinforcements, were closely studied. Statistical analyses were conducted essentially on tensile properties (which includes ultimate tensile stress, yield stress, Young's modulus, and elongation at break) and amount of moisture absorbed to ascertain if any difference observed was of any statistical significance $(P<0.05)$.

\subsection{Morphological Characteristics}

The scanning electron micrograms of the tensile fracture surfaces, as depicted in Figure 4.1, reveal the morphological effects of processing moisture content and PCL reinforcement on compression-molded plasticized pea starch. Figures 4.1a-e were outcomes of $9.3 \%$ processing moisture content while Figures $4.1 a^{\prime}$ e' resulted from $20 \%$ processing moisture content. Figures $4.1 \mathrm{a}-\mathrm{e}$ as well as Figures 4.1a'-e' reveal a progressive increase in PCL content from 0 to $40 \%$. Figure 4.1a' shows a fully gelatinized TPS while Figure 4.1a contains intact and partly destructured starch granules. This implies that under the applied processing conditions, TPS containing $20 \%$ water (Figure $4.1 a^{\prime}$ ) was able to proceed to complete gelatinization while $9.3 \%$ moisture content TPS could not. 


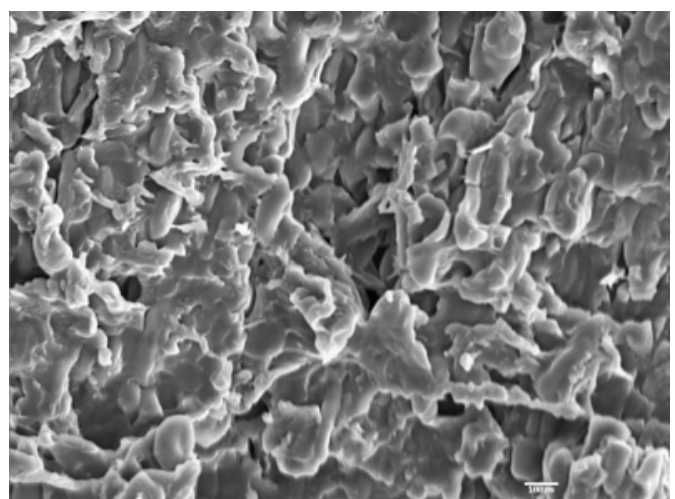

(a) $0 \%$ polycaprolactone

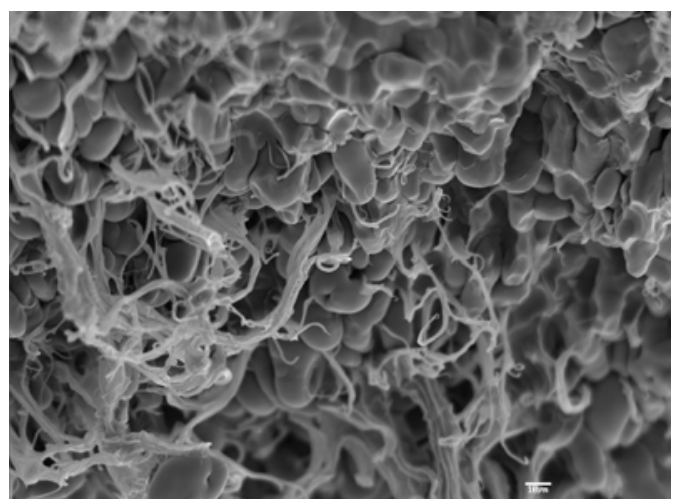

(b) $10 \%$ polycaprolactone

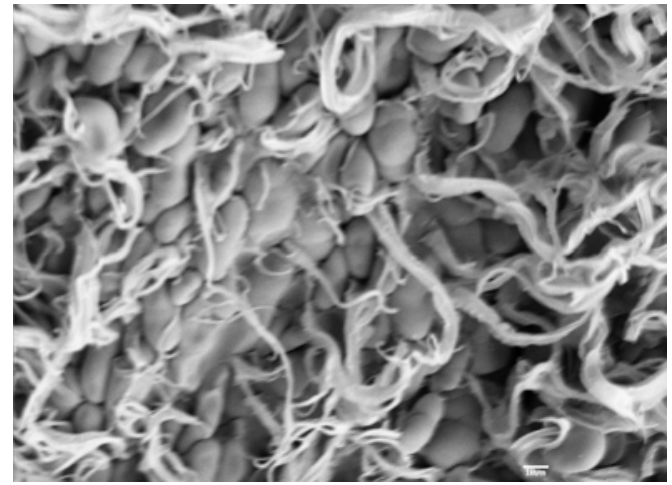

(c) $20 \%$ polycaprolactone

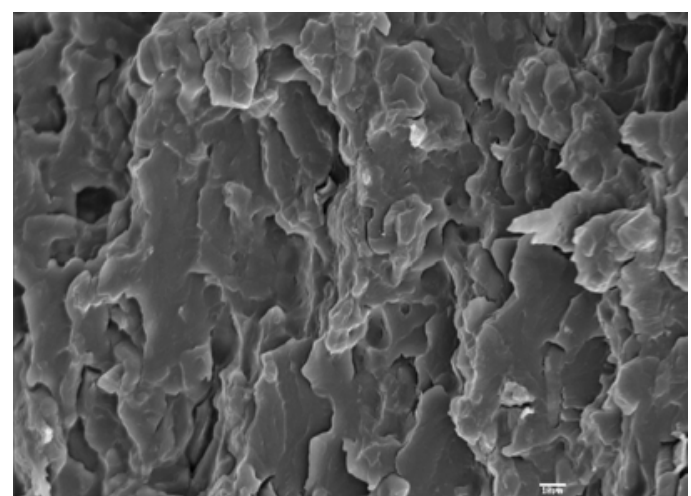

(a') $0 \%$ polycaprolactone

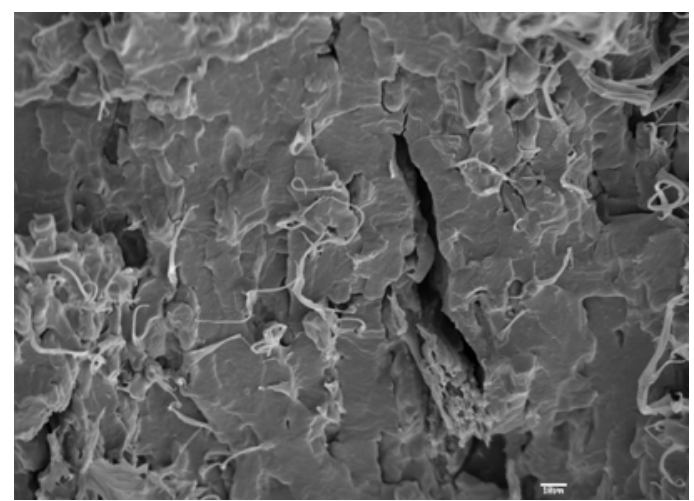

(b') $10 \%$ polycaprolactone

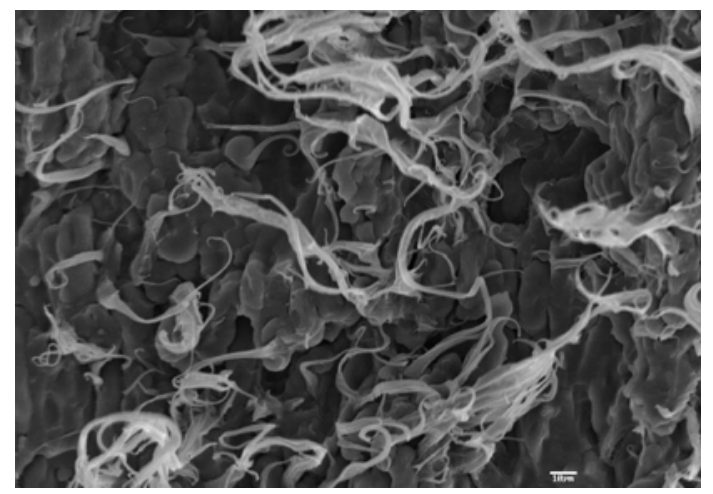

(c') $20 \%$ polycaprolactone

Figure 4.1 Scanning electron micrograms (500X) of the tensile fracture surfaces of plasticized pea starch prepared at $9.3 \%$ (left column) and $20 \%$ (right column) processing moisture content and reinforced with polycaprolactone. 


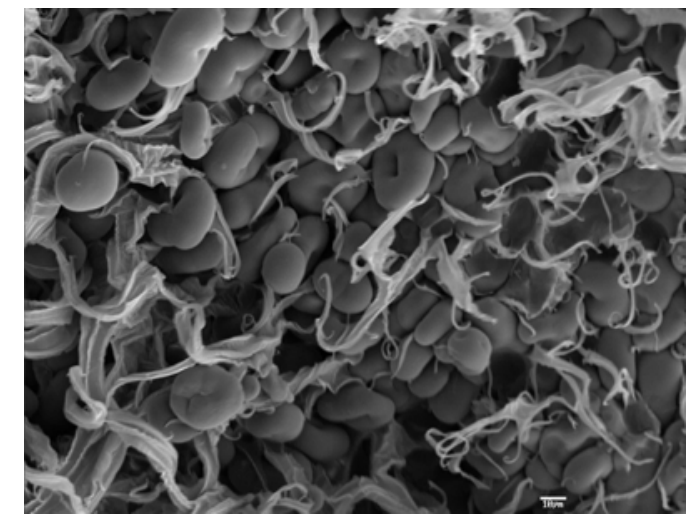

(d) $30 \%$ polycaprolactone

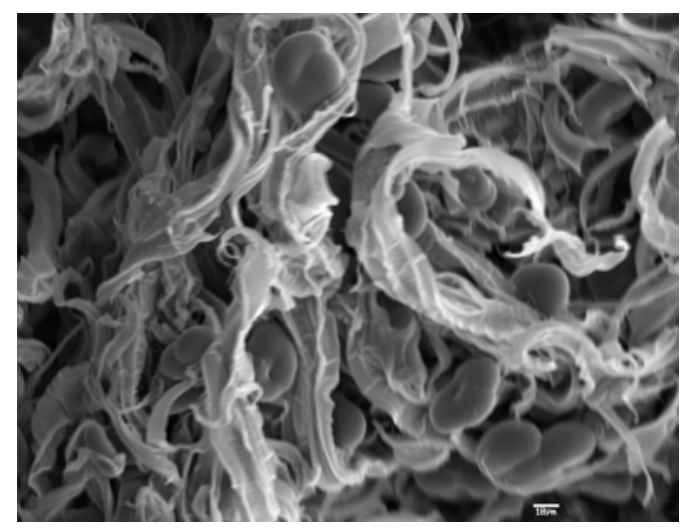

(e) $40 \%$ polycaprolactone

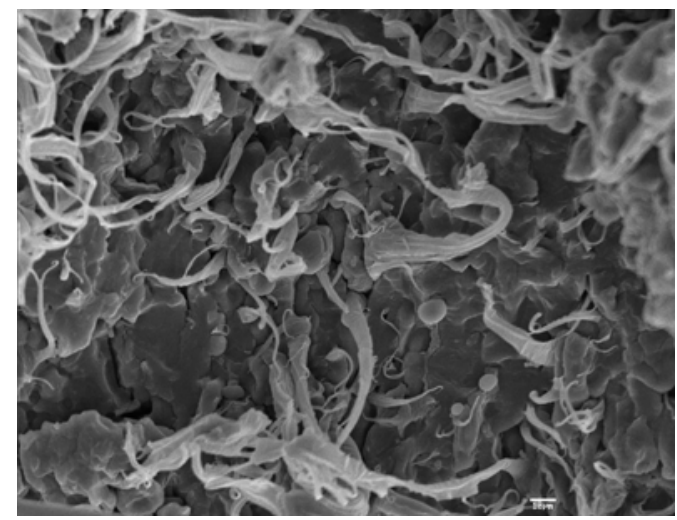

(d') $30 \%$ polycaprolactone

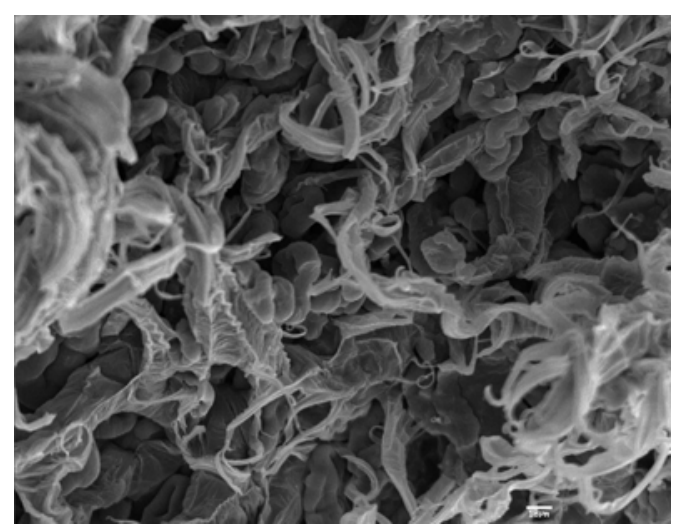

(e') $40 \%$ polycaprolactone

Figure 4.1 (Cont'd) 
This underscores the importance of moisture to starch gelatinization mechanism. In spite of its high gelatinization and plasticizing effects on starch, water alone is not recommended for the production of thermoplastic starch due to its volatility; hence, its combination with other non-volatile plasticizers such as glycerol with comparatively low plasticizing effects (Forssell et al. 1997; Sarazin et al. 2008). However, starch destructurization in this case of limited water took place at higher temperature than that in the case of excess water and was indeed facilitated by the induced shear stresses (Xie et al. 2006). In addition to playing the role of a plasticizer, glycerol is capable of effecting starch gelatinization but the onset temperature of gelatinization is higher with decrease in water content (Nashed et al. 2003). With the incorporation of PCL, ungelatinized starch granules became more evident. This was more pronounced with TPS/PCL composites made from S TPS mix (Figure 4.1b-e). In fact, ungelatinized and partly destructured starch granules did not become apparent until at $20 \%$ PCL level for TPS/PCL composites made from S20 TPS mix. This therefore implies that PCL interfered with the gelatinization mechanism of pea starch.

The fact that $\mathrm{PCL}$ melted $\left(\sim 58^{\circ} \mathrm{C}\right)$ before the onset of starch gelatinization was, on the one hand, desirable as the molten PCL would be able to penetrate the TPS mix interstices, thereby, laying out a reinforcing structure. On the other hand, the molten PCL, due to its hydrophobicity, expectedly interfered with moisture diffusion within the TPS mix, a condition crucial to starch gelatinization mechanism. The higher the PCL content, the greater the 
interference and hence, the lower the degree of starch gelatinization during compression molding. It could also be seen that gelatinization improved the interaction between PCL and starch phases. Similar improvement in compatibility (although still poor) between starch and PCL due to starch plasticization was reported by earlier studies (Matzinos et al. 2002; Shin et al. 2004; Ikeo et al. 2006). This poor compatibility was attributed to possible formation of hydrogen bonds between the ester carbonyl groups of PCL and starch hydroxyl groups (Matzinos et al. 2002; Shin et al. 2004). Better still, maleic anhydride had been found to further enhance PCL compatibility with TPS (Ikeo et al. 2006). All the scanning electron micrograms (Figure 4.1) show stretched PCL strands which could be attributable to the ability of PCL to form a rather continuous reinforcing network throughout the plasticized starch during compression molding regardless of the TPS processing moisture content.

Figure 4.2 shows the tensile fracture surface morphologies of the plasticized pea starch reinforced with flax fiber. The scanning electron micrograms reveal multi-directionally dispersed fiber in well-gelatinized TPS matrices for the fiber content range investigated. It is evident that compatibility between fiber and TPS and fiber was better than that between TPS and PCL. This was largely due to the chemical similarities between both the TPS and fiber as suggested by Wollerdorfer and Baker (1998) because both fiber and starch are polyhydroxyl materials. However, instances of fiber pull-out as noticeable in Figure 4.2 suggests that the interfacial bonding between TPS and fiber was not as strong as to cause fiber breakage instead of pull-out. This weak interfacial 
interaction could partly be attributable to thermal stress (which is a function of temperature, dwelling time, and water content available for starch plasticization (Wiedmann and Strobel 1991), developed in the TPS as the material cured.

Figure 4.3 shows the scanning electron micrograms of the tensile fracture surfaces of TPS/PCL/fiber composites. Figures $4.3 a, b$, and $c$ and Figures 4.3a', b', and c' represent 20 and 40\% PCL levels, respectively with increasing fiber

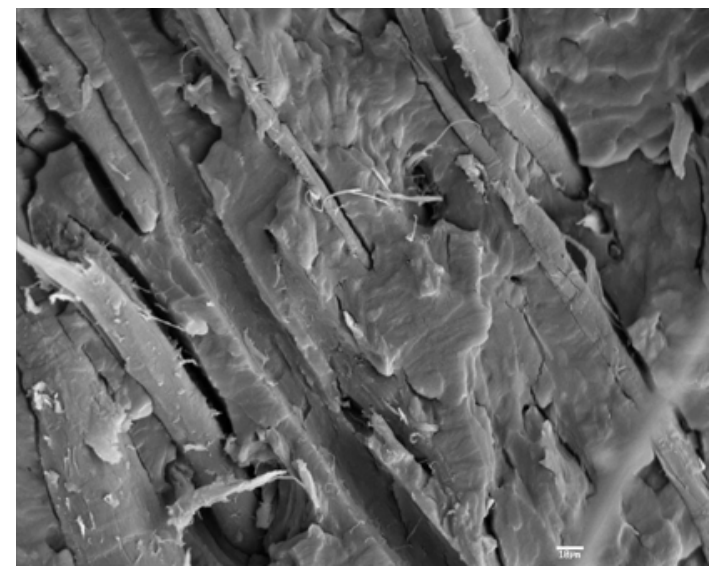

(a) $5 \%$ fiber

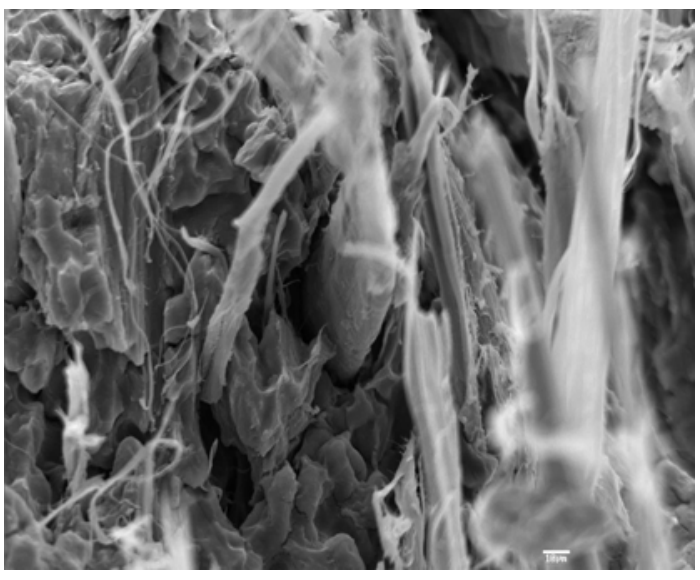

(b) $10 \%$ fiber

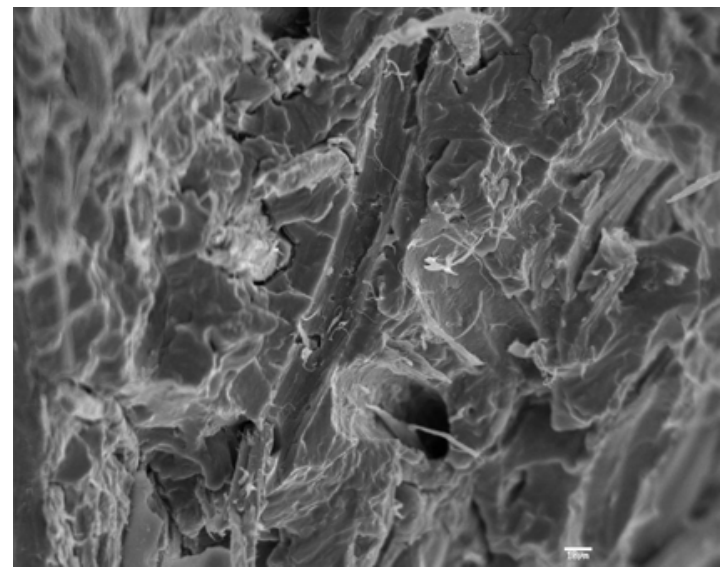

(c) $15 \%$ fiber

Figure 4.2 Scanning electron micrograms (500X) of the tensile fracture surfaces of plasticized pea starch reinforced with flax fiber. 


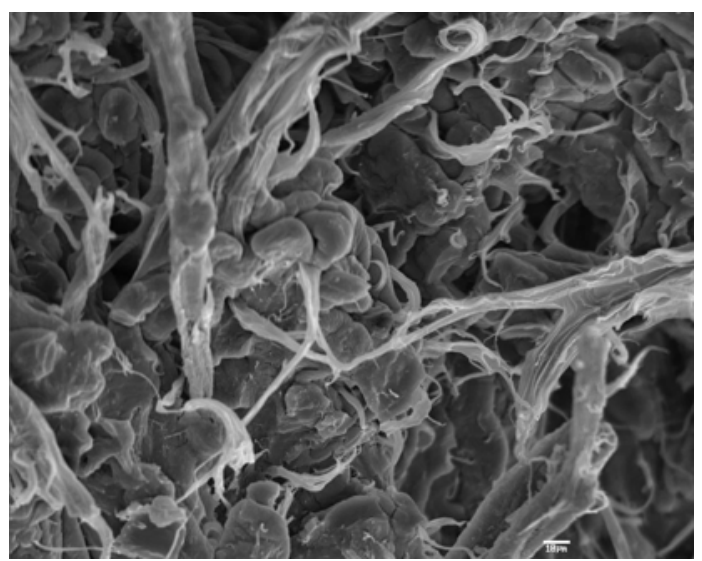

(a) $5 \%$ fiber, $20 \%$ polycaprolactone

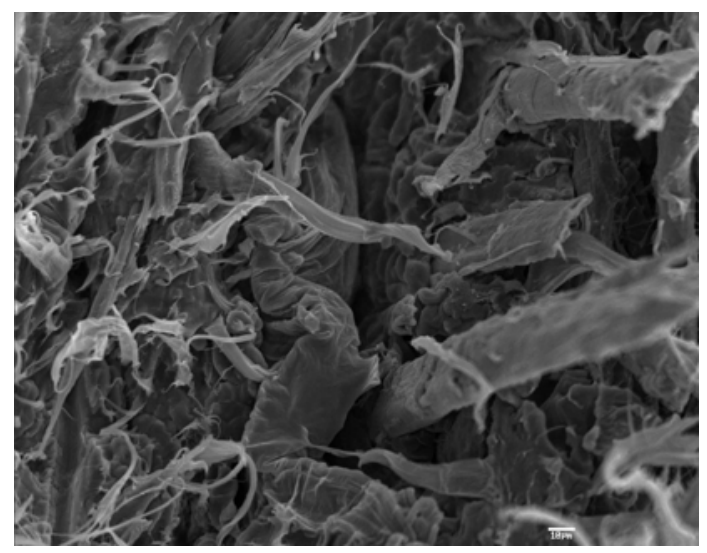

(b) $10 \%$ fiber, $20 \%$ polycaprolactone

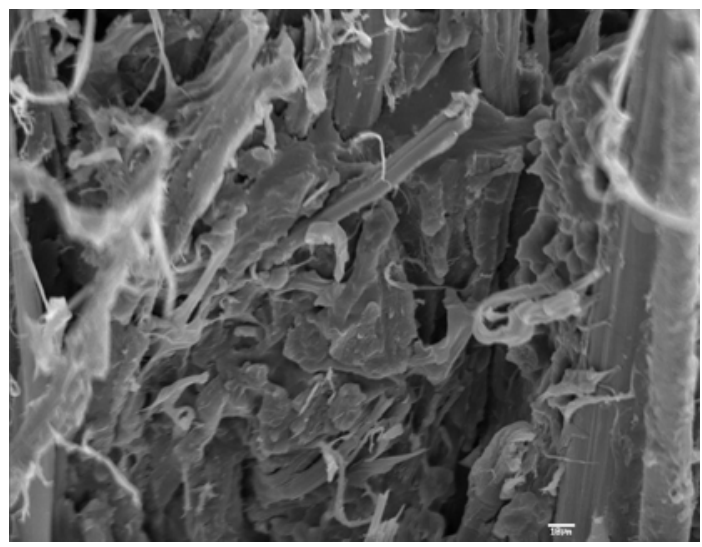

(c) $15 \%$ fiber, $20 \%$ polycaprolactone

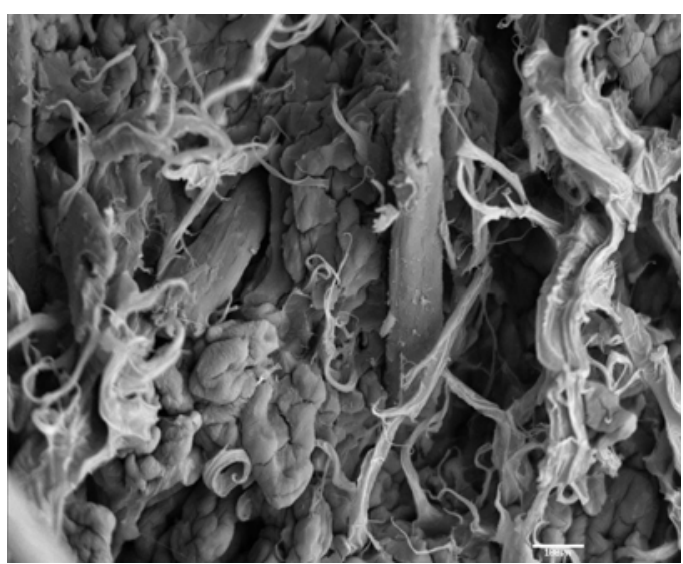

(a') $5 \%$ fiber, $40 \%$ polycaprolactone

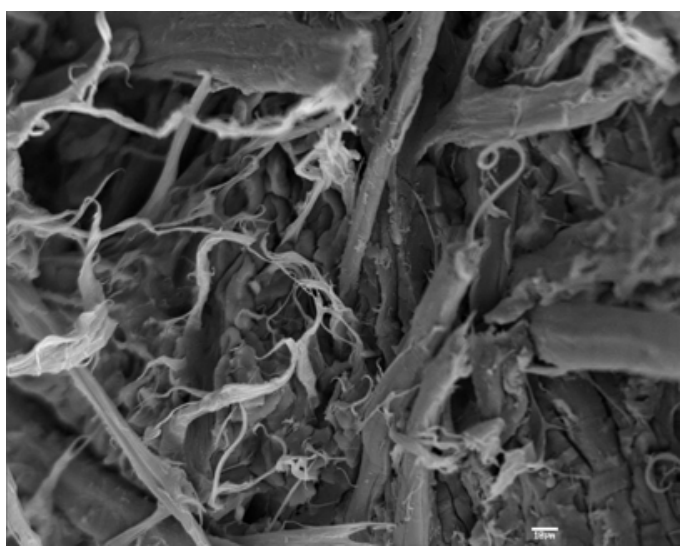

(b') $10 \%$ fiber, $40 \%$ polycaprolactone

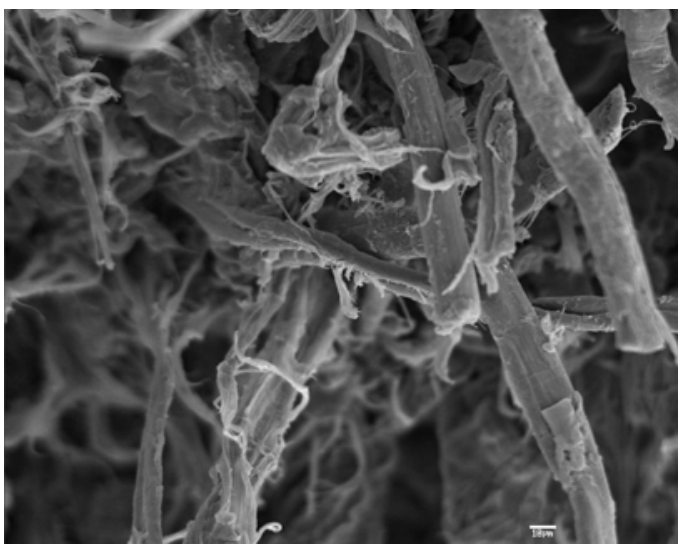

(c') $15 \%$ fiber, $40 \%$ polycaprolactone

Figure 4.3 Scanning electron micrograms (500X) of the tensile fracture surfaces of plasticized pea starch/polycaprolactone/flax fiber. 
contents from 5 to $15 \%$. As mentioned above, it would have been expected that the lower the PCL content, the greater the degree of starch gelatinization. However, the additional water (about $25 \%$ of fiber weight per formulation) added to aid fiber mixing significantly offset the gelatinization interference that $\mathrm{PCL}$ would have caused. Both fiber and PCL acted as independent reinforcements as no interfacial interaction was observed between them. Flax fiber and TPS tended to readily bind together due to their chemical similarities (Wollerdorfer and Baker 1998) unlike PCL. In other words, homogeneity of TPS/PCL/fiber ternary composites was markedly affected as PCL content increased.

\subsection{Tensile Properties}

As mentioned earlier in Section 3.4, to determine the tensile effects of the investigated variables, namely, TPS processing moisture, PCL reinforcement, and flax fiber reinforcement, tensile tests were set up in two modules. Module one compared the effects of TPS processing moisture content and PCL content on the tensile properties of TPS/PCL composites while module two was designed to investigate the effects of flax and PCL reinforcements at $20 \%$ TPS processing moisture content on the tensile properties of TPS/PCL/fiber composites. The two modules were set up as CRD at $5 \%$ level of significance and means separation was done using Tukey's method. Tensile properties measured included tensile stress (ultimate tensile strength), $0.2 \%$ offset yield stress, Young's modulus, and elongation at break. 


\subsubsection{TPS/PCL composites}

The effects of processing moisture content and $\mathrm{PCL}$ reinforcement on the tensile properties of plasticized pea starch are shown in Figure 4.4. The tensile strength curve significantly shifts upwards with increase in processing moisture content (Figure 4.4a). At 0\% PCL, the tensile strength was more than tripled (precisely $208.6 \%$ increase) at $20 \%$ moisture content. The reason for this can be seen in the morphological differences of the two materials as shown in Figure 4.1a and a'. While Figure 4.1a' shows a well-gelatinized continuous TPS phase Figure 4.1a reveals the presence of intact and partly gelatinized starch granules.

Ungelatinized granules constituted structural defects in the TPS by acting as weak points or points of stress concentration, a condition that most likely resulted in the failure of the plasticized pea starch obtained from $9.3 \%$ moisture mix, $\mathrm{T}$, at comparatively low stress. In addition, at ambient condition of about $21^{\circ} \mathrm{C}$ and $23 \%$ relative humidity, $\mathrm{T}$ was brittle and rigid while T20 (obtained from $20 \%$ moisture mix) was ductile and tough (although both were brittle when oven-dried). Yang and co-authors (2006) reasoned that ungelatinized starch granules could cause such brittleness. As mentioned earlier, addition of PCL interfered with the starch gelatinization mechanism, with the effect being more pronounced with T composites (Figure 4.1). Unlike 1T9T20, the ungelatinized starch granules in 1P9T perhaps allowed PCL to form a better reinforcing network through the TPS structure (Figure 4.1b and b'). This could explain why at $10 \% \mathrm{PCL}, \mathrm{T}$ exhibited a significant increase in tensile strength while T20 did 

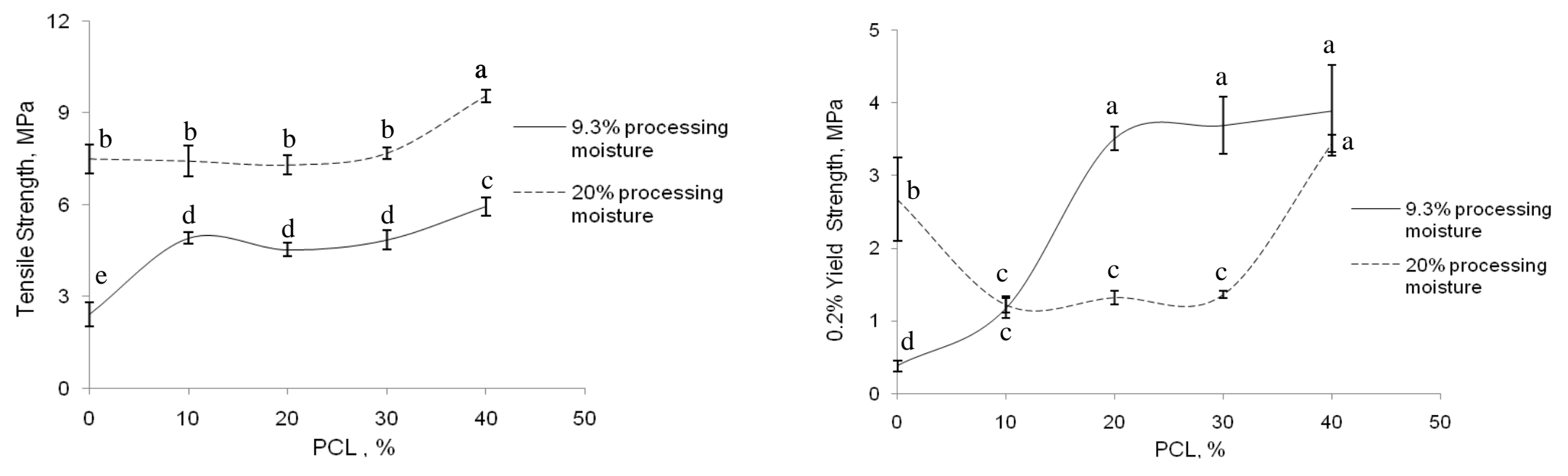

(a)

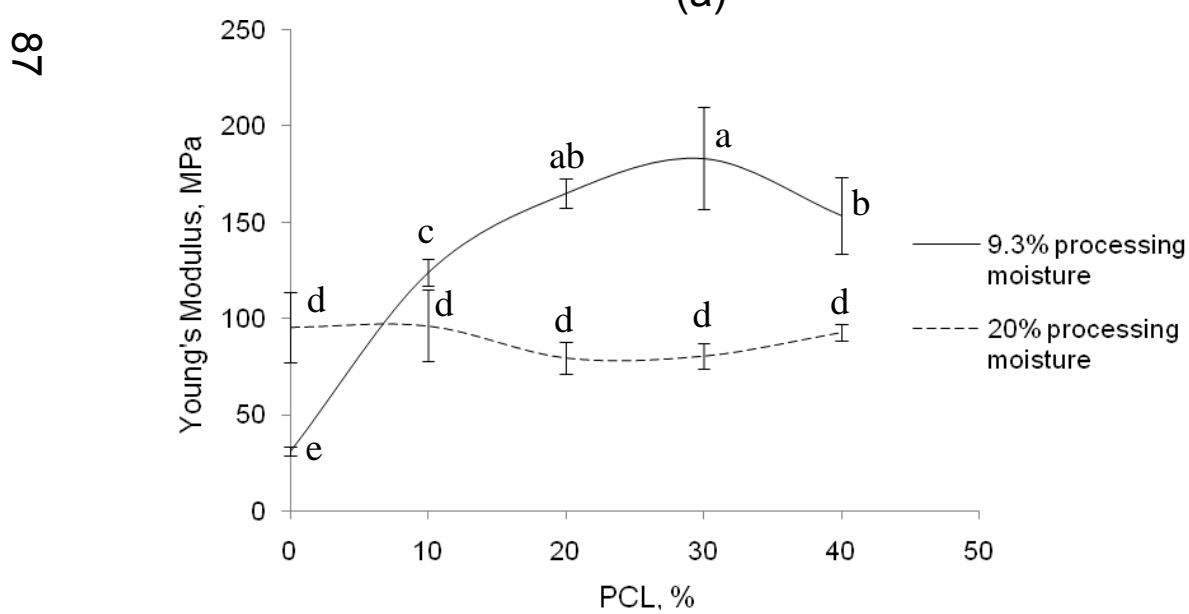

(c)

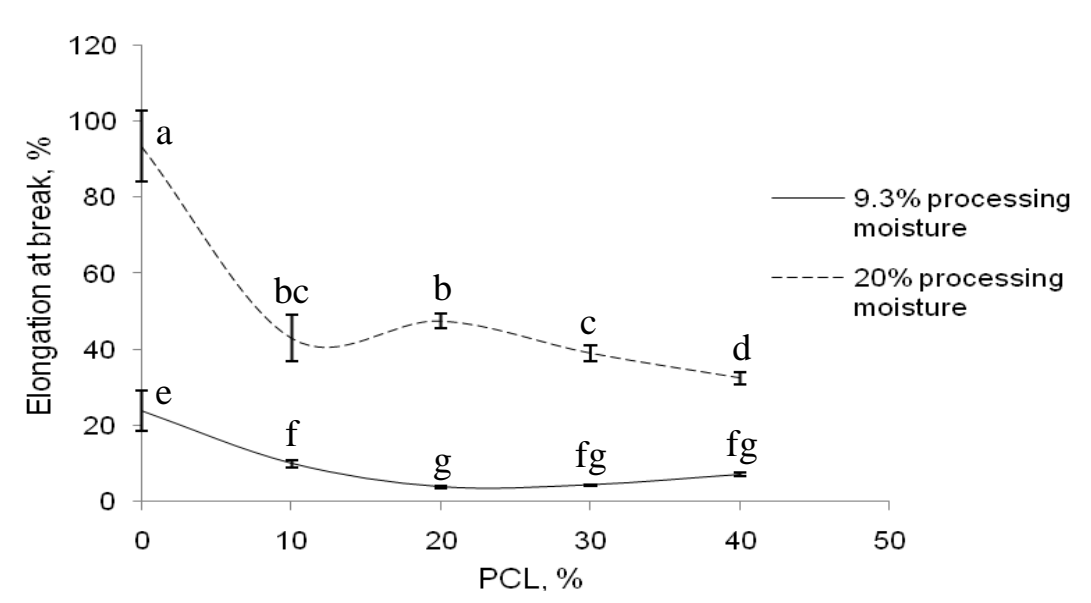

(d)

Figure 4.4 Tensile effects of processing moisture content and polycaprolactone incorporation on glycerolplasticized pea starch. Means having the same letters on the same graph are not significantly different $(P<0.05)$ based on Tukey's method of means separation. Error bars indicate standard deviation. 
not. The tensile curves remain fairly horizontal between 10 and $30 \%$ PCL. This could mean the reinforcing potentials of PCL at both moisture levels were sufficiently offset by poor compatibility between starch and PCL, and the weak points caused by ungelatinized starch granules. However, beyond this range, the curves tilt upwards possibly marking the beginning of PCL phase reversal from dispersed to continuous phase.

The tensile strength, yield strength, Young's modulus, and elongation at break of pure PCL (prepared using the same technique) were found to be 15.7 $\mathrm{MPa}, 7.38 \mathrm{MPa}, 184.77 \mathrm{MPa}$, and $>800 \%$, respectively. Furthermore, the incorporation of PCL decreased the yield strength (elastic limit) for T20 while increasing that of T (Figure 4.4b). Similar results were observed for the Young's modulus (stiffness) but with $P C L$ effect being statistically insignificant $(P<0.05)$ at $20 \%$ moisture (Figure 4.4c). The elongation at break of the plasticized pea starch was remarkably improved by $292 \%$ with increase in processing moisture content at $0 \%$ PCL (Figure 4.4d). This could be because more water, like any other plasticizer, in the system created more free volume, thus allowing for a higher degree of starch chain mobility which, in turn, translated into higher degree of flexibility/ductility. Similar results of increase in elongation at break prompted by increase in plasticizer content have been reported by other researchers (Yang et al. 2006; Teixeira et al. 2005). However, the elongation at break largely dropped with PCL incorporation. 


\subsubsection{TPS/flax fiber composites}

The tensile effects of reinforcing plasticized pea starch with flax fiber denoted as 0\% PCL curves could be seen in Figure 4.5. The tensile strength remained fairly constant up to $10 \%$ fiber content beyond which a relatively sharp increase of $41.2 \%$ was observed at $15 \%$ fiber content (Figure $4.5 a$ ). This could be ascribed to the complex interplay of some factors. Accordingly, better fiber dispersion in the TPS matrix was noticed at $15 \%$ fiber content than at any other fiber levels. In general, low bulk density of fiber poses a challenge towards achieving highly homogeneous mixing with matrix, thus, partly militating against the reinforcement potentials of flax fiber. Similar pattern was observed for the Young's modulus of TPS/fiber ( $0 \% \mathrm{PCL}$ ) composites (Figure 4.5c). Wollerdorfer and Bader (1998) also hinted an analogy between tensile strength and Young's modulus of thermoplastic starch on fiber reinforcement. However, earlier work by Karmaker and Youngquist (1996) reported that while tensile strength was significantly affected by fiber-matrix interaction, Young's modulus (stiffness) was dependent on fiber content and dispersion within the matrix and not significantly by fiber-matrix interaction. The yield strength (Figure 4.5b) of the plasticized pea starch improved significantly from 2.67 to $4.68 \mathrm{MPa}$ with fiber incorporation while elongation at break (Figure 4.5d) dropped from 93.52 to $11.17 \%$. 


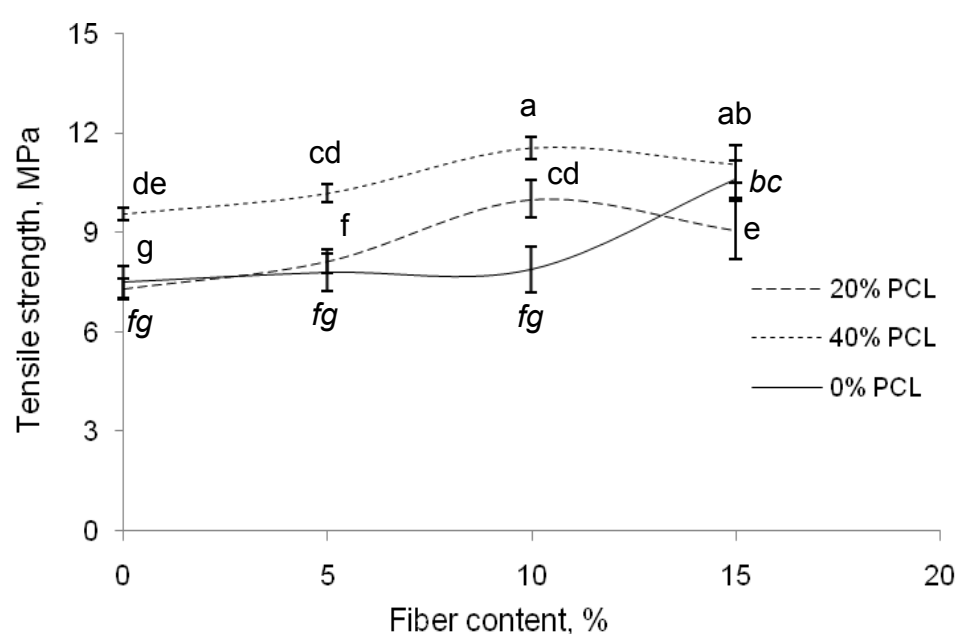

(a)

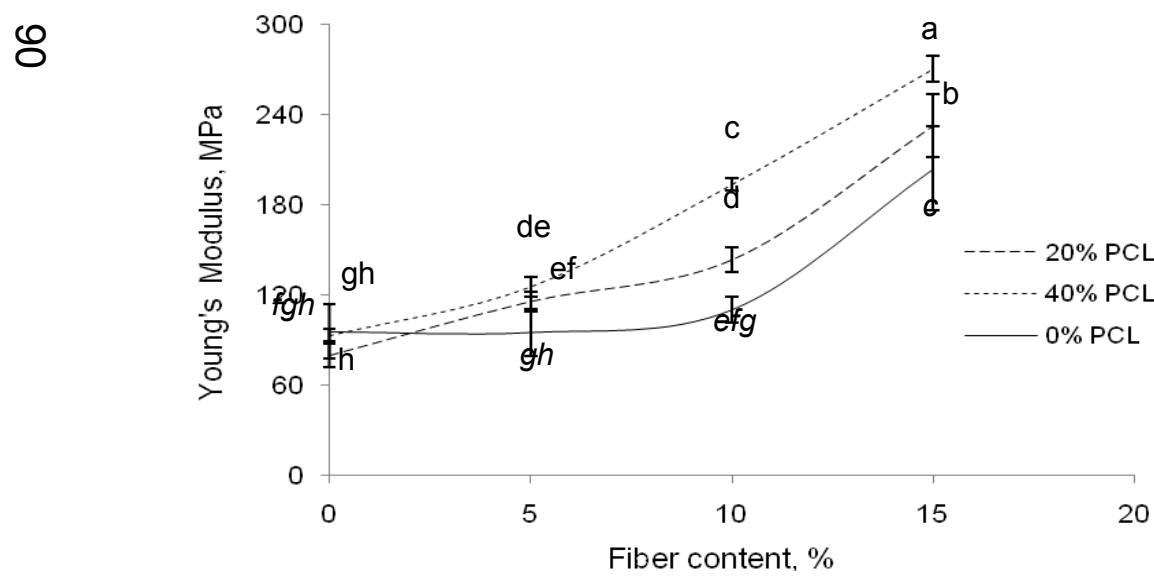

(c)

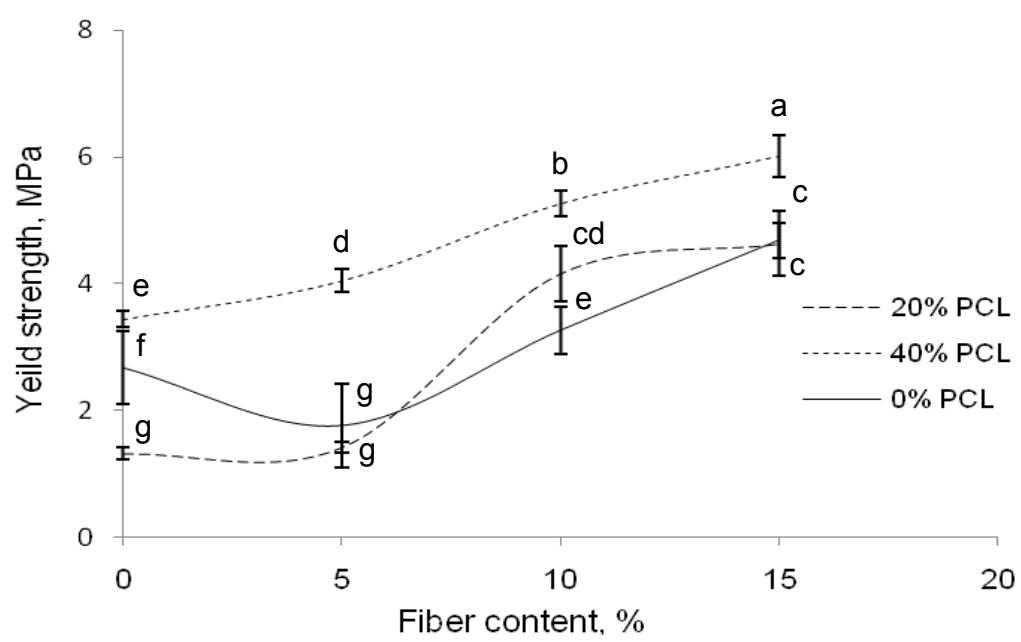

(b)

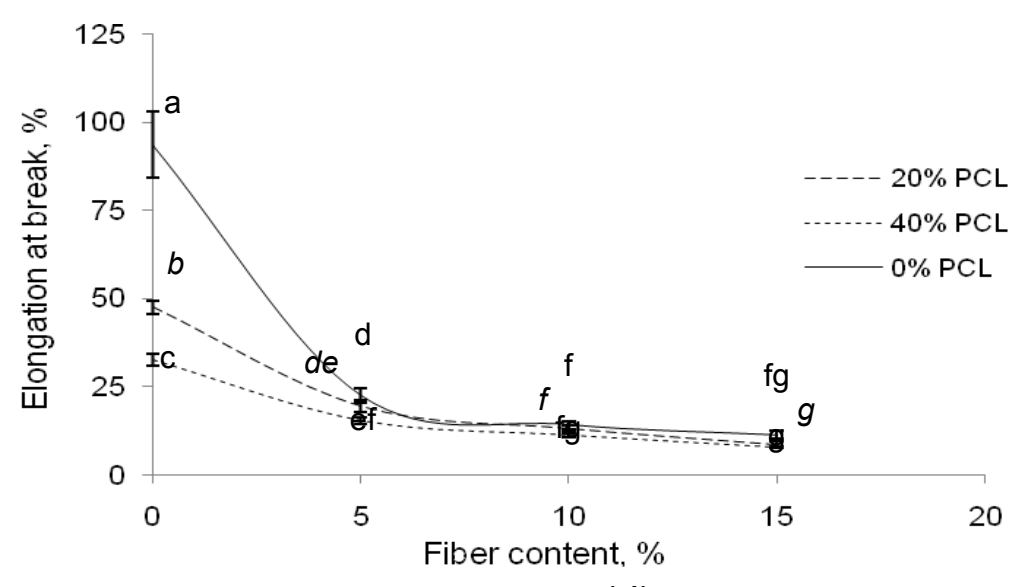

(d)

Figure 4.5 Tensile effects of polycaprolactone and flax fiber incorporation on glycerol-plasticized pea starch. Means having the same letters on the same graph are not significantly different $(P<0.05)$. Tukey's method was used for means separation. Error bars indicate standard deviation. 


\subsubsection{TPS/PCL/flax fiber composites}

Figure 4.5 shows the tensile effects of reinforcing plasticized pea starch with both flax fiber and PCL. The tensile performances of the composites at 20 and $40 \%$ PCL levels were fairly identical particularly the tensile strength and elongation at break. Unlike TPS/fiber composites, the tensile strength increased until $10 \%$ fiber, beyond which it dropped at both 20 and $40 \%$ PCL levels. In fact, the optimum tensile strength of $11.55 \mathrm{MPa}$ was reached at $10 \%$ flax fiber and $40 \%$ polycaprolactone. As shown earlier in Figure 4.3c, fiber bonded more readily with TPS due to their chemical similarity (both have $-\mathrm{OH}$ functional group) than PCL. Although both PCL and fiber acted as independent reinforcements due to the absence of interfacial bonding between the two, the fact that their reinforcing domains intertwined or interlocked is noteworthy.

Dissimilarities in polarity and moisture affinity between TPS and fiber on the one hand and PCL on the other could be responsible for the phase separation noticed in the ternary composites which became more noticeable with fiber and PCL increase (most pronounced for 15F40P), thus, hampering microscopic homogeneity (Figure 4.6). Although the tensile strength, Young's modulus, and yield strength all increased while the elongation at break decreased with fiber and PCL incorporation into the plasticized pea starch, better results could have been obtained had there been effective homogeneous dispersion of fiber and PCL in the TPS matrix. In spite of the fact that the elongation at break of PCL (>800\%) far exceeded that of TPS matrix (93.52\%), 
the elongation at break of fiber-PCL-reinforced TPS composites fell way below that of pure TPS.

\subsection{Moisture Absorption}

One of the major drawbacks of thermoplastic starch is its high moisture affinity. As such, moisture sensitivity reduction is crucial to developing starch-based products of acceptable standards. The effects of processing moisture content and PCL reinforcement on plasticized pea starch are as indicated in Figure 4.7. It is evident that increase in processing moisture content produced TPS more susceptible to moisture absorption. For instance, moisture absorbed by the TPS increased by $55.7 \%$ as the processing moisture content increased from 9.3 to $20 \%$. This was because additional water molecules increased the total number of $-\mathrm{OH}$ functional groups (with characteristic high moisture affinity) available for

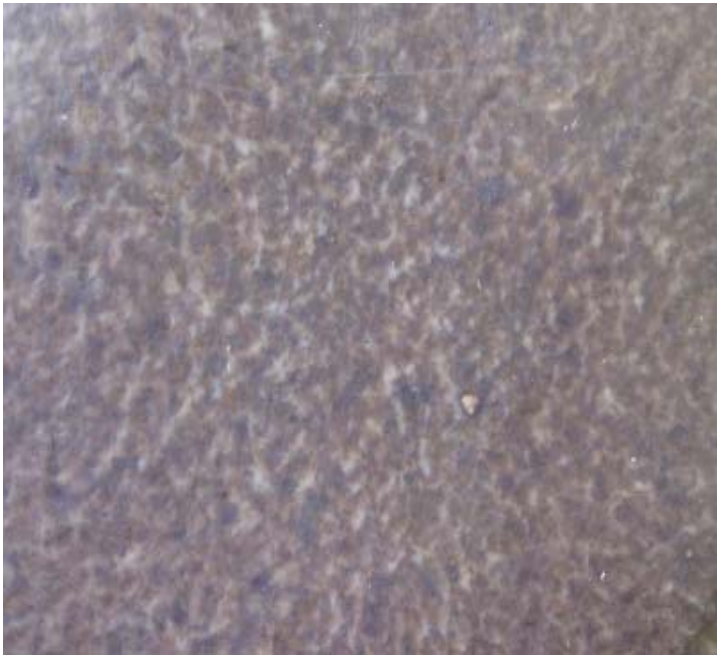

(a) $15 \%$ fiber, $20 \%$ polycaprolactone

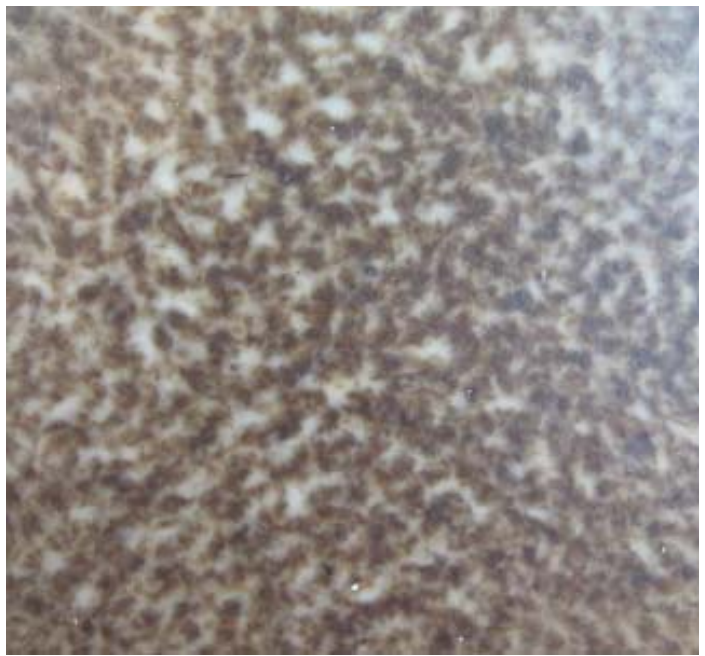

(b) $15 \%$ fiber, $40 \%$ polycaprolactone

Figure 4.6 Compression-molded glycerol-plasticized pea starch reinforced with polycaprolactone and flax fiber (1X). The dark spots denote areas of fiber population. 
hydrogen bonding with atmospheric moisture, thus, increasing the overall moisture affinity of the TPS. Generally, increase in plasticizer content results in increase in TPS moisture absorption owing to plasticizer-water interactions (Lourdin et al. 1997; Mathew and Dufresne 2002; De Carvalho et al. 2002; Yang et al. 2006, Thunwall et al. 2006b).

However, with the incorporation of PCL, moisture absorption capacity of the TPS dropped progressively at both processing moisture levels. Since PCL is hydrophobic and is not known to chemically react with starch and glycerol, both of which are hydrophilic, the observed reduction in moisture absorption capacity

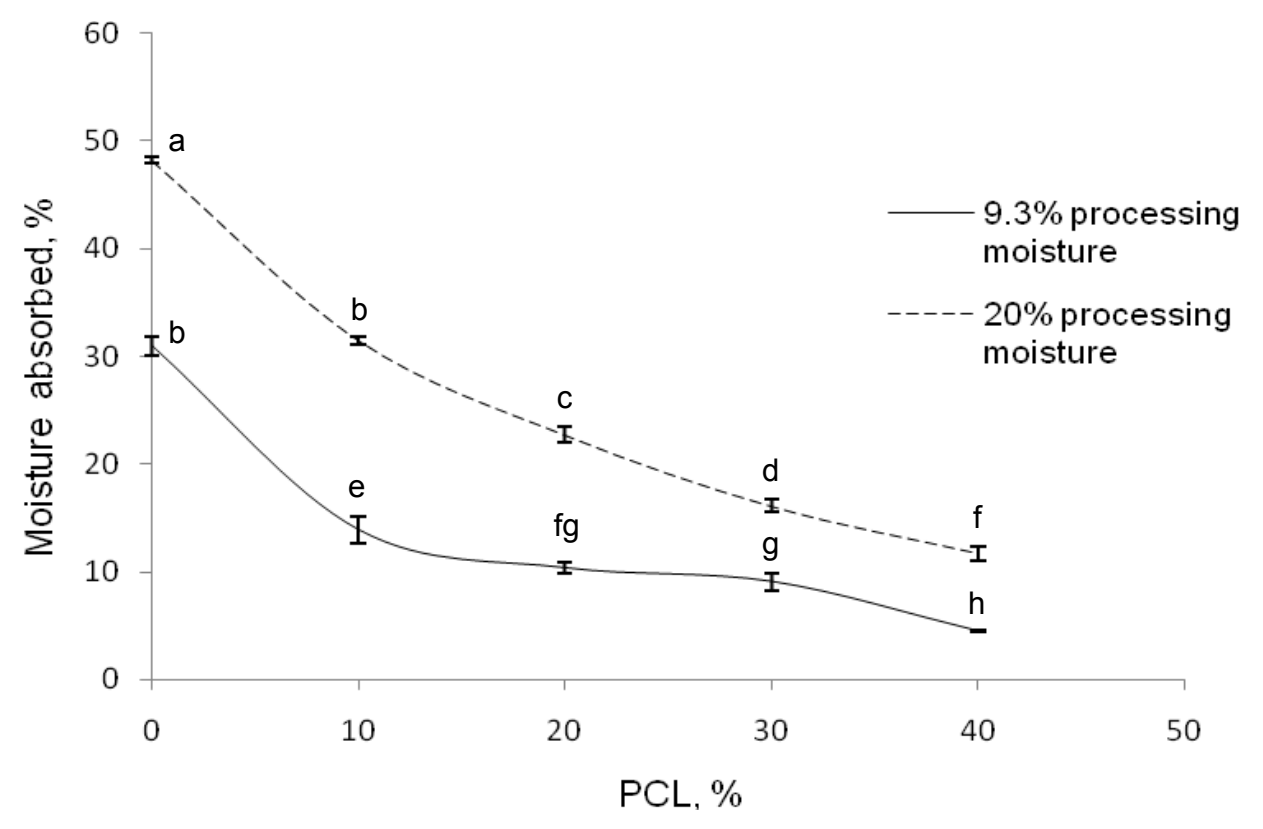

Figure 4.7 Effects of processing moisture content and polycaprolactone incorporation on the moisture absorption properties of glycerolplasticized pea starch. Means having the same letters on the same graph are not significantly different $(P<0.05)$. Tukey's method was used for means separation. Error bars indicate standard deviation. 
could be attributed to the reduction in the number of $-\mathrm{OH}$ functional groups per unit volume of the specimens available for hydrogen bonding with the atmospheric moisture. This could be ascribed to PCL forming a hydrophobic blanket around the starch and glycerol molecules, thus limiting their exposure to the surrounding moisture and/or directly reducing TPS content per unit volume of the specimens. Similar results have been reported using fly ash (Ma et al. 2007) and clay (Hwan-Man et al. 2003) as TPS reinforcements. At 10, 20, 30, and $40 \%$ PCL, the percentage decreases in moisture absorption for TPS at 9.3 and $20 \%$ processing moisture contents were $55.1,66.6,70.7$, and $85.6 \%$, and 34.7, 52.9, 66.6, and $75.7 \%$, respectively. These values indicate that PCL was more effective in reducing moisture absorption at $9.3 \%$ than at $20 \%$ processing moisture level.

Furthermore, the effects of PCL and flax fiber reinforcements on TPS moisture absorption were also investigated (Figure 4.8). At $0 \% \mathrm{PCL}$, the incorporation of $5 \%$ flax fiber dropped the TPS moisture absorption by $27.2 \%$, but subsequent fiber addition yielded little or no further significant changes. Carvalho and co-authors (2002) also reported that fiber presence and not fiber content yielded reduction in TPS moisture absorption. Similarly, fiber reinforcement at $20 \%$ PCL did not alter the moisture absorption capabilities of the plasticized pea starch while at $40 \%$ a slight elevation which was constant regardless of the fiber content was recorded. However, all TPS/fiber and TPS/fiber/PCL composites had lower moisture absorption than pure TPS. 


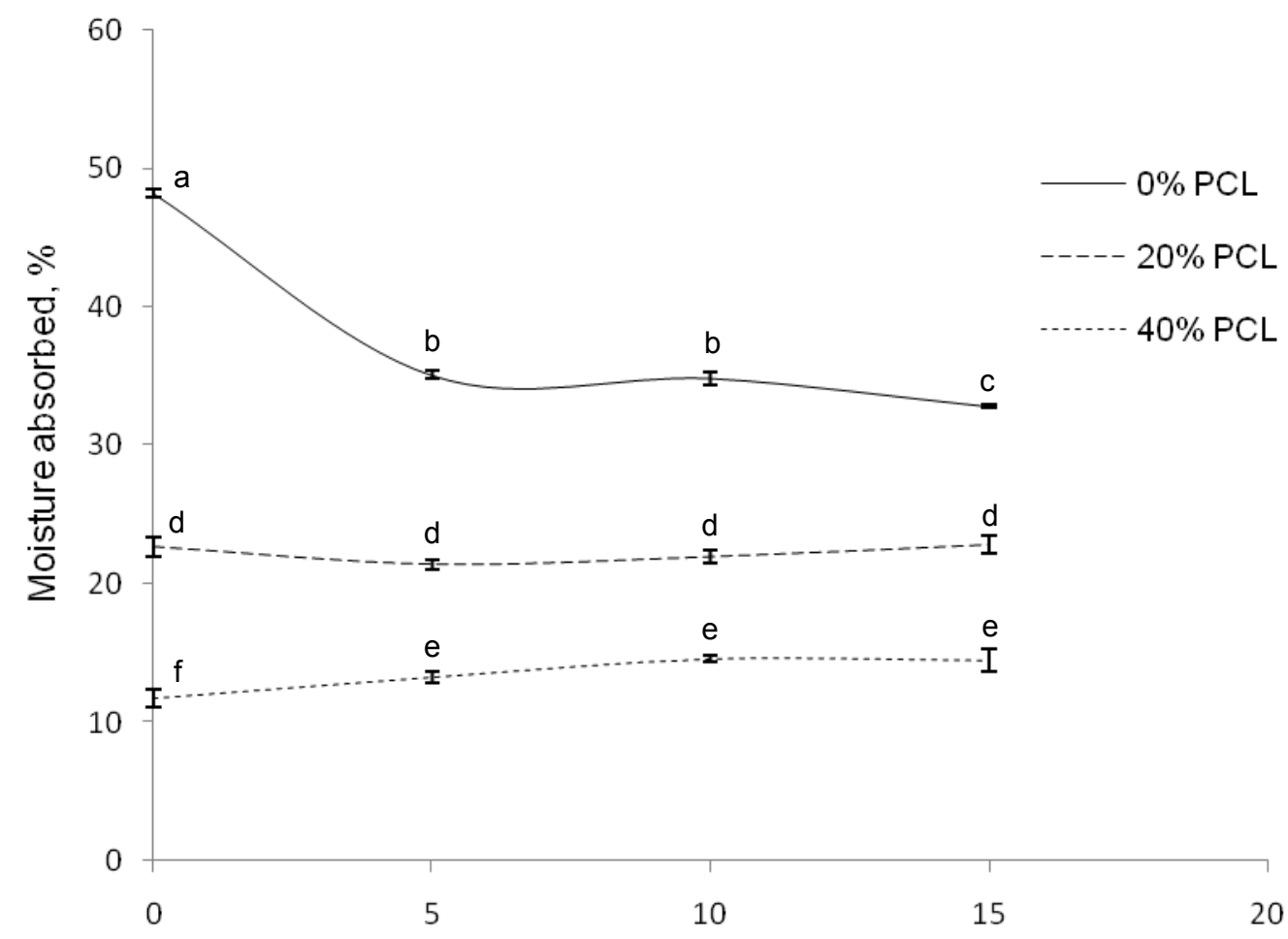

Flax fiber, $\%$

Figure 4.8 Effects of flax fiber and polycaprolactone incorporation on the moisture absorption properties of glycerol-plasticized pea starch. Means having the same letters on the same graph are not significantly different $(P<0.05)$. Tukey's method was used for means separation. Error bars indicate standard deviation. 


\subsection{Thermal Properties}

The thermal properties of the two TPSs (T and T20) as measured using DSC are presented in Figure 4.9. Between 120 and $280^{\circ} \mathrm{C}$, three thermal events, namely, glass transition, $\mathrm{T}_{\mathrm{g}},\left(162.5^{\circ} \mathrm{C}\right)$, crystallites melting $\left(198.9^{\circ} \mathrm{C}\right)$, and onset of thermal degradation (which took place concurrently as the sample melted), $\mathrm{T}_{\text {od }},\left(223.7^{\circ} \mathrm{C}\right)$ were detectable for sample $\mathrm{T}$ (Figure $\left.4.9 \mathrm{a}\right)$ whereas only $\mathrm{T}_{\text {od }}$ $\left(192.6^{\circ} \mathrm{C}\right.$ ) was detectable for sample T20 (Figure 4.9b). Since the two TPSs (T and T20) differ only in their degree of gelatinization, the two different events could be attributed to the glass transition and crystallites melting of the ungelatinized pea starch granules in sample $T$. The lower $T_{\text {od }}$ for sample T20 implied lower degree of thermal stability apparently due to its higher moisture content.

The thermal properties of TPS reinforced with PCL are presented in Table 4.1. The fact that TPS and PCL retained their respective thermal properties in the composites implied that they were thermodynamically immiscible (Shin et al. 2004). The melting point of PCL increased slightly as its content increased at both moisture levels. Similar results have been reported by other researchers (Matzinos et al. 2002; Wu 2002). However, the glass transition for pure PCL $\left(-62.6^{\circ} \mathrm{C}\right)$ was effectively suppressed for all the TPS/PCL composites. This might be attributable to the equipment's low sensitivity in that range of temperature. Likewise, the thermal properties of plasticized pea starch reinforced with PCL and flax fiber (Table 4.1) suggest thermodynamic immiscibility of the TPS, PCL, and fiber. PCL characteristic glass transition 
temperature $\left(\sim 60^{\circ} \mathrm{C}\right)$ became detectable with fiber reinforcement, increasing with increase in PCL content.

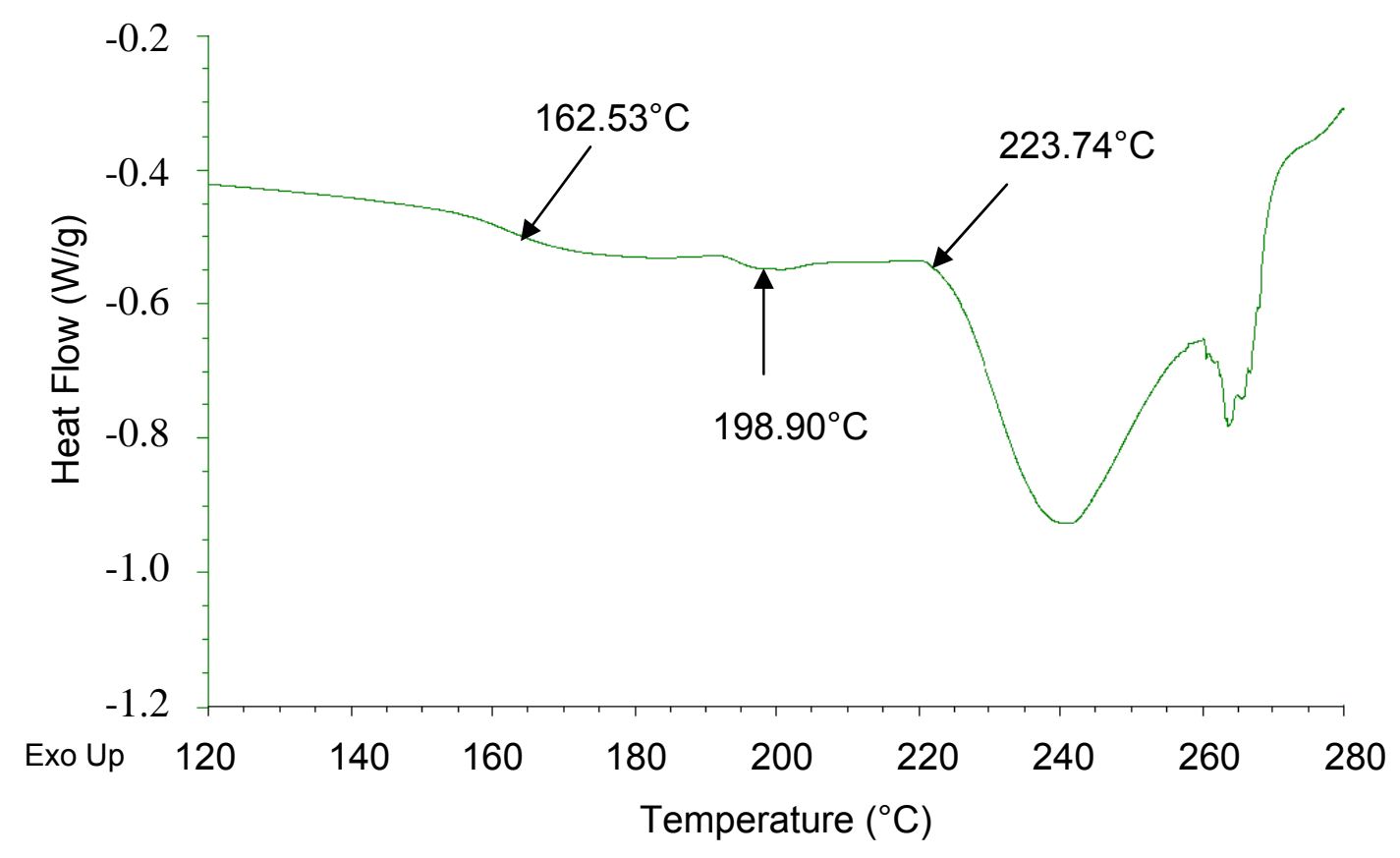

(a)

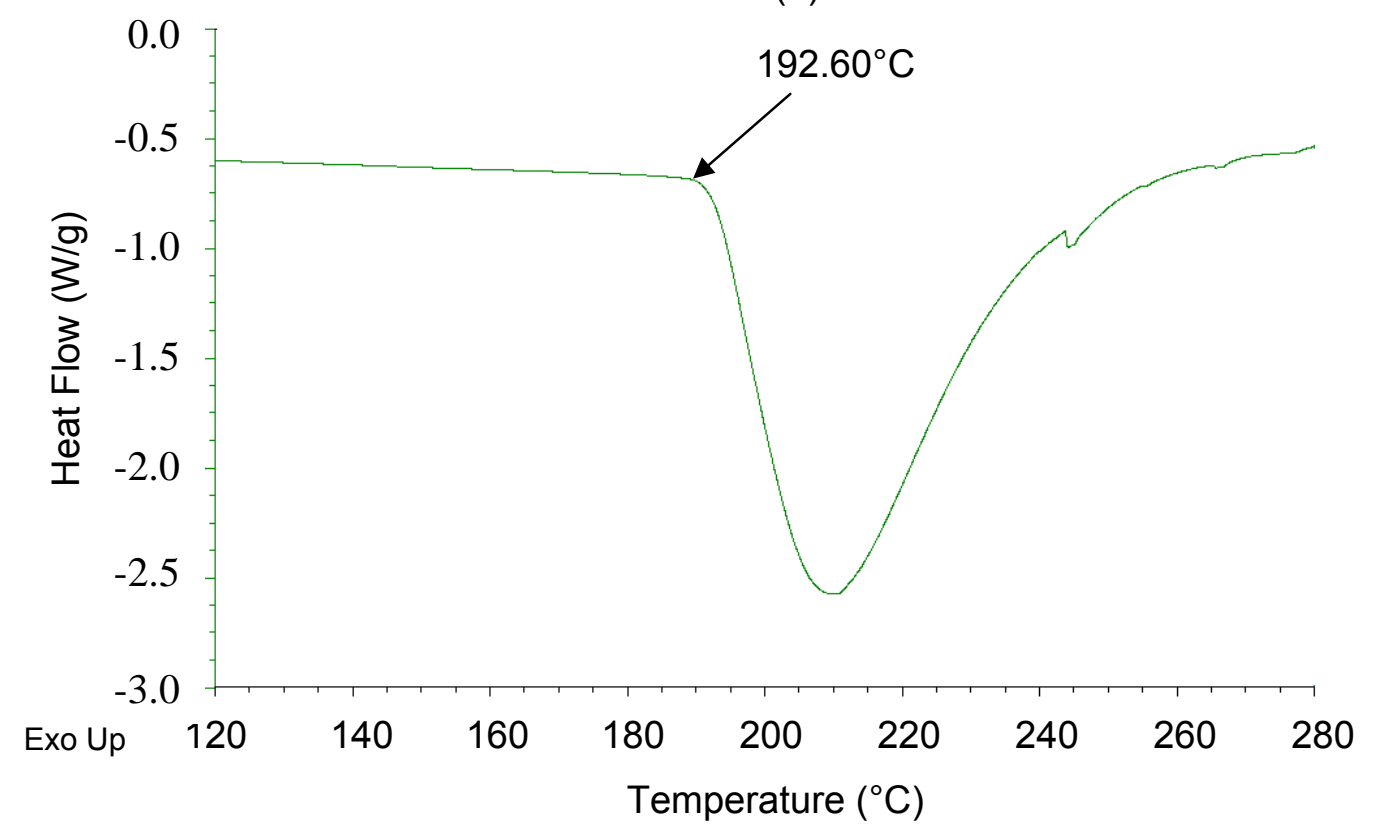

(b)

Figure 4.9 Differential scanning calorimetry thermograms of glycerol-plasticized pea starch prepared at processing moisture contents of (a) $9.3 \%$ and (b) $20 \%$. 
Table 4.1 Thermal properties of plasticized pea starch/polycaprolactone and plasticized pea starch/polycaprolactone/flax fiber composites.

\begin{tabular}{ccccc}
\hline $\begin{array}{c}\text { Sample } \\
\text { Code }\end{array}$ & $\begin{array}{c}\mathbf{T}_{\mathbf{m}}{ }^{1} \text { due to } \\
\mathbf{P C L}\left({ }^{\circ} \mathbf{C}\right)\end{array}$ & $\begin{array}{c}\mathbf{T}_{\mathbf{g}}{ }^{2} \mathbf{d u e} \text { to } \\
\mathbf{P C L}\left({ }^{\circ} \mathbf{C}\right)\end{array}$ & $\begin{array}{c}\mathbf{T}_{\text {od }}{ }^{3} \mathbf{d u e} \text { to } \\
\text { starch }\left({ }^{\circ} \mathbf{C}\right)\end{array}$ & $\begin{array}{c}\mathbf{T}_{\mathbf{g}} \text { due to } \\
\text { starch }\left({ }^{\circ} \mathbf{C}\right)\end{array}$ \\
\hline 1P9T & 56.3 & Not detected & 194.4 & 151.5 \\
2P8T & 56.9 & Not detected & 190.9 & 146.7 \\
3P7T & 56.6 & Not detected & 196.0 & 150.1 \\
4P6T & 57.9 & Not detected & 198.1 & 158.0 \\
1P9T20 & 56.0 & Not detected & 207.8 & Not detected \\
2P8T20 & 56.4 & Not detected & 211.4 & Not detected \\
3P7T20 & 57.1 & Not detected & 204.8 & Not detected \\
4P6T20 & 58.4 & Not detected & 178.8 & Not detected \\
5F20P & 56.2 & Not detected & 216.5 & Not detected \\
10F20P & 55.7 & -61.4 & 214.9 & Not detected \\
15F20P & 55.6 & -63.1 & 201.7 & Not detected \\
5F40P & 56.1 & -63.0 & 192.6 & Not detected \\
10F40P & 56.8 & -63.0 & 199.9 & Not detected \\
15F40P & 56.9 & -62.8 & 214.1 & Not detected \\
\hline 15elting point & & & & \\
2 Glass transition temperature & & &
\end{tabular}




\section{SUMMARY AND CONCLUSIONS}

In this study, efforts were geared toward overcoming the two major drawbacks of thermoplastic starch, namely, weak mechanical properties and high moisture affinity. For this purpose, pea starch was plasticized with glycerol in ratio of $7: 3$ (dry weight) and then reinforced with $\mathrm{PCL}(10,20,30$, and $40 \%$ wt) and flax

fiber $(5,10$, and $15 \% \mathrm{wt})$ both individually and collectively. Two processing moisture levels of 9.3 and $20 \%$ were considered in order to determine the effects of processing moisture content on the physical properties of plasticized pea starch. Sample preparation involved compounding the materials in the solid phase followed by compression molding. The compression molding parameters of $140^{\circ} \mathrm{C}, 45 \mathrm{~min}$, and $25000 \mathrm{~kg}$ were arrived at after some experimental trials while giving adequate consideration to the results of preliminary experiments on the thermal properties of pea starch, PCL, and flax fiber, in order to avoid thermal decomposition of these materials during compression molding. The prepared samples were then characterized using SEM, tensile test, moisture absorption, and DSC techniques.

The scanning electron micrograms of the tensile fracture surfaces revealed that the TPS prepared at $20 \%$ moisture content was able to form a rather continuous phase because complete gelatinization was attained, while at 9.3\% moisture, intact and partly gelatinized starch granules were evident. In other words, the gelatinization and, in turn, the morphology of plasticized pea starch were significantly affected by the processing moisture content. This morphological difference translated into higher tensile strength, yield strength, 
Young's modulus, and elongation at break at $20 \%$ processing moisture content. However, the moisture affinity of the plasticized pea starch was higher at $20 \%$ processing moisture content while the thermal stability was higher at $9.3 \%$ processing moisture content. Although the effects of PCL reinforcement on the tensile properties of the plasticized pea starch varied depending on the processing moisture content, the effect on the moisture absorption was the same. Due to its hydrophobicity, the addition of PCL successfully reduced the moisture absorption of plasticized pea starch.

Similarly, the flax fiber reinforcement increased the tensile strength, yield strength, and Young's modulus while decreasing the elongation at break of the plasticized pea starch. Fiber incorporation desirably decreased the moisture absorption of the plasticized pea starch. Furthermore, higher improvements in the tensile strength, yield strength, and Young's modulus were recorded when reinforcing plasticized pea starch with both $P C L$ and flax fiber than with fiber alone. In these ternary composites, decline in moisture absorption was observed and this was attributed to the hydrophobic PCL content. In addition, the prepared composites were thermodynamically immiscible as each composite component retained its individual thermal characteristics.

Although the tensile strength of plasticized pea starch improved when reinforced with $\mathrm{PCL}$, this increase could largely be ascribed to the ability of $\mathrm{PCL}$ to form a rather continuous reinforcing network through the TPS matrix as against the presence of good TPS-PCL interfacial interaction. Similarly, no interfacial interaction was noticed between $\mathrm{PCL}$ and flax fiber, thus, implying 
PCL and flax fiber acted as independent reinforcing agents. Due to their chemical similarity (both having -OH groups), some degree of TPS-fiber interfacial bonding was observed but evidence of fiber pull-out suggested the bonding was weak. This poor interfacial interaction between the PCL on the one hand and the polyhydroxy TPS and fiber on the other hand, hampered effective dispersion of the reinforcing components in the TPS matrix. Unfortunately, achieving composites with good mechanical performance demands that the reinforcing materials have strong interfacial bonding with the matrix and also be effectively dispersed in the matrix. In other words, it is logical to assert that the reinforcing potentials of PCL and flax fiber were not optimally harnessed.

Therefore, the following conclusions can be drawn from this study:

- At $20 \%$ processing moisture content, there was complete starch gelatinization, hence the formation of a rather continuous single-phase (homogeneous) TPS matrix. Instances of ungelatinized and partly gelatinized starch granules were noticed at $9.3 \%$.

- Plasticized pea starch and its composites produced at $20 \%$ processing moisture content had higher tensile strength, yield strength, Young's modulus, and elongation at break than those at $9.3 \%$ processing moisture content.

- Higher moisture affinity was observed for samples prepared at $20 \%$ than at $9.3 \%$ processing moisture content.

- Independently and jointly incorporating PCL and flax fiber generally improved the tensile properties while lowering the moisture absorption 
properties of the prepared samples. PCL performed better in reducing moisture absorption of plasticized pea starch than flax fiber.

- For the plasticized pea starch/PCL/flax fiber composites, maximum tensile strength of $11.55 \mathrm{MPa}$ was observed at $10 \%$ flax fiber and $40 \%$ PCL reinforcement.

- Both flax fiber and PCL acted as independent reinforcements for the plasticized pea starch as no interfacial bonding between the two was observed.

- Plasticized pea starch processed at 9.3\% moisture exhibited higher thermal stability than that at $20 \%$.

- The individual components of the prepared composites displayed their characteristic thermal properties, thus, suggesting thermodynamic immiscibility. 


\section{RECOMMENDATIONS}

The major limitation observed in this study was the poor compatibility between TPS and fiber on the one hand and PCL on the other hand. This affected the dispersion of the reinforcing material in the TPS matrix. Since good interfacial bonding and effective dispersion of reinforcing material are crucial to the mechanical performance of any composite, it could be asserted that the reinforcing potentials of $\mathrm{PCL}$ and flax fiber were not optimally realized. To this end, some compatibilizers such as maleic anhydride (MAH) could be incorporated in the formulation to enhance the bonding between PCL and TPS for better mechanical performance. Compatibilizers could also enhance PCLfiber interfacial bonding, thus, exploiting the synergistic reinforcing potentials of both the PCL and flax fiber. In addition, the use of surface-treated flax fiber may be investigated on both the strength and moisture absorption fronts. Related studies have reported improved fiber-matrix interfacial bonding and moisture resistance using chemically treated fibers.

Finally, further work should be conducted on facilitating pea starch gelatinization during compression molding in order to reduce processing time. This could mean using pre-gelatinized pea starch as the starting material in lieu of native pea starch. Extrusion molding technique could also be used for sample preparation. Extrusion produces relatively high degree of starch gelatinization due to the presence of shear stresses and could also enhance better fiber and PCL dispersion in the TPS matrix. 


\section{REFERENCES}

AAFC (Agriculture and Agri-Food Canada). 2004. Non-food/Non-feed Uses for Agricultural Products - Phase 2 and 3 Summary. http://www.agr.gc.ca/misb/spec/bio/pdf/non2_e.pdf (2007/02/06).

Abdul Khalil, H.P.S., W.C. Chow, H.D. Rozman, H. Ismail, M.N. Ahmad and R.N. Kumar. 2001. The effect of anhydride modification of sago starch on the tensile and water absorption properties of sago-filled linear lowdensity polyethylene (LLDPE). Polymer-Plastic Technology and Engineering 40(3): 249-263.

Aberle, T., W. Burchard, W. Vorwerg and S. Radosta. 1994. Conformation contributions of amylose and amylopectin to the structural properties of starches from various sources. Starch/Stärke 46: 329-335.

Alberola, N.D., Y. Germain and P. Mele. 1997. Binary and ternary particulate composites. II. Tensile behavior over a wide range of strain rates. Journal of Applied Polymer Science 63(8): 1041-1046.

Albertsson, A-C and S. Karlsson. 1995. Degradable polymers of the future. Acta Polymer 46: 114-123.

Angles, M.N. and A. Dufresne. 2001. Plasticized/tunicin whiskers nanocomposites materials 2: mechanical behaviour. Macromolecule 34(9): 2921-2931.

Anjum, F.M. and C.E. Walker. 1991. Review of the significance of starch and protein to wheat hardness. Journal of the Science of Food and Agriculture 56: 1-13. 
Anson, M.L. and M. Pader. 1957. Extraction of soy protein. US Patent 2785 155.

Araki, E., H. Miura and S. Sawada. 2000. Differential effects of the null alleles at the three $W x$ loci 13 on the starch-pasting properties of wheat. Theoretical and Applied Genetics 100: 1113-1120.M.

ASTM 2003. ASTM D 3039 - Standard Test Method for Tensile Properties of Polymer Matrix Composite Materials. In Annual Book of ASTM Standards, Vol. 15.03, 98-110. West Conshohocken, PA: American Society for Testing and Materials.

Atwell, W.A., L.F. Hood, D.R. Lineback, E. Varriano-Marston and H.F. Zobel. 1988. The terminology and methodology associated with basic starch phenomena. Cereal Foods World 33: 306-311.

Avella, M., M.E. Errico, P. Laurienzo, E. Martuscelli, M. Raimo and R. Rimedio. 2000. Preparation and characterization of compatibilized polycaprolactone/starch composites. Polymer 41: 3875.

Ball, S.G. and M.K. Morell. 2003. From bacterial glycogen to starch: understanding the biogenesis of the plant starch granule. Annual Review of Plant Biology 54: 207-233.

Banks, W. and C.T. Greenwood. 1969. Physicochemical studies on starches. XXXII. The incomplete $\beta$-amylolysis of amylose: A discussion of its cause and implications. Starch/Stärke 19: 197.

Banks, W. and C.T. Greenwood. 1975. The structure and biosynthesis of the starch granule. In Starch and its components, eds. W. Banks and C.T. 
Greenwood, 242-273. Edinburgh, Scotland: Edinburgh University Press.

Banks, W., C.T. Greenwood and D.D. Muir. 1973. The structure of starch. In: Molecular structure and function of food carbohydrate, eds. G.G. Birch and L.F. Green, 177. Toronto, ON: John Wiley and Sons.

Bastioli, C. 2001. Global status of the production of biobased packaging materials. Starch/Stärke 53: 351-355.

BBC. 2008. BBC News special reports. http://news.bbc.co.uk/2/hi/in_depth/7268960.stm (2008/03/15).

Benderly, D., A. Siegmann and M. Narkis. 1995. Preferential distribution of glass particles in reinforced polypropylene/polyamide immiscible blends. Journal of Materials Science Letters 14: 132-134.

Biliaderis, C.G. and J. Zawistowski. 1990. Viscoelastic behavior of aging starch gels: effect of concentration, temperature, and starch hydrolysates on network properties. Cereal Chemistry 67: 240-246.

Biliaderis, C.G., D.R. Grant and J.R. Vose. 1979. Molecular weight distributions of legume starches by gel chromatography. Cereal Chemistry 56: 475480.

Biliaderis, C.G., T.J. Maurice and J.R. Vose. 1980. Starch gelatinization phenomena studied by differential scanning calorimetry. Journal of Food Science 45(6): 1669-1674, 1680. 
Biliaderis, C.G., D.R. Grant and J.R. Vose. 1981. Structural characterization of legume starches. I. Studies on amylose, amylopectin and beta-limit dextrins. Cereal Chemistry 58: 496-502.

Biliaderis, C.G., A. Lazaridou and I. Arvanitoyannis. 1999. Glass transition and physical properties of polyol-plasticised pullulan-starch blends at low moisture. Carbohydrate Polymers 40: 29-47.

Bird, A.R., I.L. Brown and D.L. Topping. 2000. Starches, resistant starches, the gut microflora and human health. Current Issues of Intestinal Microbiology 1: 25-37.

Bledzki, A.K. and J. Gassan. 1999. Composites reinforced with cellulose based fibres. Progress in Polymer Science 24: 221-174.

Brown, A. 1984. Epicoccum nigrum, a primary saprophyte involved in the retting of flax. Transactions of the British Mycological Society 83:29-35.

Bürger, H., A. koine, R. Maron and K-P. Mieck. 1995. Use of natural fibers and environmental aspects. International Polymer Science and Technology 25(8): 22-34.

Burt, D.J. and P.L. Russell. 1983. Gelatinization of low water content wheat starch-water mixtures. Starch/Stärke 10: 354-360.

Carvalho, A.J.F., M.D. Zambon, A.A.S. Curvelo and A. Gandini. 2003. Size exclusion chromatography characterization of thermoplastic starch composites. 1. Influence of plasticizer and fibre content. Polymer Degradation and Stability 79: 133-138. 
Chandra, C. and R. Rustgi. 1998. Biodegradable polymers. Progress in Polymer Science 23(7): 1273-1335.

Chavan, J.K., S.S. Kadam and D.K. Salunkhe. 1986. Biotechnology and technology of chickpea (Cicer arietinum L.) seeds. CRC Critical Reviews in Food Science and Nutrition 25(2): 107-158.

Chen, Y., Y. Ishikawa, Z. Zhang and T. Maekawa. 2003. Mechanical properties of the extruded acetylated starch plastic filled cellulose acetate and evaluation of its biodegrade properties. ASABE Meeting Paper No. 036021. St. Joseph, Mich: ASABE.

Chrissafis, K., G. Antoniadis, K.M. Paraskevopoulo, A. Vassiliou and D.N. Bikiaris. 2007. Comparative study of the effect of different nanoparticles on the mechanical properties and thermal degradation mechanism of in situ prepared poly(e-caprolactone) nanocomposites. Composites Science and Technology 67: 2165-2174.

Colonna, P. and C. Mercier. 1984. Macromolecular structure of wrinkled-and smooth- pea starch components. Carbohydrate Research 126: 233-247.

Colonna, P.C., D. Gallant and C. Mercier. 1980. Pisum sativum and Vicia faba carbohydrates: studies of fractions obtained after dry and wet protein extraction processes. Journal of Food Science 45: 1629-163.

Colonna, P.C., A. Buleon and C. Mercier. 1981b. Pisum sativum and Vicia faba carbohydrates: structural studies of starches. Journal of Food Science 46: 88. 
Curá, J.A. and C.R. Krisman. 1990. Cereal grains: A study of their $\alpha-1,4 \alpha-1,6$ glucopolysaccharide composition. Starch/Stärke 42: 171-175.

Curá, J.A., P.E. Jansson and C.R. Krisman. 1995. Amylose is not strictly linear. Starch/Stärke 47(6): 207-209.

Cyras, V.P., C. Vallo, J.M. Kenny and A. Vazquez. 2003. Effect of chemical treatment on the mechanical properties of starch-based blends reinforced with sisal fibre. Journal of Composite Materials 38(16): 13871399.

Czuchajowska, Z., D. Sievert and Y. Pomeranz. 1991. Enzyme-resistant starch. IV. Effects of complexing lipids. Cereal Chemistry 68: 537-542.

Datta, R., S. Tsai, P. Bonsignore, S. Moon and J.R. Frank. 1995. Technological and economic potential of poly (lactic acid) and lactic acid derivates. FEMS Microbiology. Review 16: 221-231.

De Carvalho, A.J.F., A.A.S. Curvelo and J.A.M. Agnelli. 2001. A first insight on composites of thermoplastic starch and kaolin. Carbohydrate Polymers 45(2): 189-194.

De Carvalho, A.J.F, A.A.S. Curvelo and J.A.M. Agnelli. 2002. Wood pulp reinforced thermoplastic starch composites. International Journal of Polymeric Materials 51: 647-660.

Donovan, J. 1979. Phase transitions of the starch-water system. Bio-polymers 18: $263-275$. 
Dubnikova, I.L., D.K. Muravin and V.G. Oshmyan. 1997. Debonding and fracture of particulate-filled isotactic polypropylene. Polymer Engineering and Science 37(8): 1301-1313.

Dufresne, A. and M.R. Vignon. 1998. Improvement of starch film performances using cellulose microfibrils. Macromolecules 31(8): 2693-2696.

Edwards, J.J., H. Green and T.A. Rees. 1988. Activity of branching enzymes as a cardinal feature of the Ra locus in Pisum sativum. Phytochemistry 27: $1615-1620$.

Eliasson, A-C. 1984. Effect of water content on the gelatinization of wheat starch. Starch 32: 270-272.

Eliasson, A.C. and K. Larsson. 1993. Physicochemical behavior of the components of wheat flour. In Cereals in Breadmaking, eds O.R. Fennama, M. kernel, G.W. Sanderson, S.R. Taunenbanum, P. Walstra, and J.R. Whitaker, 96-129. New York, NY: Marcel Dekker, Inc.

Ellis, P.R., P.M. Cochrane, F.B.M. Dale, C.M. Duffus, A. Lynn, I.M. Morrison, D.R.M. Prentice, S.J. Swanston and S.A. Tiller. 1998. Starch Production and Industrial Use. Journal of the Science of Food and Agriculture 77: 289-311.

Elzein, T., M. Nasser-Eddine, C. Delaite, S. Bistac, and P. Dumas. 2004. FTIR study of polycaprolactone chain organization at interfaces. Journal of Colloid and Interface Science 273: 381-387. 
Emami, S., L.G. Tabil and R.T. Tyler. 2006. Isolation of starch and protein from chickpea flour using a hydrocyclone and isoelectric precipitation method. ASABE Meeting Paper No. 066090. St. Joseph, Mich: ASABE.

Endres, H-J. and A. Pries. 1995. Mechanische eigenschaften stärkegefüllter polymerverbunde. Starch/stärke 47: 384-393.

Evangelista, R.L., Z.L. Nikolov, W. Sung, J.L. Jane and R. Gelina. 1991. Effect of compounding and starch modification properties of starch-filled low density polyethylene. Industrial and Engineering Chemistry Research 30: 1841-1846.

Falk, H., R. Micura, M. Stanek and R. Wutka. 1996. Structural aspects of native and acid or enzyme degraded amylopectins - a ${ }^{13} \mathrm{C}$ NMR study. Starch/Stärke 48: 344-346.

Fanta, G.F., H.M. Muijs, K. Eskins, F.C. Felker and S.M. Erhan. 2002. Starchcontaining lubricant systems for oil field applications. US Patent 6461999.

Flemming, M., G. Ziegmann and S. Roth. 1995. Einführung, Faserverbundbauweisen: Fasern und Matrices, pp. 1-5 and 155-179, Berlin: Springer-Verlag.

Forssell, P.M., J.M. Mikkilä, G.K. Moates and R. Parker. 1997. Phase and glass transition behavior of concentrated barley starch-glycerol-water mixtures, a model for thermoplastic starch. Carbohydrate Polymer 34: 275-282. 
Frederick, T.W. and W. Norman 2004. Natural fibers plastics and composites. New York, NY: Kluwer Academic Publishers.

Fredriksson, H., J. Silverio, R. Andersson, A.C. Eliasson and P. Aman. 1998. The influence of amylose and amylopectin characteristics on gelatinization and retrogradation properties of different starches. Carbohydrate Polymer 35: 119-134.

Fukuoka, M., K. Ohta and H. Watanabe. 2002. Determination of the extent of starch gelatinization in a limited water system by DSC. Journal of Food Engineering 53: 39-42.

Gallant, D.J., B. Bouchet, A. Buleon and S. Perez . 1992. Physical characteristics of starch granules and susceptibility to enzymatic degradation. European Journal of Clinical Nutrition 46: S3-S16.

Galliard, T. and P. Bowler. 1987. Morphology and composition of starch. In Starch Properties and Potential, Critical Reports on Applied Chemistry, ed T. Galliard, 55-78. Chichester, UK: John Wiley and Sons.

Gassan, J. and A.K. Bledzki. 2001 Thermal Degradation of Flax and Jute fibers. Journal of Applied Polymer Science 82: 1417-1422.

Gernat, C., S. Radosta, H. Anger and G. Damaschun. 1993. Crystalline parts of three different conformations detected in native and enzymatically degraded starches. Starch/Stärke 45: 309-314.

Glickman, M. 1969. Gum Technology in the Food Industry. New York, NY: Academic Press. 
Gouanve, F., M. Meyer, J. Grenet, S. Marais, F. Poncin-Epaillard and J.-M.

Saiter. 2006. Unsaturated polyester resin (UPR) reinforced with flax fibers, untreated and cold He plasma-treated : thermal, mechanical, and DMA studies. Composite Interfaces $13: 355-364$.

Gough, B. M. and J. N. Pybus. 1971. Effect on the gelatinization temperature of wheat starch granules of prolonged treatment with water at $55{ }^{\circ} \mathrm{C}$. Starch/Stärke 23: 210-212.

Govindasamy, S., O.H. Campanella, and C.G. Oates. 1996. High moisture twinscrew extrusion of sago starch: 1. Influence on granule morphology and structure. Carbohydrate Polymers 30(4): 275-286.

Greenwood, C.T., and J. Thompson. 1962. Physicochemical studies on starches. XXIV. The fraction and characterization of starches of various plant origins. Journal of the Chemical Society, January-March: 222-229.

Griffin, G.J.L. 1974. Biodegradable fillers in thermoplastics. Advances in Chemistry Series 134: 159-170.

Gross, R.A. and B. Kalra. 2002. Biodegradable polymers for the environment. Science 297: 803-807.

Gueguen, J. 1983. Legume seed protein extraction, processing, and end product characteristics. Qualitas Plantarum Plant Food and Human Nutrition 32: 267-303.

Herrera Franco, P. and A. Valadez-González. 2005. Fiber-Matrix adhesion in natural fiber composites. In Natural Fiber, Biopolymers, and 
Biocomposites, eds. A.K. Mohanty, M. Misra, and L.T. Drzal, 369-410.

Boca Raton, FL: CRC Press.

Hizukuri, S. 1986. Polymodal distribution of the chain lengths of amylopectin and its significance. Carbohydratre Research 147: 342-347.

Hizukuri, S., T. Kaneko and Y. Takeda. 1983. Measurement of the chain length of amylopectin and its relevance to the origin of crystalline polymorphism of starch granules. Biochimica et Biophysica Acta 760: 188-191.

Hizukuri, S., Y. Takeda, N. Maruta and B.O. Juliano. 1989. Molecular structures of rice starch. Carbohydrate Research 189: 227-235.

Hong, S.W., K.H. Kim, J. Huh, C-H Ahn and W.H. Jo. 2005. Drug release

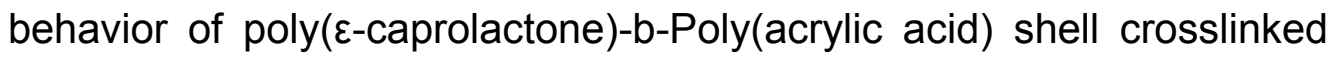
micelles below the critical micelle concentration. Macromolecular Research 13(5): 397-402.

Hoover, R. and F.W. Sosulski. 1991. Composition, structure, functionality, and chemical modification of legume starches: a review. Canadian Journal of Physiology and Pharmacology 69: 79-92.

Hoseney, C. 1994. Starch. In Principles of Cereal Science and Technology, $2^{\text {nd }}$ edition, ed. R.C. Hoseney, 29-52. St Paul, MN: American Association of Cereal Chemists, Inc.

Hulleman, S.H.D., F.H.P. Janssen and H. Feil. 1998. The role of water during plasticization of native starches. Polymer 39(10): 2043-2048. 
Huneault, M.A. and H. Li. 2007. Morphology and properties of compatibilized polylactide/thermoplastic starch blends. Polymer 48: 270-280.

Hung, S.J., and P.G. Edelman. 1995. An overview of biodegradable polymers and biodegradation of polymers. In Degradable polymers: Principles and application, eds. G. Scott and D. Gilead, 8-24. London: Chapman \& Hall.

Hwan-Man, P., C-Y.P. Won-Ki Lee and C-S.H. Won-Jei Cho. 2003. Environmentally friendly polymer hybrids part I: mechanical, thermal and barrier properties of thermoplastic starch/clay nanocomposites. Journal of Materials Science 38(5): 909-915.

Ikeo, Y., K. Aoki, H. Kishi, S. Matsuda and A. Murakami. 2006. Nano clay reinforced biodegradable plastics of PCL/starch blends. Polymers for Advanced Technologies 17: 940-944.

Idicula, M. and S. Thomas. 2004. Effects of fiber loading and aspect ratio on the mechanical properties of hybrid fiber. 5th Global Wood and Natural Fibre Composites Symposium. Kessel: Germany.

Jane, J. 1995. Starch properties, modifications and applications. Pure and Applied Chemistry A32(4): 751-757.

Jenkins P. 1994. X-ray and neutron scattering studies on starch granule structure. Ph.D. Dissertation, University of Cambridge.

Karmaker, A. C. and J. A. Youngquist. Injection moulding of polypropylene reinforced with short jute fibers. Journal of Applied Polymer Science 62: $1147-1151$ 
Kawamura, S. 1969. Studies on the starches of edible legume seeds. Journal of the Japanese Society of Starch Science 17:19-40.

Kazuo, O., Y. Isao, Y. Toshiaki, O. Shin, R. Seichi, N. Yuuko and S. Choichiro. 1998. Studies on the retrogradation and structural properties of waxy corn starch. Bulletin of the Chemical Society of Japan 71(5): 10951100.

Kennedy, J.F., A.J. Griffiths and D.P. Atkins. 1983. The application of hydrocolloids: recent development, future trends. In Gums and Stabilizers for the Food Industry 2: Application of Hydrocolloids, 417455. New York, NY: Pergamon Press.

Keetles, C.J.A.M., T. Van-Vliet and P. Walstra. 1996. Gelation and retrogradation of concentrated starch systems: 1. Gelation. Food Hydrocolloid 10: 343-353.

Kim, M. and S-J. Lee. 2002. Characteristics of crosslinked potato starch and starch-filled linear low-density polyethylene films. Carbohydrate Polymers 50: 331-337.

Kirby, A.R., S.A. Clark, R. Parker and A.C. Smith. 1993. The deformation and failure behaviour of wheat starch plasticized with water and polyols. Journal of Materials Science 28(21): 5937-5942.

Kobayashi, S., S.J. Schwartz and D.R. Lineback. 1986. Comparison of the structures of amylopectins from different wheat varieties. Cereal Chemistry 63: 71-74. 
Kolarik, J. and J. Jancar. 1992. Ternary composites of plypropylene/elastomer/calcium carbonate: effect of functionalized components on phase structure and mechanical. Polymer 33: 49614967.

Kondo T. 1994. Hydrogen bonds in regioselectively substituted cellulose derivatives. Journal of Polymer Science B: Polymer physics 32: 12291236.

Lai, C.C. and E. Varriano-Marston. 1979. Studies on the characteristics of black bean starch. Journal of Food Science 44: 528-530, 544.

Laist, D.W. 1997. Impacts of marine debris: entanglement of marine life in marine debris including a comprehensive list of species with entanglement and ingestion records. In Marine Debris: Sources, Impacts and Solutions. Eds J.M. Coe and D.B. Rogers, 99-139. Springer-Verlag, New York, NY.

Lawrence, S.T., P.S. Walia, F. Felker and J.L. Willett. 2004. Starch-filled ternary polymer composite II: room temperature tensile properties. Journal of Polymer Engineering and Science 44: 1839-1847.

Lelievre, J., J.A. Lewis and K. Marsden. 1986. The size and shape of amylopectin. A study using analytical ultracentrifugation. Carbohydrate Research 153: 195-203.

Lii, C.Y. and D.R. Lineback. 1977. Characterization and comparison of cereal starches. Cereal Chemistry 54: 138-149. 
Lim, S., J. Jane, S. Rajagopalan and P. Seib. 1992. Effect of starch granule size on physical properties of starch-filled polyethylene film. Biotechnology Progress 8: 51-57.

Lim, M.H., H. Wu and D.S. Reid. 2000. The effect of starch gelatinization and solute concentrations on T-g ' of starch model system. Journal of the Science of Food and Agriculture 80(12): 1757-1762.

Lineback, D.R. and V.F. Rasper. 1988. Wheat carbohydrate. In Wheat Chemistry and Technology, ed. Y. Pomeranz, 277-372. St Paul, MN: American Association of Cereal Chemists.

Lourdin, D., L. Coignard, H. Bizot and P. Colonna. 1997. Influence of equilibrium relative humidity and plasticizer concentration on the water content and glass transition of starch materials. Polymer 38 (21): 54015406.

Lowy, G.D.A., J.G. Sergeant and J.D. Schofield. 1981. Wheat starch granule protein: The isolation and characterization of a salt-extractable protein from starch granules. Journal for the Science of Food and Agriculture 32: $371-377$.

Ma, X.F. and J.G. Yu. 2004a. Studies on the properties of formamide plasticized-thermoplastic starch. Acta Polymerica Sinica 2: 240-245.

Ma, X. and J. Yu. 2004b. Formamide as the plasticizer for thermoplastic starch. Journal of Applied Polymer Science 93: 1769-1773.

Ma, X.F., J.G. Yu and N. Wang. 2007. Fly ash-reinforced thermoplastic starch composites. Carbohydrate Polymers 67: 32-39. 
Ma, X., P.R. Chang and J. Yu. 2008a. Properties of biodegradable thermoplastic pea starch/carboxymethyl cellulose and pea starch/microcrystalline cellulose composites. Carbohydrate Polymers 72(3): 369-375.

Ma, X., P.R. Chang, J. Yu and M. Stumborg. 2009. Properties of biodegradable citric acid-modified granular starch/thermoplastic pea starch composites. Carbohydrate Polymers 75: 1-8.

Madhusudhan, B. and R.N. Tharanathan. 1996. Enzyme debranching studies on green gram ( $P$. aureus) starch fractions. Carbohydrate Polymers 29: $41-44$.

Malvern 2008. Laser Diffraction Particle Sizing. http://www.malvern.co.uk/LabEng/technology/laser_diffraction/particle_ sizing.htm (2008/07/10).

Manfredi, L.B., E.S. Rodriguez, M. Wladyka-Przybylak and A. Vázquez. 2006. Thermal degradation and fire resistance of unsaturated polyester, modified acrylic resins and their composites with natural fibers. Polymer Degradation and Stability 91: 225-261.

Martin, O. and L. Avérous. 2001. Poly(lactic acid): plasticization and properties of biodegradable multiphase systems. Polymer 42: 6209-6219.

Mathew, A.P. and A. Dufresne. 2002. Plasticised waxy maize starch: effect of polyols and relative humidity on material properties. Biomacromolecules 3 (5): 1101-1108. 
Matters, G.L. and C.D. Boyer. 1982. Soluble starch synthases and starch branching enzymes from cotyledons of smooth- and wrinkled-seeded lines of Pisum sativum L. Biochemical Genetics 20: 833-843.

Matzinos, P., V. Tserki, A. Kontoyiannis and C. Panayiotou. 2002. Processing and characterization of starch/polycaprolactone products. Polymer Degradation and Stability 77: 17-24.

McGrance, S.J., H.J. Cornell and C.J. Rix. 1998. A simple and rapid colorimetric method for the determination of amylose in starch products. Starch/Stärke 50: 158-163.

Medcalf, D.G. and K.A. Gilles. 1965. Wheat starches I. Comparison of physicochemical properties. Cereal Chemistry 42: 558-567.

Melvin, M.A. 1979. The effect of extractable lipid on the viscosity characteristics of corn and wheat starches. Journal for the Science of Food and Agriculture 30: 731-738.

Mikus, F.F., R.M. Hixon and R.E. Rundle. 1946. The complexes of fatty acids with amylose. Journal of the American Chemical Society 68: 1115 1946.

Morrison, W.R. 1983. Acyl lipids in cereal. In Lipids in Cereal Technology, ed. P.J. Barnes, 11-32. Toronto, ON: Academic Press.

Morton, W.E. and J.W.S. Hearle. 1975. Physical Properties of Textile Fibers. 2nd edition. New York, NY: John Wiley and Sons, Inc.

Murali Mohan Rao, K., A.V. Ratna Prasad, M.N.V. Ranga Babu, K. Mohan Rao and A.V.S.S.K.S. Gupta. 2007. Tensile properties of elephant grass fiber 
reinforced polyester composites. Journal of Materials Science 42(9):

3266-3272.

Nadella, H.P., J.E. Spruiell and J.L. White. 1978. Journal of Applied Polymer Science 18: 2539.

Naivikul, O. and B.L. D’Appolonia. 1979. Carbohydrates of legume flours compared with wheat flour. II. Starch. Cereal Chemistry 56:24-28.

Nashed, G., R.P.G. Rutgers and P.A. Sopade. 2003. The plasticisation effect of glycerol and water on the gelatinisation of wheat starch. Starch/Stärke 55(3-4): 131-137.

Nawang, R., I.D. Danjaji, U.S. Ishiaku, H. Ismail and Z.A. Mohd Ishak. Mechanical properties of sago-filled linear low density polyethylene (LLDPE) composites. Polymer Testing 20: 167-172.

Nielsen, L.E. and R.F. Landel. 1994. Mechanical Properties of Polymers and Composite, 2nd edition. New York, NY: Marcel Dekker Inc.

Noda, T., T. Tohnooka, S. Taya and I. Suda. 2001. Relationship between physicochemical properties of starches and white salted noodle quality in Japanese wheat flours. Cereal Chemistry 78: 395-399.

Nolan-ITU, Department of the Environment and Heritage, Australian Government. 2002. Biodegradable plastics - developments and environmental impacts. Prepared in association with ExcelPlas Australia. http://www.environment.gov.au/settlements/publications/ waste/degradables/biodegradable/index.html (2007/07/15). 
Núñez, E. 2004. Crystallisation of star polyesters with poly ( $\varepsilon-$ caprolactone) arms: approaching the problem of early stages in polymer crystallisation. http://urn.kb.se/resolve?urn=urn: nbn:se:kth:diva-327 (2008-11-16).

Olkku, J. and C. Rha. 1978. Gelatinization of starch and wheat flour starch - a review. Food Chemistry 3: 293.

Owusu-Ansah, Y.J. and S.M. McCurdy. 1991. Pea proteins: a review of chemistry, technology of production, and utilization. Food Reviews International 7(1): 103-134.

PA (Penford Ausralia Limited). About starch modification. http://www.penford.com.au/main.php?ID=11 (2006/11/05).

Patel, M. 2002. Review of life cycle assessments for bioplastics. Paper presented to the Congress on 'The Industrial Applications of BioPlastics 2002', Central Science Laboratory, York UK.

Paul, A., K. Joseph and S. Thomas. 1997. Composites Science and Technology 57(1): 67-79.

Perez, C.J., V.A. Alvarez, I. Mondragón and A. Vázquez. 2007. Mechanical properties of layered silicate/starch polycaprolactone blend nanocomposites. Polymer International 56(5): 686-693.

Perry, M. 2008. Australia to end plastic bags in supermarkets. Reuters. http://www.reuters.com/article/environmentNews/idUSSYD41366200801 $11(2008 / 03 / 15)$. 
Polo Fonseca, C., F. Cavalcante Jr., F.A. Amaral, C.A. Zani Souza and S. Neves. 2007. Thermal and conduction properties of a PCLbiodegradable gel polymer electrolyte with $\mathrm{LiClO} 4$, $\mathrm{LiF} 3 \mathrm{CSO} 3$, and LiBF4 salts. International Journal of Electrochemical Science 2: 52-63.

Praznik, W., A. Huber, S. Watzinger and H.F. Beck. 1994. Molecular characteristics of high amylase starches. Starch/Stärke 46: 88-94.

Preet, K. and D. Punia. 2000. Proximate composition, phytic acid, polyphenols and digestibility (in vitro) of four brown cowpea varieties. International Journal of Food Sciences and Nutrition 51 (3): 189-193.

Prinos, J., D. Bikiaris, S. Theologidis and C. Panayiotou. 1998. Preparation and characterization of LDPE/starch blends containing ethyleneflinyl acetate copolymer as compatibilizer. Polymer Engineering and Science 38(6): 954-964.

Puglia, D., A. Tomassucci and J.M. Kenny. 2003. Processing, properties and stability of biodegradable composites based on Mater-Bi and cellulose fibers. Polymers for Advanced Technologies 14: 749-756.

Randall, D. and S. Lee. 2002. The Polyurethanes Book. New York, NY: John Wiley and Sons.

Ratnayake, W.S., R. Hoover and T. Warkentin. 2002. Pea starch: composition, structure and properties - a review. Starch/Stärke 54: 217-234.

Ratner, B.D., A.S. Hoffman, F.J. Schoen and J.E. Lemons. 2004. Biomaterials Science: An Introduction to Materials in Medicine. 2nd edition, San Diego, CA: Academic Press. 
Reddy, N.R. and M.D. Pierson. 1984. Chemical, nutritional, and physiological aspects of dry bean carbohydrates - a review. Food Chemistry 13: 25-69. Reichert, R.D. and C.G. Youngs. 1978. Nature of the residual protein associated with starch fractions from air-classified field pea starches. Cereal Chemistry 55: 469-480.

Reis, R.L., A.M. Cunha, P.S. Allan and M.J. Bevis. 1997. Structure development and control of injection-molded hydroxylapatite-reinforced starch/EVOH composites. Advances in Polymer Technology 16(4): 263-277.

Rundle, R.E. 1947. The configuration of starch in the starch-iodine complex. 5. Fourier projections from X-Ray diagrams. Journal of the American Chemical Society 69: 1769-1772.

Rundle, R.E. and R.R. Baldwin. 1943. The configuration of starch and the starch-iodine complex, I. The dichroism of flow of starch-iodine solutions. Journal of the American Chemical Society 65: 554-558.

Rundle, R.E. and D. French. 1943a. The configuration of starch and the starchiodine complex. 2. Optical properties of crystalline starch fractions. Journal of the American Chemical Society 65: 558-561.

Rundle, R.E. and D. French. 1943b. The configuration of starch in the starchiodine complex. 3. X-Ray diffraction studies of the starch-iodine complex. Journal of the American Chemical Society 65: 1707-1710.

Salomonsson, A.C. and B. Sundberg. 1994. Amylose content and chain profile from normal, high amylose and waxy barleys. Starch/Stärke 46: 325328. 
Sarazin, P., G. Li, W.J. Orts and B.D. Favis. 2008. Binary and ternary blends of polylactide, polycaprolactone and thermoplastic starch. Polymer 49: 599-609.

Schlemmer, D., E. de Oliveira and M. Araújo Sales. 2007. Polystyrene/thermoplastic starch blends with different plasticizers. Journal of Thermal Analysis and Calorimetry 87(3): 635-638(4).

Schoch, T.J. and E.C. Maywald. 1968. Preparation and properties of various legume starches. Cereal Chemistry 45: 564-566.

Shimao, M. 2001. Biodegradation of plastics. Biotechnology 12: 242-247.

Shin, B-Y, S. Lee, Y-S. Shin, S. Balakrishnan and R. Narayan. 2004. Rheological, mechanical and biodegradation studies on blends of thermoplastic starch and polycaprolactone. Polymer Engineering and Science 44(8): 1429-1438.

Skrypetz, S. 2006. Dry peas: situation and outlook. AAFC Bi-weekly Bulletin 19 (2): 2081/E. Winnipeg, MB: Agriculture and Agri-Food Canada.

Slinkard, A.E., R.S. Bhatty, B.N. Drew and R.A.A. Morrall. 1990. Dry pea and lentil as new crops in Saskatchewan: a case study. In Advances in new crops, eds. J. Janick and J.E. Simon, 159-163. Portland, OR: Timber Press.

Spevacek, J., J. Brus, T. Divers and Y. Grohens. 2007. Solid-state NMR study of biodegradable starch/polycaprolactone blends. European Polymer Journal 43: 1866-1875. 
SSC (Singapore Science Centre). 2006. What is gelatinization and what has it got to do with starch? http://www.science.edu.sg/ssc/detailed.jsp?artid= $2985 \&$ type $=6 \&$ root $=3 \&$ parent $=3 \&$ cat $=30(2006 / 11 / 05)$.

Sterling, D. 1978. Textural qualities and molecular structure of starch products. Journal of Texture Studies 9: 225-255.

Stevens, D.J. and G.A.H. Elton. 1971. Thermal properties of the starch-water system. Starch/Stärke 23: 8-11.

St-Pierre, N., B.D. Favis, B.A. Ramsay, J.A. Ramsay, J.A. Ramsay and H. Verhoogt. 1997. Processing and characterization of thermoplastic starch/polyethylene blends. Polymer 38(3): 647-655.

Szymanowski, H., M. Kaczmarek, M. Gazicki-Lipman, L. Klimek and B. Wozniak. 2005. New biodegradable material based on RF plasma modified starch. Surface and Coating Technology 200: 539-543.

Takagi, S., M. Koyama, H. Kameyama and Y. Tokiwa. 1994. Development of poly( -caprolactone)/gelatinized starch blends and their enzymatic degradation. In Biodegradable Plastics and Polymers, eds Y. Doi and K. Fukuda, 437-442. Amsterdam, The Netherlands: Elsevier Science.

Tanaka, Y., H. Miura, M. Fukushima, M. Ito, Z. Nishio, S-J. Kim, N. Hashimoto, T. Noda, S. Takigawa, C. Matsuura-Endo and H. Yamauchi. 2006. Physical properties of yellow alkaline noodles from near-isogenic wheat lines with different Wx protein deficiency. Starch/Stärke 58: 186-195.

Teitelbaum, R.C., S.L. Ruby and T.J. Marks. 1978. On the structure of starchiodine. Journal of the American Chemical Society 100: 3215-3218. 
Teixeira, E.M., A.L. Da Ro'z, A.J.F. Carvalho and A.A.S. Curvelo. 2005. Preparation and characterization of thermoplastic starches from cassava starch, cassava root and cassava bagasse. Macromolecular Symposia 229: 266-275.

Teixeira, E.M., A.L. Da Róz, A.J.F. Carvalho and A.A.S. Curvelo. 2007. the effect of glycerol/sugar/water and sugar/water mixtures on the plasticization of thermoplastic cassava starch. Carbohydrate Polymers doi:10.1016/j.carbpol.2007.01.022.

Tester, R. F. Influence of growth conditions on barley starch properties. 1997. International Journal of Biological Macromolecules 21: 37-45

Tester, R.F. and S.J.J. Debon. 2000. Annealing of starch - a review. International Journal of Biological Macromolecules 27(1): 1-12.

Thunwall, M., A. Boldizar and M. Rigdahl. 2006a. Extrusion processing of high amylase potato starch materials. Carbohydrate Polymer 11: 419-428.

Thunwall, M., A. Boldizar, M. Rigdahl and V. Kuthanova. 2006b. On the stressstrain behavior of thermoplastic starch melts. International Journal of Polymer Analysis and Characterization 11: 419-428.

Torres, F.G., O.H. Arroyo and C. Gómez. 2007. Processing and mechanical properties of natural fiber reinforced thermoplastic starch biocomposites. Journal of Thermoplastic Composite Materials 20: 207223.

Vallini, G., A. Corti, A. Pera, R. Solaro, F. Cioni and E. Chiellini. 1994. Effects of intensive microbial-metabolism on starch-filled polyethelene films in 
controlled composting windrows. Journal of General and Applied Microbiology 40: 445-461.

Van Soest J.J.G. and P. Essers. 1997. Influence of amylose-amylopectin ratio on properties of extruded starch plastic sheets. Journal of Macromolecular Science Pure and Applied Chemistry A34(9): 1665.

Van Sumere, C. 1992. Retting of flax with special reference to enzyme-retting. In: The biology and processing of flax, eds. H. Sharma and C. Van Sumere, 157-198. Belfast, Northern Ireland: M Publications.

Van Sumere, C. and H. Sharma. 1991. Analysis of fine flax fibre produced by enzymatic retting. Aspects Applied Biology 28:15-20.

Vasanthan, T. and R. Hoover. 1992. A comparative study of the composition of lipids associated with starch granules from various botanical sources. Food Chemistry 43: 19-27.

Varavinit, S., S. Shobsngob, W. Varanyanond, P. Chinachoti and O. Naivikul. 2003. Effect of amylose content on gelatinization, retrogradation and pasting properties of flours from different cultivars of Thai rice. Starch/Stärke 55(9): 410-415.

Vertuccio, L., G. Gorrasi, A. Sorrentino and V. Vittoria. 2009. Nano clay reinforced PCL/starch blends obtained by high energy ball milling. Carbohydrate Polymers 75: 172-179.

Vilaseca, F., J. A. Mendez, A. Pèlach, M. Llop, N. Cañigueral, J. Gironès, X. Turon and P. Mutjé. 2007. Composite materials derived from 
biodegradable starch polymer and jute strands. Process Biochemistry 42: 329-334.

Vose, J.R., M.J. Basterrechea, P.A.J. Gorin, A.J. Finlayson and C.G. Youngs. 1976. Air-classification of field peas and horsebean flours: chemical studies of starch and protein fractions. Cereal Chemistry 53: 928-936.

Wang, Y.J., P. White, L. Pollack and J. Jane. 1993. Characterization of starch structures of 17 maize endosperm mutant genotypes with Oh43 inbred line background. Cereal Chemistry 70: 171-179.

Wang, L., R.L. Shogren and C. Carriere. 2000. Preparation and properties of thermoplastic starch-polyester laminate sheets by coextrusion. Polymer Engineering and Science 40: 499-506.

Wang, H., X.Z. Sun and P. Seib. 2002. Effects of starch moisture on properties of wheat starch/poly(lactic acid) blend containing methylenediphenyl diisocyanate. Journal of Polymer and the Environment 10(4): 133-138.

Wang, X-L., K-K. Yang and Y-Z Wang. 2003. Properties of starch blends with biodegradable polymers. Journal of Macromolecular Science C43(3): 385-409.

Wang, S., J. Yu and J. Yu. 2005. Preparation and characterization of compatible thermoplastic starch/polyethylene blends. Polymer Degradation and Stability 87: 395-401.

Wang, N., J. Yu, X. Ma and Y. Wu. 2007. The influence of citric acid on the properties of thermoplastic starch/linear low-density polyethylene blends. Carbohydrate Polymer 67: 446-453. 
Widmer, J. 2003. Recycling of plastics, what to do? - some economic and social best practice aspects. Proceedings of the 1st International Symposium on Environmental Management, Zagreb, Croatia.

Wiedmann, W. and E. Strobel. 1991. Compounding of thermoplastic starch with twin-screw extruders. Starch/Stärke 43: 138-145.

Wielage, B., Th. Lampke, G. Marx, K. Nestler, and D. Starke. 1999. Thermogravimetric and differential scanning calorimetric analysis of natural fibres and polypropylene. Thermochimica Acta 337(1-2): 169177.

Willett, J.L. 1994. Mechanical properties of LDPE/granular starch composites. Journal of Applied Polymer Science 54(11): 1685-1695.

Wollerdorfer, M. and H. Bader. 1998. Influence of natural fibers on the mechanical properties of biodegradable polymers. Industrial Crops and Products 8: 105-112.

Wooton, M. and A. Bamunuarachchi. 1980. Application of differential scanning calorimetry to starch gelatinization. Starch/Stärke 32: 126-129.

Wu, C-S. 2003. Physical properties and biodegradability of maleatedpolycaprolactone/starch composite. Polymer Degradation and Stability 80: $127-134$.

Wu, C-S. 2005. Improving polylactide/starch biocomposites by grafting polylactide with acrylic acid - characterization and biodegradability assessment. Macromolecular Bioscience 5 (4): 352-361. 
Wu, Y.V. and NN Nichols. 2005. Fine grinding and air classification of field pea. Journal of Cereal Chemistry 82(3): 341-344.

Xie, F., H. Liu, P. Chen, T. Xue, L. Chen, L. Yu and P. Corrigan. 2006. Starch gelatinization under shearless and shear conditions. International Journal of Food Engineering 2(5) Art 6.

Yang, J., J. Yu and X. Ma. 2006. Preparation of a novel thermoplastic starch (TPS) material using ethylenebisformamide as the plasticizer. Starch/Stärke 58: 330-337.

Yavuz, H. and C. Babaç. 2003. Preparation and biodegradation of starch /polycaprolactone films. Journal of Polymers and Environment 11(3): 107-113.

Yeh, A-I. and J-Y. Li. 1996. A continuous measurement of swelling of rice starch during heating. Journal of Cereal Science 23: 277-283.

Yu, L. and G. Christie. 2001. Measurement of starch thermal transitions using differential scanning calorimetry. Carbohydrate Polymers 46: 179-184.

Yu, L. and G. Christie. 2005. Microstructure and mechanical properties of orientated thermoplastic starches. Journal of Materials Science 40: $111-116$

Yu, J., N. Wang and X. Ma. 2005. The effects of citric acid on the properties of thermoplastic starch plasticized by glycerol. Starch/Stärke 57: 494-504.

Zeng, M., C.F. Morris, I.L. Batey and C.W. Wrigley. 1997. Sources of variation for starch gelatinization, pasting and gelation properties in wheat. Cereal Chemistry 74: 63-71. 
Zeronian, S.H. 1977. Conservation of Textiles Manufactured from Man-Made Fibers. Advances in Chemistry Series No. 164, 208, Washington D.C.: American Chemical Society.

Zhang, J.F. and X.Z. Sun. 2004. Mechanical properties of poly(lactic acid)/starch composites compatibilized by maleic anhydride. Biomacromolecules 5(4): 1446-1451.

Zobel, H.F. 1984. Gelatinization of starch and mechanical properties of starch pastes. In Starch: Chemistry and Technology. Eds R. L. Whistler, J. N. BeMiller and B. F. Paschall. New York, NY: Academic Press. 


\section{APPENDIX A DATA SHEETS FOR PEA STARCH (ACCU-GEL) AND POLYCAPROLACTONE}




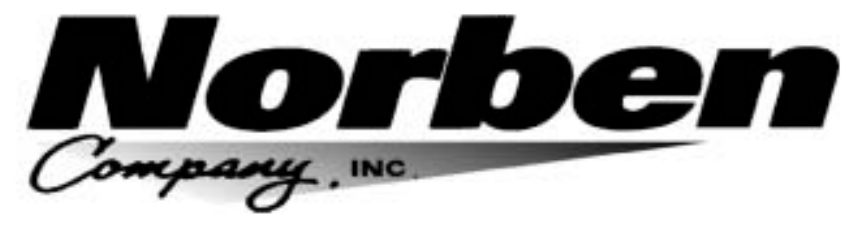

FOOD INGREDIENTS GROUP

PHONE: (440) 951-2715

FAX: (440) 951-1366

\section{Accu-Gel}

Accu-Gel is a food-grade, native vegetable starch offering excellent

Native Pea Starch gel strength, white color and bland flavor. The raw materials, Golden Canadian field peas are not genetically modified. Accu-Gel is therefore suitable for a GMO-free label.

$\underline{\text { Technical Information }}$

Origin kernel of Golden Canadian peas (100\% GMO-free)

\section{Moisture $\left(16 \mathrm{hrs} \pm 100^{\circ} \mathrm{C} \pm 5^{\circ} \mathrm{C}\right)$ \\ Protein (Kjeldahl, $\mathrm{N} \times 6.25$ ) \\ Fat (AOAC 7.000, 14 $4^{\text {th }}$ Ed) \\ Ash (AOAC 14.006, 14 $\left.4^{\mathrm{m}} \mathrm{Ed}\right)$ \\ $\mathrm{pH} \quad$ (10\% solution)}

Composition based on dry matter

\section{$8.0 \% \pm 1 \%$ \\ $<1.0 \%$ \\ $<0.1 \%$ \\ $<0.2 \%$ \\ neutral}

\section{Physical Data}

Flavor

Color

Particle Size (through a 80 mesh tyler)

Microns

$$
\begin{array}{r}
\text { very bland } \\
\text { white } \\
>95 \%
\end{array}
$$

175

\section{Carbohydrate Composition}

Amylose

Amylopectin

\section{Microbiology}

Total Plate Count (AOAC 48.015, 14 $\mathrm{Ed}$ ) $\quad<10,000 / 9$ E.Coli (AOAC 46.016, 14" Ed)

Salmonella (AOAC 46.117, $14^{\mathrm{th}}$ Ed)

negative

negative

Yeasts and Molds (AOAC 997.02, 10 $\mathrm{Ed}$ ) $\quad<100 / 9$

\section{Minerals}

Sodium

Potassium

$490 \mathrm{ppm}$

Magnesium

$320 \mathrm{ppm}$

Calcium

$43 \mathrm{ppm}$

$71 \mathrm{ppm}$

$79 \mathrm{ppm}$

$<1 \mathrm{ppm}$

Manganese

$6 \mathrm{ppm}$

Copper

$<0.1 \mathrm{ppm}$

Zinc

$<1 \mathrm{ppm}$

The above analyses are merely typical guides and are not to be construed as being specilcations. While the information contained herein is belleved to be true, accurate and rellable to the best of our knowledge, no wamanty as to accuracy, completeness or results is expressed or implled by such data.

\section{Applications}

Accu-Gel provides unique properties unlike that of wheat, corn and potato starches. Accu-Gel's superior gelling properties allow it to be used at a $20-30 \%$ lower usage level offering economic advantage to meat and confectionery industries in particular. It offers good body and mouthfeel without altering flavor. Accu-Gel exhibits excellent heat, shear, and acid stability similar to many modified starches. This native starch provides food manufacturers with "clean labeling" opportunities.

- meat and fish products - noodles - soups - canned food - light sour cream • batters · extruded snacks - pie fillings

\section{Ingredient Declaration}

Pea Starch

Native Pea Starch

Unmodified Vegetable Starch

Shelf Life

2 years (dry and cool conditions)

Packaging

$25 \mathrm{~kg}$ multi-walled, kraft paper bags 


\section{GENERAL PRODUCT DESCRIPTION}

$\mathrm{Capa}^{\oplus} 6506$ is a high molecular weight linear polyester derived from caprolactone monomer. It has a molecular weight of 50,000 and is chemically identical to Capa 6500 but is supplied in powder form. The particle size is $98 \%$ $<600$ microns. It is compatible with a wide range of common thermoplastics, and is soluble in several common solvents, such as aromatic hydrocarbons, halocarbons and some ketones.

TYPICAL PROPERTIES

\begin{tabular}{l|c}
\hline Physical Form & Powder \\
\hline Average Molecular Weight & 50,000 \\
\hline Melting Point & $58^{\circ} \mathrm{C}-60^{\circ} \mathrm{C}$ \\
\hline Water Content & Less than $1 \%$ \\
\hline Colour of $30 \% \mathrm{~m} / \mathrm{m}$ Solution (Hazen) & $<100$
\end{tabular}

PARTICLE SIZE DISTRIBUTION

\begin{tabular}{l|l} 
Less than $600 \mu$ & $98 \%$ \\
\hline Less than $425 \mu$ & $85 \%$ \\
\hline Less than $300 \mu$ & $60 \%$ \\
\hline Less than $200 \mu$ & $40 \%$ \\
\hline Less than $100 \mu$ & $10 \%$
\end{tabular}

\section{SOLUBILITY PARAMETERS}

The solubility parameter $(\delta)$ is $9.34-9.43\left(\mathrm{cal} / \mathrm{cm}^{3}\right)^{1 / 2}$.

\section{HANDLING AND STORAGE}

Capa 6506 is supplied in $25 \mathrm{~kg}$ net paper sacks, or in 'big bags' of $500 \mathrm{~kg}$ net. It should be stored in a dry place, away from sources of heat.

For further information please contact:

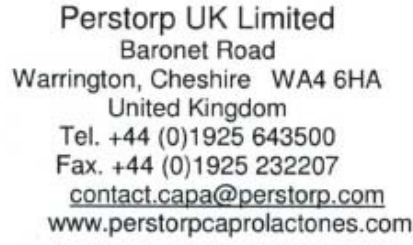

Perstorp UK Limited Baronet Road Warrington, Cheshire WA4 6HA United Kingdom

Tel. +44 (0)1925 643500

Fax. +44 (0)1925 232207

contact.capa@perstorp.com www.perstorpcaprolactones.com

Perstorp Specialty Chemicals AB

SE-284 80 Perstorp, Sweden

Tel. +4643538000

Fax +46 43537067

technical.support@perstorp.com www.perstorp.com 
APPENDIX B DERIVATION OF THE EQUATION FOR THE ADJUSTMENT OF TPS PROCESING MOISTURE CONTENT 


\section{Derivation of moisture adjustment equation}

$t=s+p+w_{a}$

where

$p=\frac{3}{7} d_{s}$

$s=d_{s}+w_{s}$

$t=\frac{w_{a}+w_{s}}{x}$

Substituting B2, B3, and B4 into B1 yields:

$$
\begin{aligned}
& \frac{w_{a}+w_{s}}{x}=d_{s}+w_{s}+\frac{3}{7} d_{s}+w_{a} \\
& \frac{w_{a}}{x}-w_{a}=d_{s}+w_{s}-\frac{w_{s}}{x}+\frac{3}{7} d_{s} \\
& w_{a}\left(\frac{1}{x}-1\right)=d_{s}+w_{s}\left(1-\frac{1}{x}\right)+\frac{3}{7} d_{s} \\
& w_{a}\left(\frac{1-x}{x}\right)=d_{s}+w_{s}\left(\frac{x-1}{x}\right)+\frac{3}{7} d_{s}
\end{aligned}
$$

Since

$$
w_{s}=\frac{M}{1-M} d_{s}
$$

Substituting B9 into B8 yields:

$$
\begin{aligned}
& w_{a}\left(\frac{1-x}{x}\right)=d_{s}+\frac{M}{1-M} d_{s}\left(\frac{x-1}{x}\right)+\frac{3}{7} d_{s} \\
& w_{a}\left(\frac{1-x}{x}\right)=\frac{10}{7} d_{s}+\frac{M}{1-M} d_{s}\left(\frac{x-1}{x}\right)
\end{aligned}
$$


$w_{a}=\frac{x}{1-x}\left[d_{s}\left(\frac{10}{7}+\frac{M}{1-M}\left(\frac{x-1}{x}\right)\right)\right]$

$t=$ total amount of TPS mix containing the desired processing moisture level, $\mathrm{g}$ $W_{a}=$ amount of extra water needed to achieve $100 x \%$ TPS processing moisture content, $g$

$w_{s}=$ amount of water in starch, $\mathrm{g}$

$x=$ targeted TPS processing moisture level (in decimal)

$M=$ moisture content of starch (in decimal)

$d_{s}=$ mass of dry starch, $\mathrm{g}$

$s=$ mass of starch

$p=$ amount of glycerol, $\mathrm{g}$ 


\section{APPENDIX C TENSILE TESTS DATA}


Table C1 Tensile properties of plasticized pea starch prepared at $9.3 \%$ processing moisture content.

\begin{tabular}{|c|c|c|c|c|}
\hline \multirow[b]{2}{*}{ Replication } & \multicolumn{4}{|c|}{ Tensile Properties } \\
\hline & $\begin{array}{c}\text { Tensile } \\
\text { Strength } \\
\text { (MPa) }\end{array}$ & $\begin{array}{l}0.2 \% \text { Yield } \\
\text { Strength } \\
\text { (MPa) }\end{array}$ & $\begin{array}{c}\text { Young's } \\
\text { Modulus } \\
\text { (MPa) }\end{array}$ & $\begin{array}{c}\text { Elongation } \\
\text { at Break (\%) }\end{array}$ \\
\hline 1 & 2.44 & 0.40 & 33.18 & 21.73 \\
\hline 2 & 1.73 & 0.26 & 29.69 & 28.83 \\
\hline 3 & 2.12 & 0.32 & 34.59 & 18.22 \\
\hline 4 & 2.18 & 0.36 & 32.11 & 19.34 \\
\hline 5 & 2.78 & 0.48 & 27.65 & 28.83 \\
\hline 6 & 2.75 & 0.40 & 29.29 & 30.19 \\
\hline 7 & 2.35 & 0.40 & 31.21 & 18.42 \\
\hline 8 & 2.72 & 0.43 & 30.91 & 28.35 \\
\hline 9 & 2.17 & 0.30 & 32.09 & 16.60 \\
\hline 10 & 3.03 & 0.48 & 28.59 & 28.10 \\
\hline
\end{tabular}

TABLE C2 Tensile properties of plasticized pea starch prepared at $20 \%$ processing moisture content.

\begin{tabular}{ccccc}
\hline & \multicolumn{4}{c}{ Tensile Properties } \\
\cline { 2 - 5 } Replication & $\begin{array}{c}\text { Tensile Strength } \\
(\mathbf{M P a})\end{array}$ & $\begin{array}{c}\text { 0.2\% Yield } \\
\text { Strength } \\
\text { (MPa) }\end{array}$ & $\begin{array}{c}\text { Young's } \\
\text { Modulus } \\
\text { (MPa) }\end{array}$ & $\begin{array}{c}\text { Elongation } \\
\text { at Break } \\
\text { (\%) }\end{array}$ \\
\hline 1 & 7.72 & 3.32 & 87.51 & 94.22 \\
2 & 8.21 & 3.04 & 114.15 & 93.71 \\
3 & 7.67 & 2.88 & 96.92 & 107.63 \\
4 & 7.20 & 2.67 & 87.72 & 89.21 \\
5 & 7.10 & 2.62 & 90.18 & 85.39 \\
6 & 7.36 & 2.95 & 118.32 & 95.48 \\
7 & 6.71 & 2.30 & 65.95 & 101.47 \\
8 & 8.16 & 2.82 & 71.98 & 77.27 \\
9 & 7.70 & 2.90 & 106.26 & 104.77 \\
10 & 7.18 & 1.22 & 115.34 & 86.00 \\
\hline
\end{tabular}


TABLE C3 Tensile properties of pure polycaprolactone.

\begin{tabular}{ccccc}
\hline Replication & \multicolumn{4}{c}{ Tensile Properties } \\
\cline { 2 - 5 } & $\begin{array}{c}\text { Tensile } \\
\text { Strength } \\
\text { (MPa) }\end{array}$ & $\begin{array}{c}\mathbf{0 . 2 \%} \text { Yield } \\
\text { Strength } \\
\text { (MPa) }\end{array}$ & $\begin{array}{c}\text { Young's } \\
\text { Modulus } \\
\text { (MPa) }\end{array}$ & $\begin{array}{c}\text { Elongation } \\
\text { at Break } \\
(\%)\end{array}$ \\
\hline 1 & 15.65 & 7.94 & 186.71 & $>800$ \\
2 & 15.55 & 7.13 & 194.19 & $>800$ \\
3 & 15.74 & 7.49 & 180.59 & $>800$ \\
4 & 15.34 & 7.49 & 184.81 & $>800$ \\
5 & 16.25 & 7.17 & 177.68 & $>800$ \\
6 & 15.46 & 7.06 & 184.63 & $>800$ \\
\hline
\end{tabular}

TABLE C4 Tensile properties of plasticized pea starch prepared at 9.3\% processing moisture content and reinforced with polycaprolactone.

\begin{tabular}{ccccc}
\hline PCL (\%) & $\begin{array}{c}\text { Tensile } \\
\text { Strength } \\
\text { (MPa) }\end{array}$ & $\begin{array}{c}\text { Tensile Properties } \\
\text { Strength } \\
\text { (MPa) }\end{array}$ & $\begin{array}{c}\text { Young's } \\
\text { Modulus } \\
\text { (MPa) }\end{array}$ & $\begin{array}{c}\text { Elongation } \\
\text { at Break } \\
\text { (\%) }\end{array}$ \\
\hline 10 & 4.94 & 1.38 & 125.14 & 9.13 \\
10 & 4.62 & 1.10 & 124.28 & 9.39 \\
10 & 5.12 & 1.01 & 122.75 & 11.03 \\
10 & 5.12 & 1.08 & 132.50 & 11.17 \\
10 & 4.90 & 1.10 & 132.30 & 9.34 \\
10 & 4.72 & 1.26 & 134.12 & 9.12 \\
10 & 4.94 & 1.19 & 113.47 & 10.76 \\
10 & 5.02 & 1.33 & 116.43 & 9.91 \\
10 & 4.59 & 0.97 & 121.40 & 8.93 \\
10 & 5.09 & 1.25 & 117.34 & 11.45 \\
20 & 4.27 & 3.72 & 164.57 & 3.55 \\
20 & 4.52 & 3.47 & 158.91 & 3.88 \\
20 & 4.67 & 3.84 & 155.50 & 3.97 \\
20 & 4.46 & 3.24 & 168.62 & 3.96 \\
20 & 4.61 & 3.43 & 156.15 & 3.80 \\
20 & 4.68 & 3.48 & 169.30 & 3.79 \\
20 & 4.32 & 3.51 & 175.56 & 3.43 \\
20 & 4.54 & 3.46 & 174.76 & 3.57 \\
20 & 4.25 & 3.50 & 159.55 & 3.64 \\
20 & 4.95 & 3.46 & 168.32 & 4.23 \\
\hline
\end{tabular}


TABLE C4 (Cont'd).

\begin{tabular}{lcccc}
\hline & \multicolumn{4}{c}{ Tensile Properties } \\
\cline { 2 - 5 } PCL (\%) & $\begin{array}{c}\text { Tensile } \\
\text { Strength } \\
\text { (MPa) }\end{array}$ & $\begin{array}{c}\mathbf{0 . 2 \%} \text { Yield } \\
\text { Strength } \\
\text { (MPa) }\end{array}$ & $\begin{array}{c}\text { Young's } \\
\text { Modulus } \\
\text { (MPa) }\end{array}$ & $\begin{array}{c}\text { Elongation at } \\
\text { Break (\%) }\end{array}$ \\
\hline 30 & 4.72 & 3.05 & 166.95 & 4.85 \\
30 & 4.61 & 3.58 & 172.72 & 4.05 \\
30 & 5.06 & 3.46 & 219.91 & 4.37 \\
30 & 5.01 & 3.71 & 160.17 & 4.11 \\
30 & 4.51 & 4.09 & 224.10 & 4.32 \\
30 & 4.44 & 4.24 & 206.08 & 4.29 \\
30 & 5.13 & - & 156.15 & 4.58 \\
30 & 4.92 & - & 169.07 & 4.11 \\
30 & 5.38 & - & 200.04 & 4.14 \\
40 & 5.61 & 2.50 & 147.81 & 6.85 \\
40 & 6.45 & 3.54 & 153.38 & 7.49 \\
40 & 5.48 & 3.91 & 150.95 & 6.40 \\
40 & 6.02 & 4.53 & 137.61 & 6.58 \\
40 & 6.09 & 4.09 & 190.28 & 7.62 \\
40 & 5.68 & 3.76 & 128.22 & 7.41 \\
40 & 6.16 & 4.49 & 165.28 & 6.73 \\
40 & 6.15 & 3.81 & 141.85 & 7.57 \\
40 & 5.84 & 4.35 & 179.99 & 6.99 \\
40 & 5.92 & - & 138.55 & 6.90 \\
\hline
\end{tabular}


TABLE C5 Tensile properties of plasticized pea starch prepared at $20 \%$ processing moisture content and reinforced with polycaprolactone.

\begin{tabular}{|c|c|c|c|c|}
\hline \multirow[b]{2}{*}{ PCL (\%) } & \multicolumn{4}{|c|}{ Tensile Properties } \\
\hline & $\begin{array}{c}\text { Tensile } \\
\text { Strength (MPa) }\end{array}$ & $\begin{array}{c}0.2 \% \text { Yield } \\
\text { Strength } \\
\text { (MPa) }\end{array}$ & $\begin{array}{c}\text { Young's } \\
\text { Modulus } \\
\text { (MPa) }\end{array}$ & $\begin{array}{c}\text { Elongation } \\
\text { at Break } \\
(\%)\end{array}$ \\
\hline 10 & 7.15 & 1.14 & 90.33 & 48.92 \\
\hline 10 & 8.15 & 1.33 & 105.38 & 33.04 \\
\hline 10 & 7.42 & 1.29 & 98.51 & 48.20 \\
\hline 10 & 6.85 & 1.36 & 64.30 & 39.62 \\
\hline 10 & 7.32 & 1.30 & 110.23 & 40.62 \\
\hline 10 & 7.71 & 1.32 & 116.21 & 41.38 \\
\hline 10 & 8.11 & 1.13 & 77.91 & 34.24 \\
\hline 10 & 7.06 & 1.17 & 101.51 & 51.00 \\
\hline 10 & 6.77 & 1.19 & 120.60 & 47.50 \\
\hline 10 & 7.76 & 1.01 & 76.14 & 45.50 \\
\hline 20 & 7.58 & 1.40 & 82.77 & 45.81 \\
\hline 20 & 7.27 & 1.40 & 87.51 & 46.46 \\
\hline 20 & 7.19 & 1.23 & 70.58 & 51.60 \\
\hline 20 & 7.94 & 1.50 & 66.74 & 47.25 \\
\hline 20 & 6.99 & 1.21 & 70.64 & 49.75 \\
\hline 20 & 7.05 & 1.28 & 75.37 & 46.82 \\
\hline 20 & 7.67 & 1.31 & 80.90 & 47.40 \\
\hline 20 & 7.17 & 1.21 & 86.26 & 46.30 \\
\hline 20 & 7.03 & 1.35 & 83.61 & 46.00 \\
\hline 20 & 7.14 & 1.33 & 89.66 & 47.85 \\
\hline 30 & 7.64 & 1.32 & 77.97 & 38.64 \\
\hline 30 & 7.82 & 1.32 & 83.92 & 42.80 \\
\hline 30 & 7.40 & 1.38 & 74.97 & 39.48 \\
\hline 30 & 7.82 & 1.39 & 82.48 & 37.11 \\
\hline 30 & 7.80 & 1.42 & 85.56 & 41.49 \\
\hline 30 & 7.54 & 1.31 & 78.00 & 37.45 \\
\hline 30 & 7.45 & 1.30 & 70.68 & 36.78 \\
\hline 30 & 7.87 & 1.34 & 92.83 & 39.13 \\
\hline 30 & 7.57 & 1.46 & 73.88 & 36.91 \\
\hline 30 & 7.85 & 1.36 & 84.00 & 40.50 \\
\hline
\end{tabular}


TABLE C5 (Cont'd).

\begin{tabular}{ccccc}
\hline & \multicolumn{4}{c}{ Tensile Properties } \\
\cline { 2 - 5 } PCL (\%) & $\begin{array}{c}\text { Tensile } \\
\text { Strength (MPa) }\end{array}$ & $\begin{array}{c}\mathbf{0 . 2 \%} \text { Yield } \\
\text { Strength } \\
\text { (MPa) }\end{array}$ & $\begin{array}{c}\text { Young's } \\
\text { Modulus } \\
\text { (MPa) }\end{array}$ & $\begin{array}{c}\text { Elongation } \\
\text { at Break } \\
\text { (\%) }\end{array}$ \\
\hline 40 & 9.39 & 3.26 & 92.77 & 31.13 \\
40 & 9.48 & 3.50 & 92.05 & 30.69 \\
40 & 9.56 & 3.52 & 94.53 & 32.07 \\
40 & 9.64 & 3.62 & 103.51 & 30.92 \\
40 & 9.57 & 3.55 & 93.20 & 34.21 \\
40 & 9.90 & 3.48 & 90.04 & 33.52 \\
40 & 9.90 & 3.45 & 91.21 & 35.12 \\
40 & 9.49 & 3.41 & 88.21 & 31.54 \\
40 & 9.33 & 3.29 & 90.91 & 32.00 \\
\hline
\end{tabular}

TABLE C6 Tensile properties of plasticized pea starch prepared at $20 \%$ processing moisture content and reinforced with polycaprolactone and flax fiber.

\begin{tabular}{cccccc}
\hline & Flax & \multicolumn{4}{c}{ Tensile Properties } \\
\cline { 3 - 6 } $\begin{array}{c}\text { PCL } \\
\mathbf{( \% )}\end{array}$ & $\begin{array}{c}\text { Fiber } \\
\text { (\%) }\end{array}$ & $\begin{array}{c}\text { Tensile } \\
\text { Strength } \\
\text { (MPa) }\end{array}$ & $\begin{array}{c}\mathbf{0 . 2 \%} \text { Yield } \\
\text { Strength } \\
\text { (MPa) }\end{array}$ & $\begin{array}{c}\text { Young's } \\
\text { Modulus } \\
\text { (MPa) }\end{array}$ & $\begin{array}{c}\text { Elongation } \\
\text { at Break } \\
\text { (\%) }\end{array}$ \\
\hline 0 & 5 & 7.74 & 2.32 & 70.63 & 22.49 \\
0 & 5 & 7.37 & 2.79 & 77.80 & 21.29 \\
0 & 5 & 7.44 & 1.37 & 118.69 & 20.91 \\
0 & 5 & 8.59 & 1.38 & 94.57 & 20.61 \\
0 & 5 & 7.94 & 1.24 & 88.95 & 24.92 \\
0 & 5 & 8.21 & 1.44 & 102.48 & 20.45 \\
0 & 5 & 7.63 & 1.43 & 87.14 & 20.02 \\
0 & 5 & 7.52 & 2.95 & 112.13 & 26.75 \\
0 & 5 & 6.86 & 1.25 & 87.19 & 23.23 \\
0 & 5 & 8.63 & 1.43 & 110.02 & 23.26 \\
0 & 10 & 7.56 & 3.03 & 107.96 & 13.61 \\
0 & 10 & 7.25 & 3.19 & 115.06 & 12.35 \\
0 & 10 & 8.40 & 3.67 & 115.24 & 13.74 \\
0 & 10 & 6.79 & 3.14 & 123.49 & 14.72 \\
0 & 10 & 8.15 & 3.05 & 117.45 & 14.24 \\
0 & 10 & 8.91 & 3.93 & 93.65 & 15.89 \\
0 & 10 & 8.69 & 3.67 & 107.09 & 13.35 \\
0 & 10 & 7.02 & 2.71 & 103.90 & 14.58 \\
0 & 10 & 8.05 & 3.20 & 112.86 & 15.75 \\
0 & 10 & 7.93 & 3.05 & 104.25 & 12.95 \\
\hline
\end{tabular}


TABLE C6 (Cont'd).

\begin{tabular}{|c|c|c|c|c|c|}
\hline \multirow[b]{2}{*}{$\begin{array}{c}\text { PCL } \\
\text { (\%) }\end{array}$} & \multirow[b]{2}{*}{$\begin{array}{c}\text { Flax } \\
\text { Fiber } \\
(\%)\end{array}$} & \multicolumn{4}{|c|}{ Tensile Properties } \\
\hline & & $\begin{array}{c}\text { Tensile } \\
\text { Strength } \\
\text { (MPa) }\end{array}$ & $\begin{array}{c}0.2 \% \text { Yield } \\
\text { Strength } \\
\text { (MPa) }\end{array}$ & $\begin{array}{l}\text { Young's } \\
\text { Modulus } \\
\text { (MPa) }\end{array}$ & $\begin{array}{c}\text { Elongation } \\
\text { at Break } \\
(\%)\end{array}$ \\
\hline 0 & 15 & 9.87 & 4.80 & 231.77 & 12.95 \\
\hline 0 & 15 & 11.69 & 4.86 & 213.47 & 10.45 \\
\hline 0 & 15 & 10.76 & 4.66 & 195.70 & 11.51 \\
\hline 0 & 15 & 11.30 & 4.96 & 221.76 & 12.27 \\
\hline 0 & 15 & 10.24 & 4.39 & 172.49 & 10.26 \\
\hline 0 & 15 & 10.50 & 4.69 & 196.35 & 12.40 \\
\hline 0 & 15 & 9.97 & 4.26 & 170.01 & 10.24 \\
\hline 0 & 15 & 10.30 & 4.82 & 222.36 & 9.47 \\
\hline 0 & 15 & 10.85 & 5.01 & 247.14 & 11.64 \\
\hline 0 & 15 & 10.40 & 4.31 & 166.87 & 10.52 \\
\hline 20 & 5 & 7.61 & 1.39 & 108.20 & 17.27 \\
\hline 20 & 5 & 8.12 & 1.32 & 105.22 & 18.51 \\
\hline 20 & 5 & 8.63 & 1.27 & 125.95 & 19.52 \\
\hline 20 & 5 & 8.32 & 1.58 & 116.08 & 19.67 \\
\hline 20 & 5 & 7.57 & 1.40 & 117.50 & 16.77 \\
\hline 20 & 5 & 7.97 & 1.38 & 109.53 & 20.53 \\
\hline 20 & 5 & 8.50 & 1.47 & 123.42 & 19.04 \\
\hline 20 & 5 & 8.13 & 1.47 & 119.04 & 20.97 \\
\hline 20 & 5 & 8.13 & 1.47 & 117.65 & 20.35 \\
\hline 20 & 5 & 8.30 & 1.40 & 112.09 & 21.81 \\
\hline 20 & 10 & 10.03 & 3.76 & 134.08 & 12.92 \\
\hline 20 & 10 & 10.22 & 4.27 & 143.65 & 14.08 \\
\hline 20 & 10 & 9.09 & 4.75 & 136.28 & 11.59 \\
\hline 20 & 10 & 10.25 & 3.67 & 144.62 & 12.30 \\
\hline 20 & 10 & 9.15 & 3.75 & 132.04 & 12.68 \\
\hline 20 & 10 & 9.88 & 3.89 & 139.06 & 14.02 \\
\hline 20 & 10 & 10.02 & 3.99 & 146.18 & 13.90 \\
\hline 20 & 10 & 9.82 & 4.13 & 155.14 & 12.60 \\
\hline 20 & 10 & 10.88 & 4.92 & 158.04 & 13.24 \\
\hline 20 & 10 & 10.62 & 4.44 & 144.08 & 13.69 \\
\hline 20 & 15 & 8.43 & 4.34 & 230.19 & 8.86 \\
\hline 20 & 15 & 7.19 & 4.58 & 208.23 & 7.97 \\
\hline 20 & 15 & 9.35 & 4.00 & 260.15 & 8.68 \\
\hline 20 & 15 & 9.11 & 4.95 & 225.58 & 7.53 \\
\hline 20 & 15 & 9.00 & 4.60 & 226.05 & 7.48 \\
\hline 20 & 15 & 9.07 & 4.08 & 241.11 & 9.56 \\
\hline 20 & 15 & 9.23 & 5.58 & 266.47 & 7.92 \\
\hline 20 & 15 & 10.75 & 4.55 & 220.11 & 7.75 \\
\hline 20 & 15 & 9.36 & 4.33 & 202.49 & 10.25 \\
\hline 20 & 15 & 9.25 & 5.30 & 246.73 & 9.11 \\
\hline
\end{tabular}


TABLE C6 (Cont'd).

\begin{tabular}{|c|c|c|c|c|c|}
\hline \multirow[b]{2}{*}{$\begin{array}{c}\text { PCL } \\
(\%)\end{array}$} & \multirow[b]{2}{*}{$\begin{array}{l}\text { Flax } \\
\text { Fiber } \\
(\%)\end{array}$} & \multicolumn{4}{|c|}{ Tensile Properties } \\
\hline & & $\begin{array}{c}\text { Tensile } \\
\text { Strength } \\
\text { (MPa) }\end{array}$ & $\begin{array}{l}0.2 \% \text { Yield } \\
\text { Strength } \\
\text { (MPa) }\end{array}$ & $\begin{array}{l}\text { Young's } \\
\text { Modulus } \\
(\mathrm{MPa})\end{array}$ & $\begin{array}{c}\text { Elongation } \\
\text { at Break } \\
(\%)\end{array}$ \\
\hline 40 & 5 & 10.21 & 3.95 & 120.41 & 16.56 \\
\hline 40 & 5 & 10.26 & 3.90 & 114.48 & 15.64 \\
\hline 40 & 5 & 9.96 & 4.11 & 118.98 & 14.85 \\
\hline 40 & 5 & 10.04 & 4.27 & 128.22 & 14.11 \\
\hline 40 & 5 & 9.80 & 3.76 & 122.97 & 14.59 \\
\hline 40 & 5 & 10.24 & 4.10 & 131.95 & 14.93 \\
\hline 40 & 5 & 10.70 & 3.90 & 128.89 & 14.99 \\
\hline 40 & 5 & 10.14 & 4.40 & 129.01 & 16.36 \\
\hline 40 & 5 & 10.44 & 4.10 & 136.21 & 16.08 \\
\hline 40 & 10 & 11.95 & 5.25 & 197.84 & 11.29 \\
\hline 40 & 10 & 11.01 & 5.12 & 191.94 & 10.98 \\
\hline 40 & 10 & 11.27 & 5.22 & 195.42 & 11.02 \\
\hline 40 & 10 & 11.08 & 5.06 & 188.38 & 10.69 \\
\hline 40 & 10 & 11.74 & 5.07 & 189.53 & 12.28 \\
\hline 40 & 10 & 11.54 & 5.40 & 196.67 & 10.59 \\
\hline 40 & 10 & 11.82 & 5.64 & 188.34 & 10.57 \\
\hline 40 & 10 & 11.99 & 5.52 & 196.99 & 10.94 \\
\hline 40 & 10 & 11.48 & 5.05 & 190.30 & 11.24 \\
\hline 40 & 10 & 11.59 & 5.36 & 198.38 & 11.63 \\
\hline 40 & 15 & 11.13 & 5.87 & 274.99 & 7.54 \\
\hline 40 & 15 & 10.61 & 6.87 & 273.73 & 7.87 \\
\hline 40 & 15 & 11.91 & 6.15 & 268.34 & 7.15 \\
\hline 40 & 15 & 10.72 & 5.72 & 280.12 & 7.95 \\
\hline 40 & 15 & 10.55 & 5.78 & 261.89 & 7.79 \\
\hline 40 & 15 & 10.85 & 5.85 & 273.56 & 7.83 \\
\hline 40 & 15 & 10.81 & 5.93 & 279.30 & 7.68 \\
\hline 40 & 15 & 11.29 & 5.90 & 274.87 & 7.42 \\
\hline 40 & 15 & 10.58 & 6.15 & 256.76 & 7.66 \\
\hline 40 & 15 & 12.11 & 5.93 & 259.08 & 7.55 \\
\hline
\end{tabular}


APPENDIX D MOISTURE ABSORPTION TEST DATA 
TABLE D1 Moisture absorption properties of plasticized pea starch prepared at $9.3 \%$ processing moisture content and reinforced with polycaprolactone.

\begin{tabular}{cccc}
\hline PCL (\%) & $\begin{array}{c}\text { Initial Mass, } \\
\mathbf{m}_{\mathbf{0 1}}(\mathbf{g})\end{array}$ & $\begin{array}{c}\text { Final Mass, } \\
\mathbf{m}_{\mathbf{f} 1}(\mathbf{g})\end{array}$ & $\begin{array}{c}\text { Moisture } \\
\text { Absorbed }(\%)\end{array}$ \\
\hline 0 & 0.716 & 0.942 & 31.56 \\
0 & 0.725 & 0.952 & 31.31 \\
0 & 0.723 & 0.940 & 30.01 \\
10 & 0.570 & 0.641 & 12.46 \\
10 & 0.606 & 0.696 & 14.85 \\
10 & 0.608 & 0.695 & 14.31 \\
20 & 0.577 & 0.638 & 10.57 \\
20 & 0.554 & 0.613 & 10.65 \\
20 & 0.551 & 0.605 & 9.80 \\
30 & 0.484 & 0.532 & 9.92 \\
30 & 0.472 & 0.511 & 8.26 \\
30 & 0.477 & 0.520 & 9.01 \\
40 & 0.519 & 0.542 & 4.43 \\
40 & 0.504 & 0.526 & 4.37 \\
40 & 0.505 & 0.528 & 4.55 \\
\hline
\end{tabular}


TABLE D2 Moisture absorption properties of plasticized pea starch prepared at $20 \%$ processing moisture content and reinforced with polycaprolactone.

\begin{tabular}{cccc}
\hline PCL (\%) & $\begin{array}{c}\text { Initial Mass, } \\
\mathbf{m}_{\mathbf{0} 1}(\mathbf{g})\end{array}$ & $\begin{array}{c}\text { Final Mass, } \\
\mathbf{m}_{\mathbf{f 1}}(\mathbf{g})\end{array}$ & $\begin{array}{c}\text { Moisture } \\
\text { Absorbed }(\%)\end{array}$ \\
\hline 0 & 0.596 & 0.885 & 48.49 \\
0 & 0.583 & 0.862 & 47.86 \\
0 & 0.588 & 0.872 & 48.30 \\
10 & 0.497 & 0.652 & 31.19 \\
10 & 0.512 & 0.673 & 31.45 \\
10 & 0.502 & 0.662 & 31.87 \\
20 & 0.487 & 0.597 & 22.59 \\
20 & 0.473 & 0.584 & 23.47 \\
20 & 0.485 & 0.592 & 22.06 \\
30 & 0.464 & 0.536 & 15.52 \\
30 & 0.463 & 0.540 & 16.63 \\
30 & 0.453 & 0.526 & 16.11 \\
40 & 0.435 & 0.488 & 12.18 \\
40 & 0.449 & 0.503 & 12.03 \\
40 & 0.447 & 0.496 & 10.96 \\
\hline
\end{tabular}


TABLE D3 Moisture absorption properties of plasticized pea starch prepared at $20 \%$ processing moisture content and reinforced with polycaprolactone and flax fiber.

\begin{tabular}{ccccc}
\hline PCL (\%) & $\begin{array}{c}\text { Flax Fiber } \\
(\mathbf{\%})\end{array}$ & $\begin{array}{c}\text { Initial Mass, } \\
\mathbf{m}_{\mathbf{0} \mathbf{1}} \mathbf{( g )}\end{array}$ & $\begin{array}{c}\text { Final Mass, } \\
\mathbf{m}_{\mathbf{f 1}} \mathbf{( g )}\end{array}$ & $\begin{array}{c}\text { Moisture } \\
\text { Absorbed } \mathbf{( \% )}\end{array}$ \\
\hline 20 & 5 & 0.508 & 0.617 & 21.46 \\
20 & 5 & 0.514 & 0.622 & 21.01 \\
20 & 5 & 0.529 & 0.644 & 21.74 \\
20 & 10 & 0.507 & 0.619 & 22.09 \\
20 & 10 & 0.523 & 0.635 & 21.41 \\
20 & 10 & 0.506 & 0.619 & 22.33 \\
20 & 15 & 0.481 & 0.594 & 23.49 \\
20 & 15 & 0.483 & 0.590 & 22.15 \\
20 & 15 & 0.476 & 0.585 & 22.90 \\
40 & 5 & 0.458 & 0.517 & 12.88 \\
40 & 5 & 0.453 & 0.515 & 13.69 \\
40 & 5 & 0.453 & 0.513 & 13.25 \\
40 & 10 & 0.467 & 0.535 & 14.56 \\
40 & 10 & 0.465 & 0.534 & 14.84 \\
40 & 10 & 0.464 & 0.531 & 14.44 \\
40 & 15 & 0.492 & 0.562 & 14.23 \\
40 & 15 & 0.487 & 0.562 & 15.40 \\
40 & 15 & 0.496 & 0.565 & 13.91 \\
\hline
\end{tabular}

